Portland State University

PDXScholar

$6-2-2020$

\title{
From Theory to Practice: Interdisciplinary Science in Undergraduate Education
}

Brie Tripp

Portland State University

Follow this and additional works at: https://pdxscholar.library.pdx.edu/open_access_etds

Part of the Biology Commons, and the Science and Mathematics Education Commons Let us know how access to this document benefits you.

Recommended Citation

Tripp, Brie, "From Theory to Practice: Interdisciplinary Science in Undergraduate Education" (2020). Dissertations and Theses. Paper 5488.

https://doi.org/10.15760/etd.7360

This Dissertation is brought to you for free and open access. It has been accepted for inclusion in Dissertations and Theses by an authorized administrator of PDXScholar. Please contact us if we can make this document more accessible: pdxscholar@pdx.edu. 
From Theory to Practice:

Interdisciplinary Science in Undergraduate Education

by

Brie Tripp

A dissertation submitted in partial fulfillment of the requirements for the degree of

\author{
Doctor of Philosophy \\ in \\ Biology
}

Dissertation Committee:

Erin E. Shortlidge, Chair

Jack Barbera

Karlyn R. Adams-Wiggins

Thomas V. Hancock

Vivek Shandas

Portland State University

2020 
(C) 2020 Brie Tripp 


\begin{abstract}
Science has undergone a major transformation in the 20th and 21 st centuries with new fields emerging at the intersection of disciplines, such as bioethics, bioinformatics, and chemical ecology. Yet, opportunities to engage with interdisciplinary science, and the skills needed to work in these fields, are largely absent from undergraduate biology classrooms. As a consequence, students are potentially deprived of opportunities to think interdisciplinarily and engage with realworld issues that often necessitate interdisciplinary efforts. To be informed citizens in society and forward-thinking scientists in the workforce, undergraduate students will undoubtedly benefit from exposure to these interdisciplinary science experiences.

Given these considerations, national conversations were initiated in 2007 on what undergraduate biology education should look like in the $21^{\text {st }}$ century. In 2011 , a summary of these deliberations were reported in Vision and Change in Undergraduate Biology Education: A Call to Action. The report detailed several core competencies that students must harness by the time they graduate to be better prepared for the workforce, one of them being "the ability to tap into the interdisciplinary nature of science". However, there is little agreement among experts on what interdisciplinary science even means, much less how to provide students with opportunities that foster their understanding or assess if and how they are conceptualizing this competency.

In this dissertation, I developed a unified definition of interdisciplinary science, leveraging survey data collected from scientists and educators nationwide $(\mathrm{n}=184)$. Using this definition and literature on interdisciplinary studies, I developed
\end{abstract}


an evidence-based theoretical model to guide practitioners in developing interdisciplinary science curricula and assessments - the Interdisciplinary Science Framework (IDSF).

With a framework in place, I next examined ways to measure undergraduates' interdisciplinary science understanding. I initially tested a preexisting interdisciplinary social science rubric by scoring natural and physical science student essays with the instrument. I examined evidence for the convergent validity of scores from essays ( $\mathrm{n}=71)$ and same-student interviews $(\mathrm{n}=25)$ across four upper-division science courses, revealing that students conceptualized interdisciplinary science more similarly to the IDSF than to the original rubric constructs.

I used these data and the criteria within the IDSF to develop a new assessment instrument — the Interdisciplinary Science Rubric (IDSR) — designed to measure students' understanding of this competency. I tested for aspects of construct validity through convergent evidence of data collected from the IDSR by scoring 102 essay assignments and conducting think-aloud novice $(n=22)$ and expert $(n=15)$ interviews across five courses from three universities. In addition, I tested for evidence of reliability of scores for the IDSR between myself and the instructors of record $(\kappa=0.67)$. The combination of these analyses revealed that the IDSF and IDSR are supported by psychometric evidence and therefore useful in designing interdisciplinary science curricula and assessing students' interdisciplinary science thinking. These resources can assist educators in meeting the benchmarks set forth by Vision and Change to better equip students with the interdisciplinary skills needed to remediate unresolved issues in society. 


\section{DEDICATION}

I dedicate this dissertation to the creature who has unwaveringly been by my sidemy dog, best friend, and confidant, Rosey Posey Tripp.

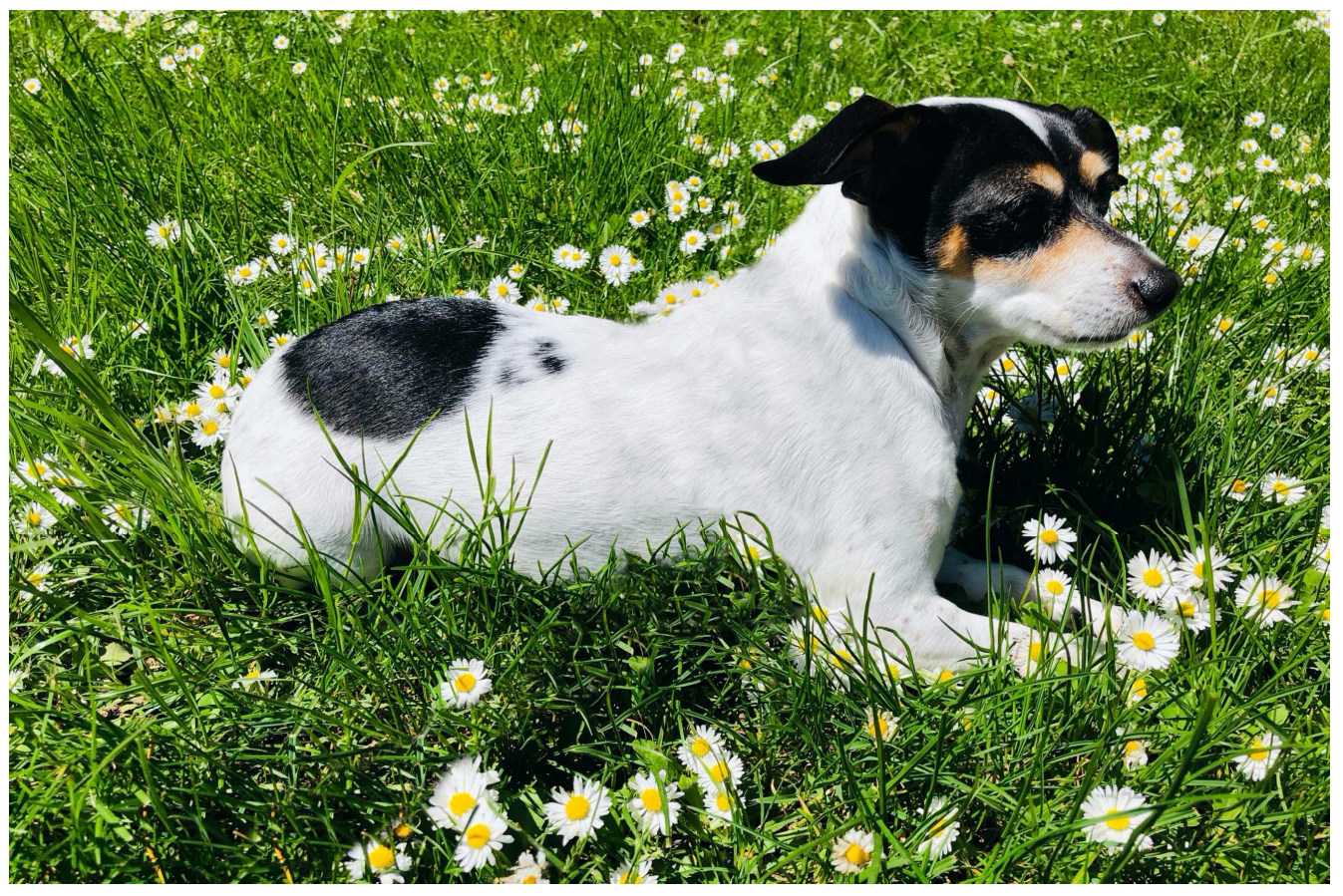




\section{ACKNOWLEDGEMENTS}

To my parents, Lynn, Tony, and Noreen Tripp: each one of you is a source of inspiration for me, and I would not be writing this dissertation without your endless generosity and faith in my ability to succeed in the face of adversity. You three know the obstacles that we have all had to overcome for me to arrive at this place and you are the biggest reason for why I am here. Mom, thank you for role modeling tenacity, grit, and compassion - I am so proud to have you as a guiding force in my life and a source of motivation. Dad, your gentle heart and moral compass steered me toward integrity and honor as I navigated my way through mental health issues and difficult times in graduate school. Noreen, you have shown me what true commitment and patience looks like, and I thank you for taking such great care of my father so that he could witness this doctoral accomplishment. I am forever grateful to have you all as my support system — without you, I'd be lost. Thank you for helping me become the best version of myself.

I owe a large portion of this dissertation to my fearless mentor, Dr. Erin Shortlidge. Thank you for pulling me through in times of distress and angst and for your infinite patience — none of this would have been possible without you. Having a mentor that is sensitive, yet can provide 'tough love' when needed has allowed me to grow in ways I never imagined. Beyond successfully guiding me in my research, I have learned valuable life lessons from you and gained skills to pragmatically, yet thoughtfully, tackle whatever obstacle is thrown at me. You have helped me understand how to navigate academia as a female in science and I am truly honored to have been under your guidance. 
I'd like to thank Dr. Jack Barbera for showing me the ropes in how to validate

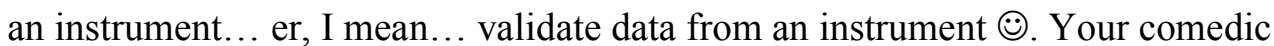
relief and wisdom in education research has been invaluable to me and my future interests as a researcher. Thank you, Dr. Tom Hancock, for patiently listening to my questions and opinions in teaching anatomy and physiology and allowing me to learn from your experiences. I'd like to also thank Dr. Karlyn Adams-Wiggins for providing your knowledge in theoretically-based literature-I appreciate how you challenged me to have a more inclusive mindset. Thank you Dr. Vivek Shandas for serving on my committee and providing your insight on interdisciplinary studies.

I'd like to thank my lab mates, Liz Rain and Emma Goodwin, for supporting me through the ups and downs inherent in grad school. Liz, your positivity and infectious smile lifted me up when I was bogged down with negative emotions. And thank you for being Rosey’s babysitter during the conferences I attended! Emma, thank you for your ability to listen and understand during some of the tougher days in grad school.

To several members of the chemistry education research group, Dr. Regis Komperda, Dr. Katy Hosbein, and Dr. Cory Henson: you all have been a unique source of support throughout the last four years. Each one of you has provided emotional care through the trials and tribulations I experienced with grad school and my personal life. I am forever grateful for your kindness and non-judgmental guidance. Additionally, I have greatly valued your knowledge in quantitative methods and was extremely fortunate to have you as resources during my studies.

I'd like to acknowledge one of my best friends that continually inspires me, Amy Seufert. Thanks for being my hiking partner, confidant, and helping me develop a sense of belonging in grad school. I'd also like to thank Erin Davis for being a 
sounding board during some of the more frustrating times in teaching. Having a team of strong, emotionally intelligent females by my side has allowed me to grow as a woman in science. You both have made my grad school experience amazing and I look forward to seeing us succeed!

To Shaphan Thomas: you have stuck with me through the biggest struggles of my life over the past several years. Your kind soul, unconditional friendship, and occasional 'reality checks' have helped me become the person I've always wanted to be. And of course, thank you for taking care of Rosey like one of your own $(-)$. And lastly, but certainly not least, thanks to my fur baby for being the best friend I've ever had. Rosey, your warm snuggles and love were the greatest source of peace for me during the intermittent whirlwinds of $\mathrm{PhD}$ life. But, alas, we made it! 
TABLE OF CONTENTS

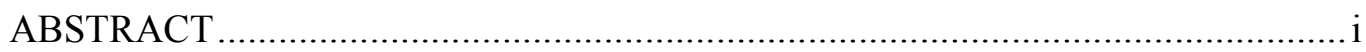

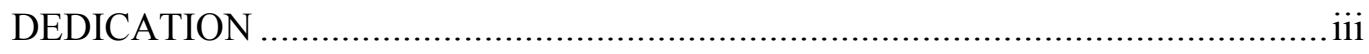

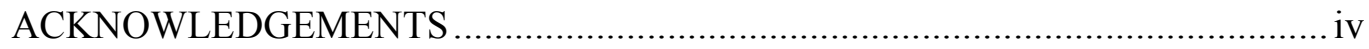

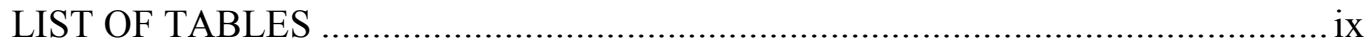

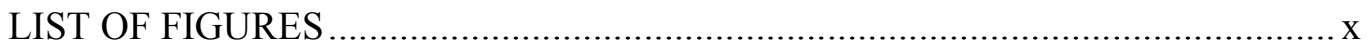

CHAPTER 1: INTRODUCTION AND RESEARCH PURPOSE ........................... 1

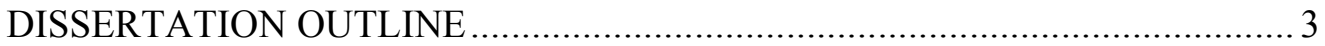

CHAPTER 2: THEORETICAL FRAMEWORK ................................................ 8

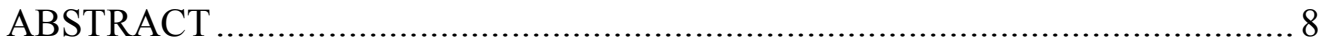

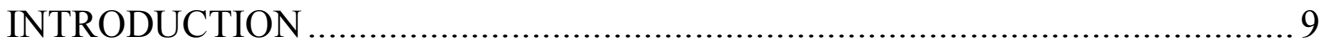

HISTORY OF INTERDISCIPLINARITY …........................................... 11

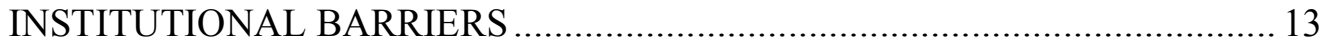

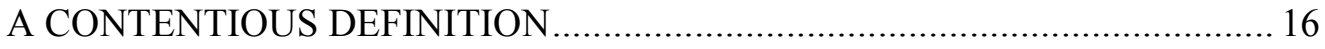

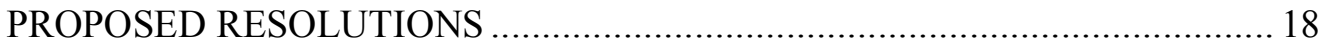

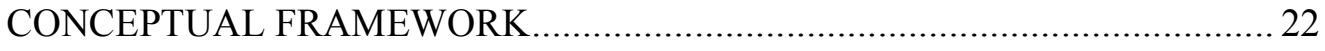

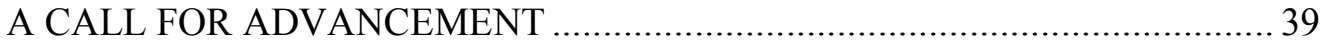

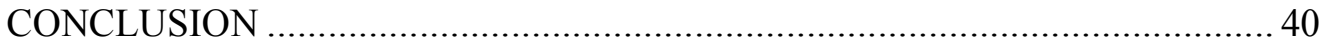

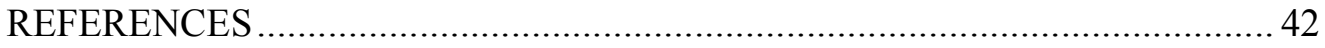

CHAPTER 3: STEPS TOWARD MEASURING INTERDISCIPLINARY SCIENCE

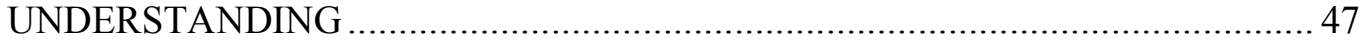

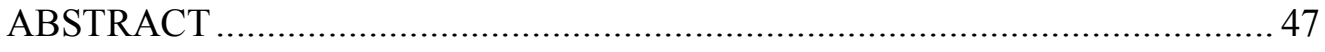

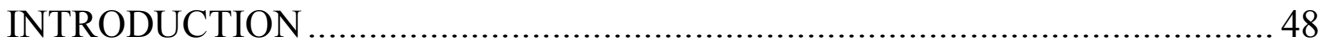

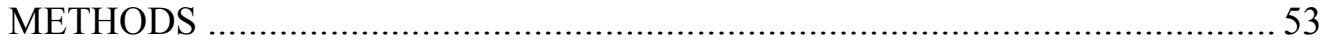

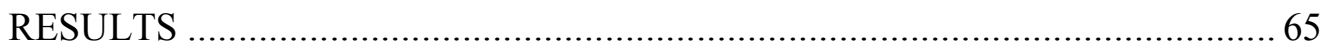

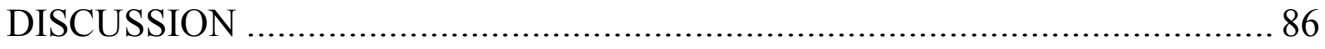

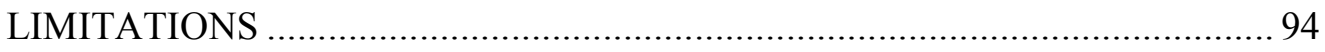

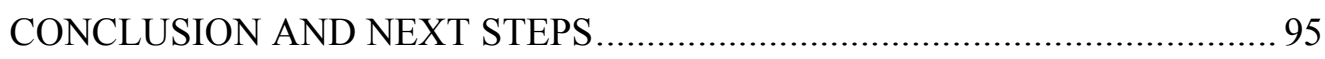

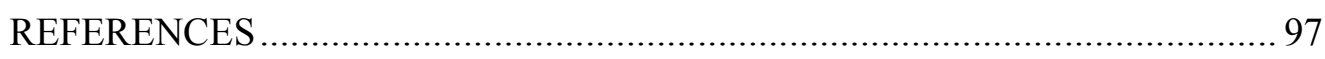

CHAPTER 4: INTERDISCIPLINARY SCIENCE RUBRIC .............................. 101

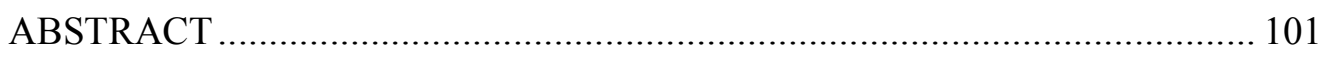

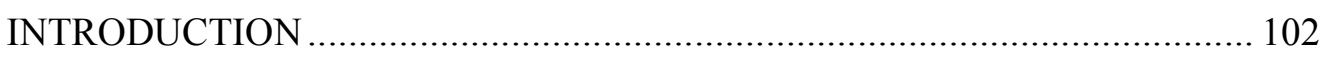

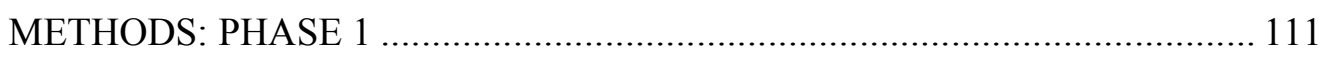

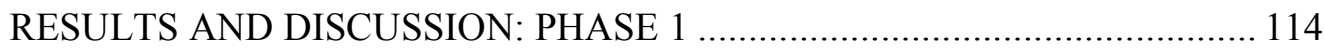




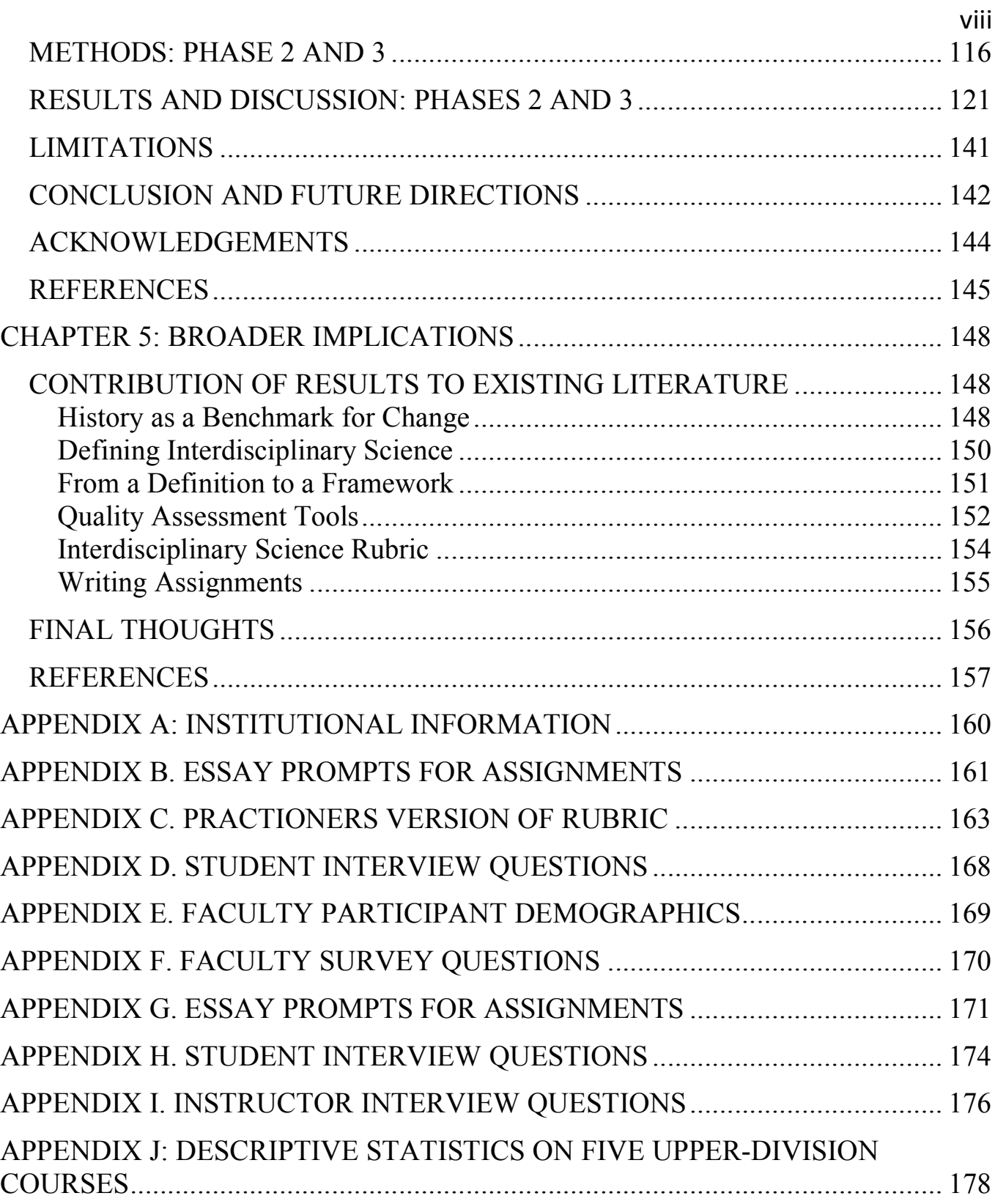




\section{LIST OF TABLES}

\section{CHAPTER 2}

TABLE 1. TOP SIX EMERGENT THEMES FROM SURVEYED SCIENCE FACULTY $(\mathrm{N}=184)$ ON HOW THEY DEFINE INTERDISCIPLINARY SCIENCE. ....................................... 22

TABLE 2. REVIEW OF INTERDISCIPLINARY INSTRUCTIONAL STUDIES THAT ALIGN WITH

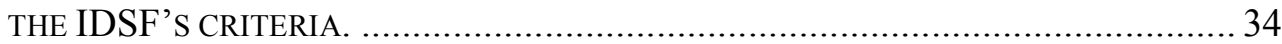

TABLE 3. EXAMPLE CURRICULUM APPLYING THE IDSF TO AN INTERDISCIPLINARY COURSE ASSIGNMENT. STUDENTS IN AN UPPER-DIVISION ENVIRONMENTAL COURSE ARE TASKED TO ADDRESS THE DECLINE IN HONEYBEE POPULATIONS VIA AN ACTIVITY AND ASSIGNMENT. STUDENTS ARE ASKED TO CONSTRUCT A PROPOSAL TO MITIGATE THIS ISSUE AND ARE SCORED ON THE INCLUSION OF THE FIVE IDSF

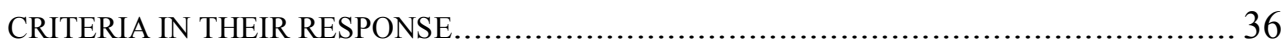

\section{CHAPTER 3}

TABLE 1. SHORTENED RUBRIC PROVIDED TO STUDENTS 58

TABLE 2. CODING RUBRIC FOR SURVEY QUESTION: PLEASE EXPLAIN HOW YOU ASSESS LEARNING OUTCOMES RELATED TO STUDENTS' UNDERSTANDING OF INTERDISCIPLINARY SCIENCE $(\mathrm{N}=68)$.

TABLE 3. COURSE CHARACTERIZATION OF FOUR UPPER-DIVISION NATURAL AND PHYSICAL SCIENCE COURSES.

TABLE 4. EXAMPLES OF MATCHED AND MISMATCHED UNDERSTANDING OF ID OF SAME STUDENT ESSAY AND INTERVIEW RESPONSES.

\section{CHAPTER 4}

TABLE 1. SUMMARY OF FIVE UNIVERSITIES AND ASSOCIATED UPPER-DIVISION COURSE FORMAT (ID=INTERDISCIPLINARY; $\mathrm{D}=$ DISCIPLINARY) AND SAMPLE SIZES OF ESSAYS AND INTERVIEWS COLLECTED OVER THE COURSE OF ONE ACADEMIC CALENDAR YEAR.....

TABLE 2. THE INSTRUCTOR VERSION OF INTERDISCIPLINARY SCIENCE RUBRIC (IDSR) TO MEASURE STUDENTS' UNDERSTANDING OF ID SCIENCE. THE 'CATEGORY' AND 'CRITERIA' COLUMNS WERE PROVIDED TO STUDENTS IN ESSAY ASSIGNMENTS (I.E. STUDENT VERSION OF RUBRIC).

TABLE 3. EXAMPLES OF STUDENT ESSAY AND INTERVIEW RESPONSES AND FACULTY INTERVIEW RESPONSES SUPPORTING THE CRITERIA IN THE IDSR. 


\section{LIST OF FIGURES}

\section{CHAPTER 2}

FIGURE 1. INTERDISCIPLINARY SCIENCE FRAMEWORK (IDSF) FOR GUIDING STUDENTS TO TAP INTO THE INTERDISCIPLINARY NATURE OF SCIENCE.

\section{CHAPTER 3}

FIGURE 1. BOX PLOTS COMPARE STUDENT PERFORMANCE ON OVERALL MEAN CONSTRUCT SCORES $(\mathrm{N}=71)$..

FIGURE 2. BOX PLOTS COMPARE STUDENT PERFORMANCE STUDENTS' MEAN ESSAY

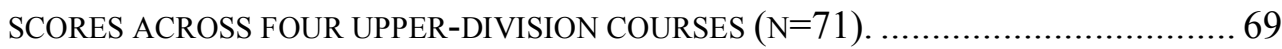

FIGURE 3. COMPARISON OF MEAN CONSTRUCT SCORES FOR STUDENTS ENROLLED IN

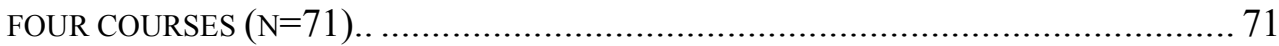

Figure 4. Numeric Construct SCORes ((1) NAÏve (2) Novice (3) ApPrentice (4) MASTERY) MATCHED WITH SAME-STUDENT BINARY INTERVIEW SCORE (YES, NO); A) Disciplinary Grounding, B) InTEgRation, C) Critical Awareness...... 74

\section{CHAPTER 4}

FIGURE 1. INTERDISCIPLINARY SCIENCE FRAMEWORK (IDSF) REDRAWN FROM TRIPP \& SHORTLIDGE 2019. 104

FIGURE 2. SCHEMATIC REPRESENTATION OF THE MULTIPLE SOURCES OF EVIDENCE FOR VALIDITY AND RELIABILITY. 108

Figure 3. A threE-PHASE OUTLINE FOR THE DEVELOPMENT (PhASE 1) AND TESTING (PHASES 2 \& 3) OF THE INTERDISCIPLINARY SCIENCE RUBRIC. 


\section{CHAPTER 1: INTRODUCTION AND RESEARCH PURPOSE}

By now, many acknowledge that the world is interdisciplinary (ID). As a nation, we have witnessed a surge of societal issues that cannot be fully addressed from the confines of a single discipline. To work within this ID system, collaborations across disciplines must ensue to successfully create solutions to unresolved issues. These ID collaborations are even more pronounced in the science, technology, engineering, and mathematics (STEM) fields that are often faced with ameliorating issues such as pandemics, health disparities among underrepresented populations, nuclear warfare, and increasing global temperatures (Stokols et al., 2005, Masse et al., 2008, National Research Council [NRC], 2009). In this wake of burgeoning realworld dilemmas, we have witnessed scientific fields gain momentum in solving issues driven by innovative discoveries and cross-cutting advancements that were previously unfathomable (e.g. gene therapy, bionics, bioremediation) (NRC, 2003). But as one question is answered, new questions surface that require a continuation of ID efforts and collaborations both within, and outside, STEM fields (NRC, 2003, 2009).

Many funding agencies and initiatives recognize the immediacy of these current world issues, and likewise, the intellectual benefit of ID partnerships (NRC, 2003, NRC, 2009, American Association for the Advancement of Science [AAAS], 2011, National Institute of Health, 2019). Thus, stakeholders are investing in projects that foster ID workspaces, often prioritizing ID partnerships in grant and program development proposals (Gazzinga, 1998, Besterfield-Sacre et al., 2004 ). Similarly, the job market increasingly seeks individuals with the intellectual prowess and training to effectively solve problems through an interdisciplinary lens (AAAS, 
2011). To meet these requirements, future scientists must have the necessary skillset to work across disciplines in order develop novel solutions to complicated issues. However, undergraduate biology students are lagging behind these benchmarks. According to the National Research Council $(2003,2009)$, biology curricula has been much slower to engage students in ID practices for a myriad of reasons discussed in this dissertation. Given these setbacks, national science reform efforts turned the responsibility on instructors to start instilling ID science learning opportunities in their classrooms to better prepare biology students for the workforce and the everchanging landscape of a complicated world (NRC, 2009, AAAS, 2011).

In 2007, hundreds of biology researchers, instructors, and policy makers united to identify the necessary knowledge and skills that undergraduate biology students would need to succeed as scientists in the $21^{\text {st }}$ century. A monumental report was published in 2011, Vision and Change in Undergraduate Biology Education (AAAS, 2011), that outlined these efforts along with six core competencies that undergraduate biology students should develop by the time they graduate. One of these six competencies includes students' ability to "tap into the interdisciplinary nature of science". To provide students the opportunity to gain this competency, instructors are not only faced with implementing ID science curricula, but they also must have ways to accurately assess if students are truly meeting this benchmark. As mentioned, there are several reasons that these expectations have been particularly difficult for instructors to meet, such as: 1) ambiguity in a clear definition of ID science, 2) the absence of a theoretical model to guide the design of ID science curricula, and 3) a lack of assessment tools to measure if students are meeting ID science learning objectives. My dissertation work addresses all three of these outlined 
needs, with a focus to provide knowledge and evidence-based resources to aid practitioners in developing ID science curricula and an assessment tool to measure students' ID science thinking.

\section{DISSERTATION OUTLINE}

\section{Chapter 2}

I first review the historical literature of ID science and institutional barriers to ID studies. One of the most fundamental barriers is a fractured definition of ID science, with differing opinions from experts on what "interdisciplinary" means (Bennington, 1999, Lattuca \& Knight, 2010). Before practitioners can begin to design ID science curricula, they must have a united understanding of the meaning behind these terms. To address this, I surveyed science experts across institutions to formulate an evidence-based definition of how experts currently define ID science $(\mathrm{n}=184)$. I used this definition and ID social science literature (Lattuca, 2001, Boix Mansilla \& Durasignh, 2007, Repko, 2008, Öberg 2009) to develop the Interdisciplinary Science Framework (IDSF) as a guide for instructors to design curricula that fosters ID science comprehension (Tripp \& Shortlidge, 2019) (Chapter 2).

\section{Chapter 3}

As instructors are on the frontline of designing and teaching curricula that meet ID learning outcomes, they are expected to assess if students are meeting these goals. To gauge how science instructors currently assess ID science understanding in undergraduate classrooms, I analyzed a question within the same survey described 
above inquiring how experts teaching science courses currently assess ID science $(\mathrm{n}=68)$. Individual writing activities surfaced as the most prevalent form for assessing this competency (Tripp et al., 2020).

As I searched the literature for an ID assessment tool that contained a writing component, I found one published rubric, designed to measure social science students understanding of interdisciplinarity in the humanities through a writing assignment (Boix Mansilla et al., 2009). Constructs within this rubric also partially aligned with similar criteria in the IDSF. These components of the instrument provided reasonable justification to test the robustness of this rubic on natural and physical science populations.

I first developed writing assignments that tasked students with addressing a current real-world issue relevant to their course content and then subsequently used the rubric to score students' work. I administered the assignment to students enrolled in four upper-division biology courses at a northwestern research-intensive university $(n=71)$. Evidence of convergent validity of the instrument scores was examined through semi-structured student interviews $(n=25)$, resulting in several constructs in the rubric that did not fully meet validity standards. During this process, I noticed that students were conceptualizing ID science similarly to criteria within the IDSF. Thus, I used the constructs within this model to deductively re-analyze student interviews, resulting in evidence of convergent validity of data for the IDSF as a robust model.

\section{Chapter 4}

Based on the collective findings from Chapters 2 and 3, I developed a new instrument guided by criteria in the IDSF — the Interdisciplinary Science Rubric 
(IDSR) (Chapter 4) (Tripp et al., 2020). I created similar writing assignments to those in Chapter 3 to test the ability for the IDSR to fully capture students' ID science understanding in five upper-division courses across three different universities $(\mathrm{n}=102)$. Through a series of validity and reliability tests in which I interviewed students $(n=22)$, experts $(n=15)$, and obtained interrater reliability with the instructors of each course $(n=4)$, I provided evidence that the IDSR is a quality assessment tool that accurately measures students' ID science thinking across varying course formats and institutions.

\section{Chapter 5}

Lastly, implications of the aforementioned studies are outlined in Chapter 5. The work provided in this dissertation marks the beginning of an opportunity to better train undergraduate students to think interdisciplinarily and collaborate across different fields of study, while increasing their ability to create outward-facing solutions to complex problems. 


\section{REFERENCES}

Bennington, G. (1999) Inter. In M. McQuillan, G. MacDonald, R. Purves, \& S. Thompson (Eds.), Post-theory: New directions in criticism. (p. 104). Edinburgh: Edinburgh University Press.

Boix Mansilla, V., \& Duraisingh, E. D. (2007). Targeted Assessment of Students' Interdisciplinary Work: An Empirically Grounded Framework Proposed. The Journal of Higher Education, 78(2), 215-237.

Boix Mansilla V., Duraisingh, E.D. Wolfe, C.R., Haynes, C. (2009). Targeted Assessment Rubric: An Empirically Grounded Rubric for Interdisciplinary Writing. The Journal of Higher Education, 80(3), 334-353.

Gazzaniga, M. S. (1998). How to change the university. Science, 282(5387), 237.

Lattuca, L. R. (2001). Creating interdisciplinarity: Interdisciplinary research and teaching among college and university faculty. Vanderbilt University Press.

Lattuca, L., \& Knight, D. (2010). In the eye of the beholder: Defining and studying interdisciplinarity in engineering education. In American Society for Engineering Education. American Society for Engineering Education.

Masse, L. C., Moser, R. P., Stokols, D., Taylor, B. K., Marcus, S. E., Morgan, G. D., ... Trochim, W. M. (2008). Measuring collaboration and transdisciplinary integration in team science. American Journal of Preventative Medicine, 35(2 Suppl), S151-60.

National Research Council. (2003). BIO2010: Transforming undergraduate education for future research biologists. National Academies Press.

National Research Council. (2009). A new biology for the 21st century. Washington, D.C.: National Academies Press.

Öberg, G. (2009). Facilitating interdisciplinary work: using quality assessment to create common ground. Higher Education, 57(4), 405-415.

Repko, A. F. (2008). Interdisciplinary research: Process and theory. Thousand Oaks, CA: Sage.

Stokols, D., Harvey, R., Gress, J., Fuqua, J., \& Phillips, K. (2005). In vivo studies of transdisciplinary scientific collaboration: Lessons learned and implications for active living research. American Journal of Preventive Medicine, 28(2 Suppl 2), 202-213.

Tripp, B., \& Shortlidge, E. E. (2019). A Framework to Guide Undergraduate Education in Interdisciplinary Science. CBE_Life Sciences Education, 18(2), es3. 
Tripp, B., Voronoff, S. A., \& Shortlidge, E. E. (2020). Crossing Boundaries: Steps Toward Measuring Undergraduates' Interdisciplinary Science Understanding. $C B E-$ Life Sciences Education, 19(1), ar8.

Tripp, B. \& Shortlidge, E. E. (2020). From Theory to Practice: Gathering Evidence for the Validity of Data Collected with the Interdisciplinary Science Rubric (IDSR). CBE-Life Sciences Education, in review. 


\title{
CHAPTER 2: THEORETICAL FRAMEWORK
}

\section{Published}

Tripp, B., \& Shortlidge, E. E. (2019). A Framework to Guide Undergraduate Education in Interdisciplinary Science. CBE—Life Sciences Education, 18(2), es3.

\begin{abstract}
An expanded investment in interdisciplinary research has prompted greater demands to integrate knowledge across disciplinary boundaries. Vision \& Change (2011) similarly made interdisciplinary expectations a key competency for undergraduate biology majors; however, we are not yet synchronized on the meaning of interdisciplinarity, making this benchmark difficult to meet and assess. Here we discuss aspects of interdisciplinarity from a historical lens and address various institutional barriers to interdisciplinary work. In an effort to forge a unified path forward, we provide a working definition of interdisciplinary science derived from both the perspectives of science faculty members and scientific organizations. We leveraged the existing literature and our proposed definition to build a conceptual model for an Interdisciplinary Science Framework (IDSF) to be used as a guide for developing and assessing interdisciplinary efforts in undergraduate science education. We believe this will provide a foundation from which the community can develop learning outcomes, activities, and measurements to help students meet the Vision \& Change core competency of "tapping into the interdisciplinary nature of science".
\end{abstract}




\section{INTRODUCTION}

Interdisciplinarity has evolved from a "buzzword" to a necessity with several leading funding agencies calling for shifts from predominantly disciplinary focused research endeavors to interdisciplinary collaborations (e.g. the National Science Foundation (NSF) and the National Institutes of Health (NIH)) (Rosenfield, 1999, Stokols et al., 2005, Masse et al., 2008, President's Council of Advisors on Science and Technology (PCAST), 2012). These organizations have acknowledged that key issues facing our society increasingly require the integration of multiple disciplines to propose solutions to vital, complex problems like global climate change, loss of biodiversity, and epidemics of infectious disease (Stokols et al., 2008, Klein, 2015, You et al., 2016). On a smaller scale, the bridging of traditional disciplines has occurred to address complex research questions, often resulting in new fields of study such as chemical ecology, biomedical engineering, and sociobiology (Lattuca, 2001, Klein, 2015). These emerging fields of research open up new arenas where researchers think, act, and potentially teach beyond the scope of a single discipline (Repko, 2008, Boix Mansilla et al. 2009, Frodeman et al., 2017).

In alignment with funding agencies' initiatives, the NSF and the American Association for the Advancement of Science (AAAS) held a series of meetings that outlined a number of priorities, including the idea that higher education should be better preparing undergraduate biology students for an increasingly interdisciplinary scientific workforce. A report from these meetings, Vision and Change in Undergraduate Biology Education (2011), charged the community to equip undergraduate biology students with an improved skillset which includes harnessing six core competencies by the completion of their undergraduate degree. The ability to 
"tap into the interdisciplinary nature of science" is one of these competencies. This competency may be challenging to meet for a variety of reasons including: (1) the historical prominence of siloed disciplines (Klein, 1990, Moran, 2002, Repko, 2008, Weingart, 2010), (2) institutional barriers that inhibit cross-pollination of disciplines (Moran, 2002, Weingart, 2010, Scott et al., 2014), and (3) ambiguity and discord on a unified definition (Bennington, 1999, Lattuca \& Knight, 2010). If institutions nationwide are charged with distilling this competency to undergraduates, we must first have a unified understanding of: what the competency entails; the kinds of experiences an undergraduate student might feasibly gain in interdisciplinary science; what proficiency in this competency would look like; and how to measure those expected outcomes. Simply put, the problem of how to meet this competency and what to measure remains largely ambiguous.

In this essay we provide an overview of the challenges that interdisciplinary studies have generally faced, address the current state of academic culture as it relates to interdisciplinarity, and summarize varying definitions of interdisciplinarity borrowed from the humanities and the sciences. We then provide a working definition of interdisciplinary science, derived from both the literature and our own research probing the expertise of over 180 faculty members. We conclude by presenting an Interdisciplinary Science Framework (IDSF), curricula that align with the model, and an example of how to apply the IDSF to a science course as a launch point for practitioners to develop and/or assess instruction that fosters students' ability to tap into the interdisciplinary nature of science. 


\section{HISTORY OF INTERDISCIPLINARITY}

The term 'interdisciplinary' first surfaced in the early twentieth century, being used by the Social Science Research Council as a bureaucratic shorthand for the promotion of research that involves more than one discipline (Frank, 1988). Around the same time, an increased interest in the meaning of integration at the postsecondary level surfaced, with emphasis on developing the "whole" person through the general education movement (Klein, 2005). Through the publication of a book called Integration: Its Meaning and Application (Hopkins, 1935), ideas of unity emerged but were quickly stifled, as participants in a meeting held by the National Education Association concluded that complete unity was impossible (Klein, 2005), clarifying that deeper knowledge in the disciplines was more important. This favor toward the disciplines dates back to Aristotle's influence in $387 \mathrm{BC}$, when classical division of knowledge was enacted based on a hierarchy of disciplines, with philosophy at the top, physical and natural sciences following, and all other disciplines ranked by importance in a step-wise fashion toward the bottom (Moran, 2002).

Although hints of interdisciplinarity slowly continued to be woven into research and education, little attention was paid to the underlying cultural and societal implications of interdisciplinarity until the 1960s. Philosopher Michael Foucault, guided by ideas from German philosopher Friedrich Nietzsche, stated that the separation of disciplines was not only a way to produce and categorize knowledge, but also a sophisticated means for "regulating human conduct and social relations" (Moran, 2002). Foucault believed that the hierarchical structure of disciplines legitimized and substantiated social and cultural power differentials by advantaging 
individuals that had the financial means to attend specialized, disciplinary training (e.g. college, trade school) (Moran, 2002). This led to certain opportunities being funneled to wealthy, gender-race-dependent populations that had the disciplinary training and skillset required to occupy exclusive, high paying professions (Katz, 2001).

During the Vietnam War and subsequent student revolutions, a shift in the nature of the academic environment began to take place (Repko, 2008). This shift edged towards Foucault's perspective, highlighting the limitations of disciplines' abilities to adequately address burgeoning social issues that characterized the period, such as civil rights, anti-imperialism, and feminist movements (Katz, 2001). Thus, a desire for interdisciplinary connections between disciplines emerged. Nevertheless, this enthusiasm towards academic and social reform through interdisciplinary study wavered until pioneers in the humanities, namely, Julie Thompson Klein and William H. Newell, resurrected its importance in the late 1970's (Repko, 2008). Klein began to question what constituted legitimate subjects of inquiry by examining the history, theory, and taxonomies surrounding interdisciplinarity (Klein, 1990, 1996, 2000). Newell formed a professional organization, the Association for Integrative Studies (AIS), and journal, Issues in Integrative Studies, to analyze interdisciplinary methodology, curricula, and administration, which became a professional home for interdisciplinarians (Repko, 2008). Following their lead, incremental but consistent advances in interdisciplinary studies emerged in the social sciences and humanities (Weingart, 2010).

In the 21 st century, this mode of thinking is increasingly being adopted in science, technology, engineering, and mathematics (STEM), as researchers struggle to 
answer radically complex issues from a single disciplinary viewpoint (Pellman \& Eisenberg, 2000, Welch, 2003, Masse et al., 2008, National Research Council (NRC), 2009, PCAST, 2012). A NRC report (2009) makes this clear in a 'New Biology Initiative' aimed to achieve solutions to societal issues requiring "the creative drive and deep knowledge base of individual scientists from across biology and many other disciplines including physical, computational and geosciences, mathematics, and engineering." Further, it states that: "Science and technology, alone, of course, cannot solve all of our food, energy, environmental, and health problems. Political, social, economic, and many other factors have major roles to play in both setting and meeting goals in these areas. Indeed, increased collaboration between life scientists and social scientists is another exciting interface that has much to contribute to developing and implementing practical solutions." The BIO2010 report (NRC, 2003) extends this need from interdisciplinary research to science education: "Exposing today's undergraduates to a more interdisciplinary curriculum will help them to better collaborate with their scientific peers in other disciplines as well as design more interdisciplinary projects on their own." In the wake of this ongoing revelation, Vision and Change catapulted interdisciplinarity to the forefront of life science higher education, by calling for students to tap into the interdisciplinary nature of science as one of six core competencies.

\section{INSTITUTIONAL BARRIERS}

In our intention to understand interdisciplinarity within an undergraduate environment, we would be remiss to ignore the university's role in reinforcing disciplinary boundaries in research and teaching practices. Establishing a productive 
research environment can be an important marker of a university's success and requires hiring experts trained in specific disciplinary areas. This brings in highly coveted skills and provides social recognition for successes and innovation at the department and institutional level. Although disciplinary research undeniably produces essential building blocks of knowledge (Repko, 2008, Frodeman, 2017), attempts to cross over well-defined disciplinary boundaries can come with a litany of bureaucratic barriers, including that research is often geared towards external funding and donor interests (Klein 1990, 1996, Giri, 2002). Until recently, funding agencies dominantly rewarded discipline-specific projects and proposals, thus placing higher value on disciplinary work, possibly at the expense of building knowledge across disciplines (Klein, 2000, Weingart 2010). These reward structures favoring disciplinary work over interdisciplinary work inevitably impacts academic culture and attitudes around interdisciplinary pursuits (Fennel \& Sandefur, 1983, Klein, 1996, Gazzaninga, 1998, Weingart, 2010). Faculty may have diminished motivation to pursue interdisciplinary research if it is not recognized or rewarded.

A 1998 editorial in Science (Gazzinga, 1998) also discusses the modern university system being subdivided into disciplinary lines in science for the purpose of bureaucratic interests. Reward systems seem particularly salient in the sciences given the heavy dependence on external funding. Further, if disciplinary research is incentivized in the university system, it inadvertently permeates teaching practices (Lattuca, 2001). For example, logistical issues associated with cross-listed courses from multiple departments can be complicated, with confusion about which department pays instructors, receives student tuition credit hours, and/or develops curricula that aligns with each department's vision. Furthermore, faculty hiring 
decisions are subject to the same departmental structures that preside over career advancements (e.g. promotion and tenure) (Gazzinga, 1998, Pellmar \& Eisenberg, 2000). If departments mostly seek, hire, and promote faculty highly trained in discrete areas of science, a lack of expertise in interdisciplinary sciences will be a barrier to teaching interdisciplinary courses. Likewise, disciplinary identities among these faculty can trickle down to the students who are taught and mentored in such departments, potentially shaping students into scientists that embody similar identities (Pellmar \& Eisenberg, 2000). Moran (2002) highlights the disciplinary reward system and teaching feedback loop:

"The emergence of a new academic subject depends partly on internal factors: on elite universities recognizing [disciplines] through the creation of separate departments, sufficient students and lectures being recruited to study and teach it, learned societies and journals forming around it, and recognized career structures developing, usually based on the acquisition of a PhD in that subject. Moreover, since disciplines [are] influenced by such institutional factors, they tend, like many institutions, to reproduce themselves and become self-perpetuating."

This is not to say that deep, grounded knowledge in disciplines is not advantageous. A traditional approach to disciplinary understanding serves great value and is necessary as "students begin to feel a sense of mastery and develop a professional identity" (Pellmar \& Eisenberg, 2000); however, expertise and identity may fall short of being able to address the rapid changes in the life sciences (NRC, 2003, 2009, PCAST, 2012). Being cognizant of such patterns is important as we seek 
to conceptualize and assess interdisciplinary understanding from the perspective of our students.

Despite various barriers that departments and practitioners may face, interdisciplinary science programs and courses are increasingly being developed and championed through funding agencies, with local and national incentivization for interdisciplinary collaborations among practitioners and students alike. As educators, we can begin to navigate the landscape by first identifying the core meaning of interdisciplinarity.

\section{A CONTENTIOUS DEFINITION}

A constellation of disciplinary hierarchy, departmental siloes, and institutional barriers have created the perfect storm for a fractured understanding of the term interdisciplinarity (Bennington, 1999, Repko, 2008). This lack of common ground can be amplified in the sciences due to jargon, professional norms, and practices that vary across disciplines (Fennel \& Sandefur, 1983). As there is a perception that interdisciplinary studies emerge from disciplines themselves (Fuchsman, 2009), it seems appropriate to first define its root word 'discipline'. A 'discipline' is a particular branch of learning or body of knowledge that can be distinguished by several factors including the questions it asks via its ontological lens, epistemology, and methodology regarding how these ideas are used to contribute to a body of knowledge comprised of concepts, theories, and facts (Newell \& Green, 1982). In a general sense, disciplines are the foundation with which we make sense of the world around us. However, each discipline comes with its own underlying assumptions and nuanced lens (Bauer, 1990, Repko, 2008). Exchanging those lenses for a unified eye- 
piece can require layered and intentional amalgamation of differing paradigms, which is by no means simple. As the borders between disciplines blur, epistemologies are challenged, which can in turn, hinder integration (Guba \& Lincoln, 1994, Rogers et al., 2005, Fuchsman, 2009).

Another discrepancy surrounding the definition of interdisciplinarity arises from its undefined role related to disciplinary foundations. Moran (2002) describes this discrepancy as competing impulses - in one camp, the concept of interdisciplinarity is founded on traditional disciplines through a "wide-ranging total knowledge of a single subject"; in the other camp, interdisciplinarity is radically subversive to this - it seeks to answer questions that cannot be answered by the very disciplinary foundations that support it. Furthermore, the etymology of the prefix 'inter' can have multiple meanings: between or joining (e.g. intercellular or intercalate) to being separated and lying apart (e.g. interval or intervene) (Bennington, 1999). Bennington states, "The term interdisciplinarity is slippery: It can suggest forging connections across the disciplines; but it can also mean establishing a kind of undisciplined space in the interstices between disciplines, or even attempting to transcend disciplinary boundaries altogether”. Bennington suggests that this ambiguity is what gave the term interdisciplinarity a myriad of other prefixes - post-, cross-, pluri-, multi-, anti-, trans-disciplinary_and are often used interchangeably with the term interdisciplinary causing further ambiguity. This exchange of prefixes is directly reflected within the Vision and Change report where the term 'multidisciplinary' describes 'interdisciplinary’ practices in the fourth Core Competency, and calls for 'cross-disciplinary' work to achieve connections between science and society in the last Core Competency (AAAS, 2011). For the purposes of 
this essay and to minimize confusion, we will use the term interdisciplinarity - the integration of multiple disciplines, leading to new ideas - to remain in line with the most common verbiage and distilled meanings from national initiatives and literature. A more nuanced analysis of the definition is provided below.

Despite the aforementioned barriers, as researchers have taken detached pieces of information and/or tools from existing disciplinary frameworks_-added, modified, deleted, or reshaped them to fill gaps of knowledge - new boundaries have been drawn, which we label as interdisciplinary fields (Repko, 2008). Sometimes, as mentioned previously, an "interdiscipline" becomes disciplinary in nature, such as sociobiology or biochemistry (Klein, 2000), creating a cyclical loop from disciplinary-to-interdisciplinary-to-new disciplinary fields. It takes time for a field to gain enough momentum to become a new discipline (Lattuca, 2001, Klein, 2005). Interdisciplinarity is a process — not an outcome — perhaps explaining slow recognition and adoption by disciplinary purists on the meaning and value of interdisciplinary studies.

\section{PROPOSED RESOLUTIONS}

The Disciplines' Definitions

Despite the historical, institutional, and etymological barriers surrounding interdisciplinary endeavors, literature in the social sciences and natural/physical sciences has attempted to define interdisciplinarity. Interdisciplinary understanding has been defined in social sciences as "the capacity to integrate knowledge and modes of thinking in two or more disciplines or established areas of expertise to produce a cognitive advancement—such as explaining a phenomenon, solving a problem, or 
creating a product — in ways that would have been impossible or unlikely through single disciplinary means" (Boix Mansilla et al., 2000).

The NSF has accepted the definition of interdisciplinary research set forth by a National Academies of Science report from the Committee on Facilitating Interdisciplinary Research and the Committee on Science, Engineering, and Public Policy (2004): "Interdisciplinary research is a mode of research by teams or individuals that integrates information, data, techniques, tools, perspectives, concepts, and/or theories from two or more disciplines or bodies of specialized knowledge to advance fundamental understanding or to solve problems whose solutions are beyond the scope of a single discipline or area of research practice." The main difference between these two definitions reside in their objective - the former describes a way of understanding, while the latter involves the application of interdisciplinary research.

\section{The Faculty's Definition}

As the above definitions are derived from interdisciplinary understanding in the social sciences and interdisciplinary research in the natural and physical sciences, respectively, we sought for a definition targeted toward what interdisciplinary science might look like in the context of undergraduate science students. Current higher education faculty are on the frontline of planting the seed for science students to start thinking interdisciplinarily. Yet, there is little understanding of how faculty conceptualize interdisciplinary science — from both a research and a pedagogical perspective. To establish a universal definition addressing both of these aspects, we collected multiple definitions of "interdisciplinary science" by surveying faculty across scientific disciplines and departments asking: "How do you define 
interdisciplinary science?” (see APPENDIX A: for sample demographics). Three researchers conducted content analysis of 184 open-ended survey responses resulting in six salient themes (Table 1). Interrater reliability was obtained through multiple iterations of prevalent themes on 80 responses $(\kappa=.73)$, resulting in a final codebook. All three researchers then equally divided the remaining 90 responses and coded them based on thematic identification. As a final check for coding consistency, an additional researcher unrelated to the initial coding process, but trained on the project details and application of the codebook, examined all survey responses for accuracy of themes. We used the emergent themes and our analysis of the literature to develop a working definition of interdisciplinary science with the intention of it being relevant to undergraduate science students and experts alike.

Five of the six salient themes from faculty responses offered definitions of interdisciplinary science that contain constituent parts from both of the previously presented definitions from the social sciences literature and scientific research funding agencies. A theme that was regularly included in our participants' and NSF's definitions, but was excluded from the social science literature, was the idea that interdisciplinarity involves collaboration (Table 1). The relevance of this theme is supported by a study that evaluated expected learning outcomes for graduate students involved in the NSF's (former) Integrative Graduate Education and Research Traineeship (IGERT) program (Borrego \& Newswander, 2010). Using elements from the humanities (Repko, 2008) and an interdisciplinary social science rubric (BoixMansilla et al., 2009), researchers scored IGERT grant proposals with the rubric to look for interdisciplinary elements in the stated graduate student learning outcomes. Their findings provided a compelling argument that interdisciplinary science requires 
collaboration between disciplines, as an essential factor for interdisciplinary work in the natural and physical sciences. This should come as no surprise as science is simply too vast for any one individual to be an expert in the multiple fields necessary to solve complex issues (NRC, 2003, 2009). Thus, we propose a working definition of interdisciplinary science derived from a survey of science faculty and various published work:

Interdisciplinary science is the collaborative process of integrating knowledge/expertise from trained individuals of two or more disciplines-leveraging various perspectives, approaches, and research methods/methodologies - to provide advancement beyond the scope of one discipline's ability.

Aside from collaboration being identified as essential to interdisciplinary science, all three definitions are not markedly different from one another. This suggests that science faculty are indeed aware of the key elements involved in interdisciplinary science as defined by STEM and non-STEM disciplines; however, whether they are also developing learning goals related to this competency remains unknown. Of 184 faculty participants in our survey study, $45 \%(n=84)$ did state having interdisciplinary learning outcomes in response to the question: "Does your course have learning outcomes related to students' understanding of the interdisciplinary nature of science?". With ongoing calls for interdisciplinary science efforts, it is important to determine how we can better support faculty to create and embed learning outcomes related to interdisciplinary science for undergraduates. Here we aim to provide an evidence-based launch point for undergraduate instructors to develop learning goals and outcomes relate to interdisciplinary science practices. This study was approved by Portland State University’s Internal Review Board \#174219. 
Table 1. Top six emergent themes from surveyed science faculty $(n=184)$ on how they define interdisciplinary science*.

\begin{tabular}{lcc}
\hline Top themes among Interdisciplinary Science Definitions & $\mathrm{n}$ & $(\%)^{+}$ \\
\hline Involves two or more disciplines & 173 & 94.0 \\
Use of multiple/differing research methods/methodology & 79 & 43.0 \\
Collaboration among individuals & 52 & 28.3 \\
Need for other/additional disciplinary knowledge/expertise & 52 & 28.3 \\
Having various perspectives, theories, approaches & 48 & 26.1 \\
Addresses problems that cannot be solved by one discipline & 37 & 20.1
\end{tabular}

* Interrater reliability of greater than $80 \%$ was obtained.

${ }^{+}$Themes do not add up to $100 \%$ as individuals made statements that were coded to multiple themes.

\section{CONCEPTUAL FRAMEWORK}

We leveraged the above science faculty definition as a blueprint for

developing a framework for educators to engage undergraduate students in interdisciplinary understanding. The theoretical base of our model incorporated constructs from researchers who suggest that students need multiple ways of knowing to address interdisciplinary understanding, including: a basic understanding of contributing disciplines (disciplinary grounding) and how the disciplines integrate to advance the solution of a question toward a common goal (advancement through integration) (Boix Mansilla \& Duraisingh, 2007, Öberg 2009). The influence of these two interrelated criteria, combined with the concept of disciplinary humility, gleaned from the environmental sustainability literature (Byrne et al., 2016); and different research methods and collaboration across disciplines, salient constructs from our faculty experts, formed the groundwork for our conceptual model: the Interdisciplinary Science Framework (IDSF) (Figure 1). In the next portion of this essay, we provide justification for the selection and inclusion of these five criteria we have found to be relevant to interdisciplinarity in the natural and physical sciences. 
By defining these elements, we intend for practitioners to conceptualize and identify activities and anticipated learning outcomes that foster and demonstrate students' interdisciplinary science understanding. On a much broader scale, we hope that this framework serves as a platform by which to foster communication and collaboration within and between STEM and non-STEM disciplines.

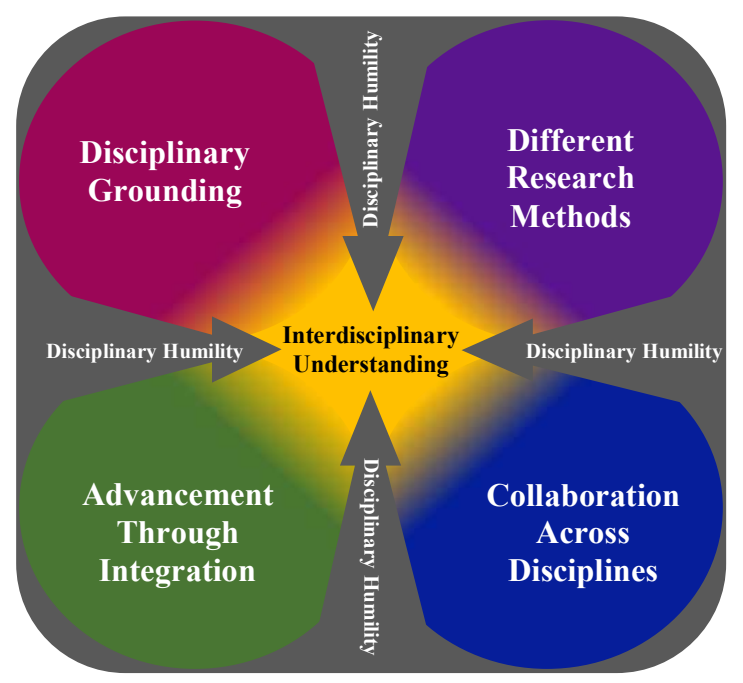

Figure 1. Interdisciplinary Science Framework (IDSF) for guiding students to tap into the interdisciplinary nature of science.

\section{CRITERIA OUTLINED}

\section{Disciplinary Humility}

As students begin an exploration of disciplines outside of their major, developing a mindset, or epistemic perspective, that is infused with humility, inclusivity and respect for other disciplinary epistemologies is a foundational criterion we label as disciplinary humility. Disciplinary humility has been deemed a 
“prerequisite to and basis for transdisciplinary conversations and transcendent knowledge generation" (Byrne et al., 2016). We have adapted and applied this phrase to interdisciplinary understanding - in order to work across disciplines, it is imperative to remain reflexive about one's limitations in knowledge, skill, and awareness of personal biases (NRC, 2015). We encourage students to start this metacognitive effort by infusing disciplinary humility into their mindset at the inception of interdisciplinary thinking, research, and collaborations. Doing so will allow space for respectful evaluation of similarities and differences between disciplines and among individuals.

To acquire disciplinary humility, we suggest that undergraduate STEM students make connections between STEM and non-STEM disciplines in relation to real-world issues. Students should be given the opportunity to recognize how STEM disciplines constantly interface with society, policy, economy, community relations, and relevant stakeholders to effectively progress towards workable solutions (NRC, 2003, 2009, AAAS, 2011, Bammer, 2013). Longitudinal comparisons of STEM students engaged in interdisciplinary work that intersects with the social sciences and humanities have shown that these populations have more receptivity to new ideas; are more sensitive to ethical issues due to the exposure of non-STEM perspectives; integrate disciplinary insights more holistically; exhibit more humility, and "move beyond tolerance to a celebration of diversity" (Newell, 1986, 1990). Likewise, we believe that the acquisition and growth of disciplinary humility has the potential to reduce the positive feedback loop of disciplinary superiority, and is therefore a thread that runs throughout the IDSF. 


\section{Disciplinary Grounding and Different Research Methods}

As students begin their journey toward interdisciplinary science understanding, a grounding in disciplinary knowledge must be present. The notion that a student should develop a strong disciplinary grounding has been recommended to reduce the risk of "a mile wide and an inch deep" or a "light educational experience" (Boix-Mansilla \& Duraisingh, 2007). We agree that if no foundation of disciplinary knowledge is present, the ability to draw accurate connections between disciplines would be tenuous. Clearly the depth of a student's knowledge (on a novice to expert scale) in any one discipline will depend on programmatic expectations and vary among individual's past experiences and knowledge. Although many students do begin to develop robust disciplinary-knowledge platforms, requiring undergraduate students to be experts in any one discipline, let alone all disciplines involved, is likely unreasonable (Boix-Mansilla \& Duraisingh, 2007, Full et al., 2013). We suggest that being grounded in disciplinary content means that students must be at least provisionally knowledgeable in possible disciplines involved in a question or activity at hand, yet maintain accessible, deeper knowledge from a single discipline. For example, if a student/student group is tasked with solving a problem regarding declining bee populations, a plant biology major will have discipline-specific knowledge to contribute, such as factors influencing plant-pollinator interactions; yet they may have less depth of (but provisional) knowledge regarding agriculture, chemistry, and climatological factors influencing honeybee populations. The NRC (2009) supports this idea: “The New Biologist is not a scientist who knows a little bit about all disciplines, but a scientist with deep knowledge in one discipline and a "working fluency" in several." 
Alongside the development of disciplinary knowledge, acquisition of different research methods can aid in students' operationalization of how best to tackle realworld problems. In our search for an all-encompassing definition from faculty, the inclusion of different research methods was indeed a seminal theme in interdisciplinary science (Table 1). Reinforcing this idea, the Committee on Facilitating Interdisciplinary Research (National Academy of Sciences, 2004) suggested that "educators should facilitate interdisciplinarity by providing educational and training opportunities for undergraduates... such as data gathering and analysis, and research activities to other fields of study and to society at large."

We would like to distinguish research methods from methodology: methods are the tools and/or instruments used to answer a problem or research question, while methodology is the deep, philosophical assumptions and rationale for using said methods (Hyett et al, 2014). Undergraduates may not have enough exposure to philosophical or epistemological rationales for why certain methods are used, especially across non-STEM disciplines. Current undergraduate science curricula are often lacking ontological and epistemological underpinnings that govern disciplinary bodies of knowledge, contributing to students falling short in these areas (Lederman, 2007, Vasquez et al, 2016). But it is reasonable for students to understand the general purpose of using different methods such that they can create a toolkit of possible techniques/instruments that are appropriate from each discipline. To reach beyond a "grab bag" of methods, we encourage integration and collaboration between individuals who hold disciplinary expertise, potentially incorporating more methodological reasoning behind the selected methods. 


\section{$\underline{\text { Integration and Collaboration }}$}

Another criterion outlined by Boix Mansilla \& Duraisingh (2007) was advancement through integration which included the "capacity to use knowledge flexibly". Students should to be able to use previous information flexibly to create new understanding or knowledge, rather than regurgitating siloed pieces of information that were given to them. When students use knowledge flexibly, they can apply different pieces of disciplinary knowledge in a unique way that culminates in an outcome that would not have been possible through the use of one discipline alone. This means that students are not only collecting the appropriate disciplinary pieces of information and placing them in a central repository, but are also proficient at integrating — mixing, connecting, and applying them to discover new insights or ideas. A defining element of integration is combining disciplinary components into unique combinations to produce a product entirely distinguishable from its constituent parts. In doing so, the whole becomes greater than the sum of the individual disciplines (Newell, 1990, Boix Mansilla \& Duraisingh, 2007). Students can best accomplish this by collaboratively leveraging different disciplinary chunks of knowledge, methods, and methodological reasoning to advance their understanding.

The fourth criterion, collaboration, is an interaction that complements and enhances all previous criteria and would likely help students develop disciplinary humility, understand their own disciplinary grounding, enhance awareness toward the purpose of various research methods/methodologies, and help them achieve integration across disciplines. Although collaboration is best embodied through the practice of interdisciplinarity and the participation of players, a student in their undergraduate career may not have an opportunity to engage in interdisciplinary 
research and collaboration, as indicated by an overwhelming call for interdisciplinary ideas in undergraduate education. However, we uphold that students can at least start thinking and preparing for interdisciplinary collaborations by identifying markers that make collaboration successful. A successful collaboration involves the establishment of common ground (Lattuca, 2001, Klein, 2005, Öberg, 2009). According to a National Academy of Sciences study (NAS, 2005) on interdisciplinary research, "Researchers desiring to work on interdisciplinary research, education, and training projects should immerse themselves in the languages, cultures, and knowledge of their collaborators." Scholars suggest that "newcomers" of interdisciplinarity, however, do not spend enough time on creating common ground, which leads to frustration, anger, inability to cope, and ultimately discontinued work. Ways to circumvent these barriers is by becoming aware of one's own tradition (disciplinary grounding) and becoming familiar with traditions of other disciplines (content, perspectives, and associated research methods). Another aspect of common ground involves identification of commonalities and discrepancies (Klein, 2005): What are the terms/phrases and underlying assumptions between disciplines? Do they have similarities (meaning of electrical current in physics vs. electrical current in biology)? Do they have differences (meaning of heat in climatology vs. thermal energy in chemistry)? In order to identify these similarities and differences, each member of the collaboration must approach the partnership with an open-mind (disciplinary humility) and an aim to integrate each contributing discipline to further advance the solution beyond the capability of a single discipline (advancement through integration). 
Öberg (2009) suggests that the final part of establishing common ground is sharpening the aim of the research question or issue - this involves anchoring the approach all the way from the framing of the study or solution, to the choice and use of methods, and into the analysis. In the evolution of becoming a team, individuals from both STEM and non-STEM disciplines can leverage one another to frame the study appropriately through disciplinary grounding, selection of different research methods appropriate to the research question or problem, become familiar with the general purpose behind certain methods and a deeper understanding of other disciplines' methodologies, and analyze how each discipline will be integrated to contribute to the whole. Through the ongoing infusion of disciplinary humility, these pieces can coalesce in an integrated fashion.

\section{Applying IDSF to CURRICULA}

To set the stage for students to understand the interdisciplinary nature of science, faculty will need to create authentic opportunities for students to think about and/or engage in interdisciplinary science. Here we provide several examples of studies that highlight elements of the IDSF in their published instructional materials (Table 2).

When designing interdisciplinary curricula, instructors may grapple with the degree of appropriate integration between disciplines. Newell (1990) reviews several mechanisms to support varying levels of integration - from traditional disciplinary courses that borrow one learning objective from another discipline, to fully integrated courses that have no disciplinary divisions. Gouvea et al. (2013) provide a useful 
guide for instructors to assess what level of interdisciplinarity must be present to support the learning objectives of science instruction when designing interdisciplinary curricular tasks.

Many researchers recognize that students must be provided with baseline knowledge from contributing disciplinary perspectives, methods, and ways of addressing questions about the real world before they can successfully integrate those disciplinary pieces of information (Newell, 1990, Boix Mansilla et al, 2007, Repko, 2009, Caudill et al., 2012). Watkins et al. (2012) highlight the importance of disciplinary grounding as they expose students to what they deem "disciplinary authenticity." The authors contextualize how methods used by physicists and biologists can address similar phenomena in different but complimentary ways. For example, they describe how physicists may employ concepts of van der Waals forces and capillarity action when investigating how geckos climb smooth surfaces, while evolutionary biologists may examine the anatomy of modern-day gecko toes and compare them with fossils of geckos' prehistoric ancestors. Here, students were able to examine different disciplinary methods and concepts to better understand multiple angles of the same phenomenon. In a more heavily emphasized disciplinary approach, Gouvea et al. (2013) and Thompson et al. (2013) introduced interdisciplinary science concepts only after students had exposure to prerequisite disciplinary courses, as this provided students with firm disciplinary knowledge that could then be integrated and applied toward interdisciplinary problems.

The implementation of modules has been a popular approach to integrating physics and biology courses, as adoption of such practices are easier to embed into a course than redesigning an entire curriculum. Thompson et al. (2013) reports on the 
National Experiment in Undergraduate Science Education (NEXUS) project that integrates modules containing basic understanding of biological and physical properties and general scientific skills, such as modeling, problem solving, multiple scientific representations, and experimental design. Similarly, Woodin et al. (2012) provides an extensive list of eleven projects that feature modules and materials for specific courses that advance integration though different disciplinary research methods and concepts, including active learning activities that involve collaboration across disciplines. In the $\mathrm{BIO} 2010$ report (NRC, 2009), a comprehensive review of modules is provided that support integration of STEM disciplines, as well as useful websites that compile interdisciplinary science education resources. Examples of project-based laboratories that compile different research methods from STEM disciplines are also covered, further elucidating the importance of interdisciplinary laboratory skills. In addition, a study by Full et al. (2015) outlines a framework for interdisciplinary laboratory courses that involved students rotating between "stations" of different disciplines where they learned concepts and research techniques. This was followed by students collaboratively addressing a novel issue by employing the different methods that they learned from each discipline.

Another common thread in the literature is an increase in the number of different disciplinary faculty required to develop interdisciplinary curricula. In particular, collaboration between faculty in different disciplines was necessary to correctly identify commonalities and overlapping concepts among disciplines (NRC, 2009). For instance, Redish \& Cooke (2013) provide a case study of two faculty member's efforts in developing curricula between physics and biology by acknowledging commonalities and differences, and as a byproduct, an increased 
space for common ground and mutual respect of the each other's disciplinary domains were developed (i.e. disciplinary humility). This could be an opportunity to transfer these lessons to students: allowing students to work in tandem with one another, ideally students from different majors, could potentially foster disciplinary humility through collaboration.

In our curricular review, we noted a paucity of literature on partnerships and connections outside of STEM disciplines, possibly for reasons related to the sociohistorical and institutional challenges of interdisciplinarity previously discussed in this essay. Similarly, there are reports of a pervasive attitude among STEM students about what science is and is not, deeply rooted in epistemic beliefs about what constitutes domains of scientific knowledge (Redish \& Hammer, 2009, Gouvea et al., 2013). This often comes at the expense of non-STEM disciplines. We propose that changing these attitudes starts with faculty providing real-world applications for students to connect science and society.

Although inclusion of students connecting social sciences and humanities to STEM is not explicitly stated in Vision and Change (AAAS, 2011), it is impossible to address the complex issues of today without connecting STEM and non-STEM disciplines. Science instructors ought to inclusively teach science as it exists in the real-world - in constant flux between and within cultural, social, and political influences (NRC, 2009). Situating interdisciplinary science pedagogy in the context of students' everyday lives (real-world) can thus provide relevance and pathways to meaningful learning (Newell, 1990, Weber, 2016, Cooper \& Stowe, 2018). In this vein, Newell (1990) recommends a topical approach to interdisciplinary pedagogy where instructors design curricula through the lens of a relatively broad but singular, 
complex topic, such as "energy crisis", pulling on the perspectives of chemistry, physics, geology, biology, mental health, and community. These topical approaches not only provide an avenue for students to naturally integrate seemingly disparate disciplines, but it can develop a level of disciplinary humility by recognizing the necessity of non-STEM disciplines. Similarly, to facilitate disciplinary humility more directly, opportunities for philosophical dialogue regarding other disciplines should also be woven into curricula. Eigenbrode et al. (2007) provide a toolbox of questions designed to marry competing philosophical aspects of disciplinary research and may aid in STEM students' inclusion of non-STEM disciplines and their development of disciplinary humility. 
Table 2. Review of interdisciplinary instructional studies that align with the IDSF's criteria.

\begin{tabular}{|c|c|c|c|c|c|c|}
\hline AUTHOR(S) & RESOURCES & $\begin{array}{l}\text { DISCIPLINARY } \\
\text { GROUNDING }\end{array}$ & $\begin{array}{l}\text { DIFFERENT } \\
\text { RESERCH } \\
\text { METHODS }\end{array}$ & INTEGRATION & COLLABORATION & $\begin{array}{l}\text { DISCIPLINARY } \\
\text { HUMILITY }\end{array}$ \\
\hline $\begin{array}{l}\text { Full et al., } \\
2013\end{array}$ & $\begin{array}{l}\text { Framework for creating } \\
\text { interdisciplinary labs }\end{array}$ & $\sqrt{ }$ & & $V$ & & \\
\hline $\begin{array}{l}\text { National } \\
\text { Research } \\
\text { Council, } \\
2009\end{array}$ & $\begin{array}{l}\text { Examples of modules, } \\
\text { teaching materials, } \\
\text { interdisciplinary content \& } \\
\text { laboratory guidelines }\end{array}$ & & & & & \\
\hline $\begin{array}{l}\text { Woodin et } \\
\text { al., } 2012\end{array}$ & $\begin{array}{l}\text { Provides eleven projects } \\
\text { that feature materials to } \\
\text { embed in specific courses } \\
\text { or modules }\end{array}$ & & & & & \\
\hline $\begin{array}{l}\text { Gouvea et } \\
\text { al., } 2013\end{array}$ & $\begin{array}{l}\text { Framework for analyzing } \\
\text { models, graphs, and essay } \\
\text { questions }\end{array}$ & & & & & 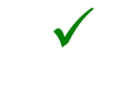 \\
\hline $\begin{array}{l}\text { Gentile et } \\
\text { al., } 2012\end{array}$ & $\begin{array}{l}\text { Examples and materials for } \\
\text { integrating STEM } \\
\text { disciplines }\end{array}$ & & & & & \\
\hline $\begin{array}{l}\text { Thompson } \\
\text { et al., } 2013\end{array}$ & $\begin{array}{l}\text { Examples of modules that } \\
\text { integrate physics and } \\
\text { biology }\end{array}$ & & & & & \\
\hline $\begin{array}{l}\text { Newell, } \\
1990\end{array}$ & $\begin{array}{l}\text { Instructor guidelines for } \\
\text { implementing } \\
\text { interdisciplinary curricula }\end{array}$ & $\sqrt{ }$ & & $\sqrt{ }$ & & \\
\hline $\begin{array}{l}\text { Weber, } \\
2016\end{array}$ & $\begin{array}{l}\text { Examples of multiscalar } \\
\text { topics that address real- } \\
\text { world problems }\end{array}$ & $\sqrt{ }$ & & $\sqrt{ }$ & & \\
\hline $\begin{array}{l}\text { Watkins et } \\
\text { al., } 2012\end{array}$ & $\begin{array}{l}\text { Examples of how to create } \\
\text { exams and homework } \\
\text { questions that use concepts } \\
\& \text { tools from biology and } \\
\text { physics to address a similar } \\
\text { problem }\end{array}$ & & $\sqrt{ }$ & & & \\
\hline $\begin{array}{l}\text { Redish \& } \\
\text { Cooke, } \\
2013\end{array}$ & $\begin{array}{l}\text { Case study on instructor } \\
\text { perspectives of disciplinary } \\
\text { humility and collaboration }\end{array}$ & $\sqrt{ }$ & & & & \\
\hline $\begin{array}{l}\text { Eigenbrode } \\
\text { et al., } 2007\end{array}$ & $\begin{array}{l}\text { Provides a toolbox for } \\
\text { facilitating different } \\
\text { philosophical perspectives } \\
\text { and aspects of research }\end{array}$ & & & & & \\
\hline
\end{tabular}

\section{$\underline{\text { IDSF Curricular Example }}$}

To provide a concrete example of how to apply our theoretical model to a classroom, this section outlines a module developed with the IDSF through backward design. Backward design is a pedagogical strategy that intentionally aligns learning goals, outcomes, assessments, and activities (Wiggins \& McTighe, 1998, Handelsman et al., 2007). We present a hypothetical upper-division Environmental Issues course 
that uses a novel, active-learning deliberative democracy (DD) pedagogy designed by researchers at Portland State University (Komperda et al., 2018). The goal of DD is to present modern issues in science and society where students work in peer groups to reach consensus on how to address a complex, real-world problem that relates to scientific topics learned in the course. Here, we use DD as a pedagogical tool to challenge students to address declining honeybee populations. We then assess students' knowledge through a DD group worksheet followed by an individual writing assignment related to a separate, real-world issue.

First, we recommend selecting learning goals based on the five criteria in the IDSF (Table 3). Students could be assigned to groups of six and tasked with identifying what disciplines may need to be involved to fully address the problem of declining honeybee populations. Next, students could assign disciplinary roles to one another, representative of the disciplines needed to tackle the problem, such as: an agronomist, an entomologist, an evolutionary biologist, an organic chemist, a climatologist, and an anthropologist. Students then independently and thoroughly research the discipline they are assigned as it relates to the issue, and reconvene to collaboratively brainstorm: disciplinary knowledge (disciplinary grounding); the different research methods and methodological reasoning; and identify the limitations of their disciplinary role (disciplinary humility). For example, an entomologist would provide knowledge on honeybees and their social systems, but would require the knowledge of an agronomist, evolutionary biologist, chemist, climatologist, and an anthropologist to fully understand the implications of factors such as changes in farming, genetic disruptions, and environmental shifts that all relate to the honeybee decline, as well as the social impacts (cultural implications and health related issues in 
areas that heavily rely on food produced by honeybee pollination). Deep discussion and deliberation involving the what, how, and why behind each disciplinary contribution is necessary in this phase. Through a growing mutual respect (disciplinary humility), students could then collectively decide how each discipline and method(s) will be leveraged to remediate the issues involved in declining honeybees, culminating in a new discovery or insight about this societal issue (integration).

For an instructor to identify if their learning goals are being met, formative and summative assessments can be embedded into the curriculum (Handelsman et al., 2007) (Table 3). As a group, students could discuss, complete, and submit a worksheet containing questions related to the honeybee issue (see "Deliberative Democracy", 2019 for example worksheets). Instructors could develop quiz and/or exam questions related to the DD activity to assess if students are making connections across disciplines and understanding related content. This could be followed by an individual writing intensive assignment (e.g. essay, proposal, research paper) that scores students based on the criteria in the IDSF. These assessment examples could provide evidence that students are meeting associated learning goals as well as give students opportunities to apply their interdisciplinary science knowledge to new situations. Table 3 can be modified to include various interdisciplinary science topics or problems, and collaborative and/or individual activities of the instructor's choice.

Table 3. Example curriculum applying the IDSF to an interdisciplinary course assignment. Students in an upper-division environmental course are tasked to address the decline in honeybee populations via an activity and assignment. Students are asked to construct a proposal to mitigate this issue and are scored on the inclusion of the five IDSF criteria in their response. 


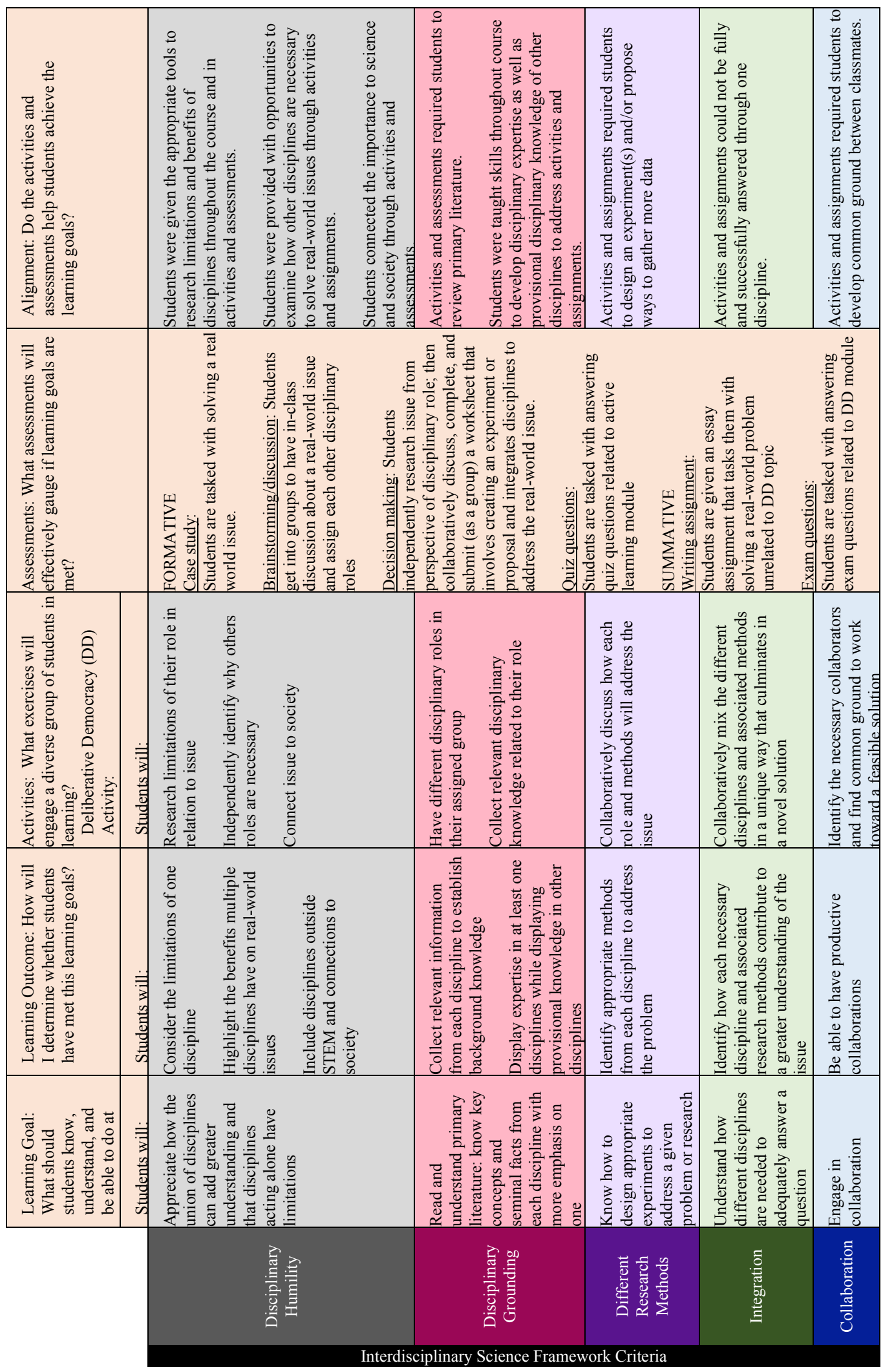




\section{IMPLICATIONS FOR CORE COMPETENCIES}

In addition to students being able to tap into the interdisciplinary nature of science (Competency 4), Vision and Change suggests five other Core Competencies that undergraduate biology students must cultivate by the end of their degree program. Core Competencies 1, 2 and 3 are action skills that task students to: 1) apply the process of science, 2) use quantitative reasoning and, 3) use modelling and simulation, and the last two Core Competencies, 5 and 6 are: 5) the ability to communicate and collaborate with other disciplines and 6) to understand the relationship between science and society. We hypothesize that as students cycle through the criteria outlined in the IDSF, they are also likely to at least be thinking about the other competencies. We have made the case that once students can apply and use common scientific practices with disciplinary grounding, different research methods and humility (Competencies 1-3), they may be well-prepared to work effectively with others to solve interdisciplinary problems. As illustrated in our definition of interdisciplinary science and recommendations for designing curricula, communicating and collaborating with other disciplines (Competency 5) is an integral part of working interdisciplinarily, and is thus inextricably linked to the ability to tap into the interdisciplinary nature of science (Competency 4). And lastly, Core Competency 6, understanding the relationship between science and society, is at the root of many interdisciplinary efforts. If scientific mandates require students to be better prepared to address the complex issues of society, providing them an opportunity to address real-world problems may foster science and society connections. 
We would like to emphasize that only as a student nears the end of their undergraduate degree would they become proficient in understanding the complete nature of interdisciplinary science. Therefore, we foresee that undergraduates will not fully harness all constructs of the IDSF just after completing their introductory courses, but additively over time. If students meet the criteria outlined in the IDSF, they will ideally be prepared to apply those skills to work interdisciplinarily. And if students are granted an authentic opportunity to work in interdisciplinary groups to solve real-world problems, then undergraduates will conceivably be meeting all six of the core competencies outlined in Vision in Change.

\section{A CALL FOR ADVANCEMENT}

In the face of challenges encountered in interdisciplinary science, the contributions of the IDSF coupled with curricular suggestions is a small, yet important step forward in addressing the interdisciplinary science demands of this century. We realize that the deep sociohistorical challenges that may undermine interdisciplinary integration are difficult to navigate and warrant further review and additional research. As a starting point, we aim for the criteria in our model to provide helpful targets for researchers to begin to answer the more difficult questions that the IDSF poses: What levels of integration are necessary to develop true interdisciplinary understanding? How much integration must be enforced to solve real-world problems? How much breadth of disciplinary knowledge can be afforded before depth becomes sacrificed? What does disciplinary humility look like in a classroom? The largest, and perhaps most challenging, question from this essay lands on the doorstep of academic culture — what changes must be made within academic culture 
to move beyond interdisciplinary importance to actually providing interdisciplinary opportunities to students? More attention to and advancements in interdisciplinary science education must occur for us to answer these small and larger scale questions. Our hope is that researchers and educators can use the IDSF to begin to address these issues.

\section{CONCLUSION}

The ability for undergraduate biology students to "tap into the interdisciplinary nature of science" is relevant and important, yet challenging to understand and operationalize. Here our intention was to clarify what this competency might reasonably look like as an expected outcome for biology undergraduates. We discuss interdisciplinary studies through its history, barriers, and multiple definitions, ultimately constructing a working definition of interdisciplinary science which can be applied to undergraduate education. We provide a platform, the Interdisciplinary Science Framework (IDSF), supported by current interdisciplinary curricula, and an example from which educators can begin scaffolding elements of interdisciplinary understanding into their classrooms. Practitioners are encouraged to begin formulating curricula through backward design to meet criteria described in the IDSF, which we hope will be broadly useful for undergraduate students in all STEM fields as they move through their studies and into the workforce. By embedding the elements of interdisciplinary thinking and understanding into our undergraduate science curricula, we will begin to prepare students to effectively untangle the complicated challenges of today, ultimately, tapping into the interdisciplinary nature of science. More broadly, and perhaps ambitiously, we ultimately envision the IDSF 
as a foundation to promote institutional change surrounding the deeper sociohistorical issues embedded in academic culture.

\section{ACKNOWLEDGEMENTS}

We would like to thank the faculty participants who generously offered their perceptions on interdisciplinary science. We thank Alexa Clemmons, Alison Crowe, Sophia Voronoff, and Analee Pham for their reviews of previous drafts of the manuscript, and Vivek Shandas for engaging us in insightful interdisciplinary conversations. We also thank the Biology Education Research Group at PSU for feedback on manuscript revisions. 


\section{REFERENCES}

American Association for the Advancement of Science. (2011). Vision and change: A call to action, final report. Washington, DC. Retrieved July 3, 2018, from http://visionandchange.org/finalreport

Bammer, G. (2013). Disciplining interdisciplinarity: Integration and implementation sciences for researching complex real-world problems.

Canberra, Australia: ANU Press.

Bauer, H. H. (1990). Barriers against interdisciplinarity: Implications for studies of science, technology, and society (STS). Science, Technology, \& Human Values, 15(1), 105-119.

Bennington, G. (1999). Inter. In McQuillan, M., MacDonald, G., Purves, R., \& Thompson, S. (Eds.), Post-theory: New directions in criticism (pp. 103119). Edinburgh: Edinburgh University Press.

Boix Mansilla, V., \& Duraisingh, E. D. (2007). Targeted assessment of students' interdisciplinary work: An empirically grounded framework proposed. Journal of Higher Education, 78(2), 215-237.

Boix Mansilla, V., Duraisingh, E. D., Wolfe, C. R., \& Haynes, C. (2009). Targeted assessment rubric: An empirically grounded rubric for interdisciplinary writing. Journal of Higher Education, 80(3), 334-353.

Boix Mansilla, V., Miller, W. C., \& Gardner, H. (2000). On disciplinary lenses and inter-disciplinary work. In Wineburg, S., \& Grossman, P. (Eds.), Interdisciplinary curriculum: Challenges to implementation (pp. 17-38). New York: Teachers College Press.

Borrego, M., \& Newswander, L. K. (2010). Definitions of interdisciplinary research: Toward graduate-level interdisciplinary learning outcomes. Review of Higher Education, 34(1), 61-84.

Byrne, E., Sage, C., \& Mullally, G. (2016). Transdisciplinarity perspectives on transitions to sustainability. Routledge.

Cooper, M. M., \& Stowe, R. L. (2018). Chemistry education research-From personal empiricism to evidence, theory, and informed practice.

Chemical Reviews, 111, 6053-6087.

Eigenbrode, S. D., O’Rourke, M., Wulfhorst, J. D., Althoff, D. M., Goldberg, C. S., Merrill, K., ... \& Bosque-Pérez, N. A. (2007). Employing philosophical dialogue in collaborative science. BioScience, 57(1), 55.

Fennell, M. L., \& Sandefur, G. D. (1983). Structural clarity of interdisciplinary teams: A research note. Journal of Applied Behavioral Science, 19(2), 
$193-202$.

Frank, R. (1988). "Interdisciplinary": The first half century. Issues in Integrative Studies, 40(6), 139-151.

Frodeman, R., Klein, J. T., \& Pacheco, R. C. D. S. (Eds.). (2017). The Oxford handbook of interdisciplinarity. Oxford, UK: Oxford University Press.

Fuchsman, K. (2009). Rethinking integration in interdisciplinary studies. Issues in Integrative Studies, 85(27), 70-85.

Full, R. J., Dudley, R., Koehl, M. A. R., Libby, T., \& Schwab, C. (2015).

Interdisciplinary laboratory course facilitating knowledge integration, mutualistic teaming, and original discovery. Integrative and Comparative Biology, 55(5), 1-14.

Gazzinga, M. S. (1998). How to change the university. Science, 282(5387), 237.

Gentile, L., Caudill, L., Fetea, M., Hill, A. L., Hoke, K., Gentiles, L., ... \& Szajda, D. (2012). Challenging disciplinary boundaries in the first year: A new introductory integrated science course for STEM majors. Journal of College Science Teaching, 41(5), 44-50.

Giri, A. K. (2002). The calling of a creative transdisciplinarity. Futures, 34(1), $103-116$.

Gouvea, J. S., Sawtelle, V., Geller, B. D., \& Turpen, C. (2013). A framework for analyzing interdisciplinary tasks: Implications for student learning and curricular design. CBE—Life Sciences Education, 12(2), $187-205$.

Guba, E. G., \& Lincoln, Y. S. (1994). Competing paradigms in qualitative research. In Denzin, N. K., \& Lincoln, Y. S. (Eds.), Handbook of qualitative research (pp. 105-117). Thousand Oaks, CA: Sage Publications.

Handelsman, J., Ebert-May, D., Beichner, R., Bruns, P., Chang, A., DeHaan, R., ... \& Wood, W. B. (2007). Scientific teaching. New York: Freeman.

Hopkins, L. T. (1937). Integration: Its meaning and application. New York: Appleton-Century.

Hyett, N., Kenny, A., \& Dickson-Swift, V. (2014). Methodology or method? A critical review of qualitative case study reports. International Journal of Qualitative Studies on Health and Well-Being, 9(1), 23606.

Katz, C. (2001). Response: Disciplining interdisciplinarity. Feminist Studies, 27(2), 519-525.

Klein, J. T. (1990). Interdisciplinarity: History, theory, and practice. Detroit, MI: Wayne State University Press. 
Klein, J. T. (1996). Crossing boundaries: Knowledge, disciplinarities, and interdisciplinarities. Charlottesville: University of Virginia Press.

Klein, J. T. (2000). A conceptual vocabulary of interdisciplinary science. In Stehr, N., \& Weingart, P. (Eds.), Practising interdisciplinarity (pp. 3-24). Toronto, Canada: University of Toronto Press.

Klein, J. T. (2005). Integrative learning and interdisciplinary studies. Peer Review, 7(4), 8-10.

Klein, J. T. (2015). Reprint of "Discourses of transdisciplinarity: Looking back to the future." Futures, 65, 10-16.

Komperda, R., Barbera, J., Shortlidge, E. E., \& Shusterman, G. P. (2018). Connecting chemistry to community with deliberative democracy. In Maguire, C. F., \& Sheardy, R.D. (Eds.), Citizens first! Democracy, social responsibility, and chemistry: ACS Symposium Series, 1297, 81-98.

Lattuca, L. R. (2001). Creating interdisciplinarity: Interdisciplinary research and teaching among college and university faculty. Nashville, TN: Vanderbilt University Press.

Lattuca, L. R., \& Knight, D. B. (2010). In the eye of the beholder: Defining and studying interdisciplinarity in engineering education. In Proceedings of the 117th annual conference of the American Society of Engineering Education. Louisville, KY: American Society for Engineering Education.

Lederman, N. G. (2007). Nature of Science: Past, present, and future. In Abell, S. K., \& Lederman, N. G. (Eds.), Handbook of research on science education (pp. 831-879). Mahwah, NJ: Lawrence Erlbaum Publishers.

Masse, L. C., Moser, R. P., Stokols, D., Taylor, B. K., Marcus, S. E., Morgan, G. D., ... \& Trochim, W. M. (2008). Measuring collaboration and transdisciplinary integration in team science. American Journal of Preventative Medicine, 35(2 Suppl), S151-S160.

Moran, J. (2002). Interdisciplinarity. London, England: Routledge.

National Academy of Sciences, National Academy of Engineering, and Institute of Medicine. (2005). Facilitating interdisciplinary research (p. 2), Washington, DC: National Academies Press.

National Research Council (NRC). (2003). BIO2010: Transforming undergraduate education for future research biologists. Washington, DC: National Academies Press. NRC. (2009). A new biology for the 21st century. Washington, DC: National Academies Press. 
NRC. (2015). Enhancing the effectiveness of team science. Washington, DC: National Academies Press.

Newell, W. H. (1990). Interdisciplinary curriculum. Issues in Integrative Studies, 8, 69-86.

Newell, W. H., \& Green, W. J. (1982). Defining and teaching interdisciplinary studies. Improving College and University Teaching, 30(1), 23-30.

Öberg, G. (2009). Facilitating interdisciplinary work: Using quality assessment to create common ground. Higher Education, 57(4), 405-415.

Pellmar, T. C., \& Eisenberg, L. (2000). Bridging disciplines in the brain, behavioral, and clinical sciences. Washington, DC: National Academies Press.

Portland State University. (2019). Deliberative democracy. Retrieved February 25, 2019, from www.pdx.edu/stem/deliberative-democracy

President's Council of Advisors on Science and Technology. (2012). Engage to excel: Producing one million additional college graduates with degrees in science, technology, engineering, and mathematics. Washington, DC: U.S. Government Office of Science and Technology.

Redish, E. F., \& Cooke, T. J. (2013). Learning each other's ropes: Negotiating interdisciplinary authenticity. CBE-Life Sciences Education, 12(2), 175186.

Redish, E. F., \& Hammer, D. (2009). Reinventing college physics for biologists: Explicating an epistemological curriculum. American Journal of Physics, 77(7), 629642.

Repko, A. F. (2008). Interdisciplinary research: Process and theory. Thousand Oaks, CA: Sage.

Rogers, Y., Scaife, M., \& Rizzo, A. (2005). Interdisciplinarity: An emergent or engineered process? In Derry, S. J., Schunn, C. D., \& Gernsbacher, M. A. (Eds.), Interdisciplinary collaboration: An emerging cognitive science (pp. 265-285). Mahwah, NJ: Erlbaum.

Rosenfield, P. L. (1992). The potential of transdisciplinary research for sustaining and extending linkages between the health and social sciences. Social Science \& Medicine, 35(11), 1343-1357.

Scott, T. D., Hazari, Z., Potvin, G., Sadler, P. M., \& Sonnert, G. (2014).

Interdisciplinary affinity: Definitions and connections to physics identity. In Engelhardt, P. V., Churukian, A. D., \& Jones, D. L (Eds.), 2014 PERC Proceedings held July 30-31, 2014, in Minneapolis, MN. 
Stokols, D., Harvey, R., Gress, J., Fuqua, J., \& Phillips, K. (2005). In vivo studies of transdisciplinary scientific collaboration: Lessons learned and implications for active living research. American Journal of Preventive Medicine, 28(2 Suppl 2), 202-213.

Stokols, D., Misra, S., Moser, R. P., Hall, K. L., \& Taylor, B. K. (2008). The ecology of team science. Understanding contextual influences on transdisciplinary collaboration. American Journal of Preventive Medicine, $35(2$ Suppl), S96-S115.

Thompson, K. V., Chmielewski, J., Gaines, M. S., Hrycyna, C. A., \& LaCourse, W. R. (2013). Competency-based reforms of the undergraduate biology curriculum: Integrating the physical and biological sciences. CBE-Life Sciences Education, 12(2), 162-169.

Vázquez Alonso, Á., Manassero Mas, M. A., García Carmona, A., \& Montesano de Talavera, M. (2016). Diagnosing conceptions about the epistemology of science: Contributions of a quantitative assessment methodology. In Asia-Pacific Forum on Science Learning and Teaching, 17(1), 1-28.

Watkins, J., Coffey, J. E., Redish, E. F., \& Cooke, T. J. (2012). Disciplinary authenticity: Enriching the reforms of introductory physics courses for life-science students. Physical Review Special Topics Physics Education Research, 8(1), 1-17.

Weber, C. F. (2016). Beyond the cell: Using multiscalar topics to bring interdisciplinarity into undergraduate cellular biology courses. CBE-Life Sciences Education, 15(2), es1.

Weingart, P. (2010). A short history of knowledge formations. In Frodeman, R., Klein, J. T., \& Pacheco, R. C. D. S. (Eds.), The Oxford handbook of interdisciplinarity (pp. 3-14). Oxford, UK: Oxford University Press.

Welch, J., IV. (2003). Future directions for interdisciplinary effectiveness in higher education. Issues in Integrative Studies, 21(21), 170-203.

Wiggins, G., \& McTighe, J. (1998). What is backward design? Understanding by Design, 1, 7-19.

Woodin, T., Vasaly, H., McBride, D., \& White, G. (2013). Integration of physics and biology: Synergistic undergraduate education for the 21 st century. CBE—Life Sciences Education, 12(2), 120-123.

You, H. S., Marshall, J. A., \& Delgado, C. (2018). Assessing students' disciplinary and interdisciplinary understanding of global carbon cycling. Journal of Research in Science Teaching, 55(3), 377-398. 


\title{
CHAPTER 3: STEPS TOWARD MEASURING INTERDISCIPLINARY SCIENCE UNDERSTANDING
}

\section{Published}

Tripp, B., Voronoff, S. A., \& Shortlidge, E. E. (2020). Crossing Boundaries: Steps Toward Measuring Undergraduates' Interdisciplinary Science Understanding. $C B E-$ Life Sciences Education, 19(1), ar8.

\author{
ABSTRACT \\ A desired outcome of education reform efforts is for undergraduates to \\ effectively integrate knowledge across disciplines in order to evaluate and address \\ real-world issues. Yet, there are few assessments designed to measure if and how \\ students think interdisciplinarily. Here, a sample of science faculty were surveyed to \\ understand how they currently assess students' interdisciplinary science \\ understanding. Results indicate that individual writing-intensive activities are the \\ most frequently utilized assessment type (69\%). To understand how writing \\ assignments can accurately assess students' ability to think interdisciplinarily, a \\ preexisting rubric, designed to measure social science students' interdisciplinary \\ understanding, was used to assess writing assignments from 71 undergraduate science \\ students. Semi-structured interviews were conducted with 25 of those students to \\ explore similarities and differences between assignment scores and verbal \\ understanding of interdisciplinary science. Results suggest that certain constructs of \\ the instrument did not fully capture this competency for our population, but instead, \\ an interdisciplinary framework may be a better model to guide assessment \\ development of interdisciplinary science. These data suggest that a new instrument \\ designed through the lens of this model could more accurately characterize
}


interdisciplinary science understanding for undergraduate students to address society's bigger issues.

\section{INTRODUCTION}

The interplay of science, technology, engineering, and mathematics (STEM) fields has impacted research in profound ways with new discoveries accelerating scientific advancements (President's Council of Advisors on Science and Technology [PCAST], 2012). The integration of STEM with disciplines, such as economics and sociology, has created new interdisciplinary (ID) fields that hold tremendous promise for surmounting societies' most vexing challenges (National Research Council [NRC], 2009). Also driving these important avenues of study are transformations in how scientists communicate and collaborate across disciplines (American Association for the Advancement of Science [AAAS], 2011). Novel theories and methods often arise from these interactions, warranting continued ID efforts to advance scientific fields and address complex issues (NRC, 2003, 2009, AAAS, 2011). As such, future scientists must be equipped with a skillset that enables them to effectively address problems that span multiple disciplinary domains. However, undergraduate education has not entirely kept up with this need, as universities have been slower in engaging students in ID ways (NRC, 2003, 2009, AAAS, 2011). Accordingly, national calls have developed mandates for improving undergraduate education to match ID scientific advancements (NRC, 2003, 2009, AAAS, 2011, PCAST, 2012). The NRC (2003) specifically highlights this need for life science majors: "Connections between biology and other scientific disciplines need to be developed and reinforced so that interdisciplinary thinking and work become second nature” (p. 1). 
In response to reform calls, AAAS (2011) outlined several core competencies in the meeting report Vision and Change in Undergraduate Biology Education to better prepare undergraduate biology students for the increasingly ID workforce. The ability to "tap into the interdisciplinary nature of science" is one of these competencies that science educators have been working to incorporate into curricula; however, this competency can be difficult to operationalize and evaluate (Tripp \& Shortlidge, 2019). If science educators are tasked with instilling this proficiency, we must find ways to assess if students are meeting this benchmark.

\section{Assessment of Interdisciplinary Science Understanding}

Instructors are at the forefront of designing and teaching curricula that meet ID learning outcomes with an expectation to assess if students are meeting these goals. Therefore, shedding light on instructor assessment practices can provide steps toward meeting the ID recommendations outlined in Vision and Change (AAAS, 2011). A small number of studies have published on their efforts to measure ID science competencies through concept maps and writing activities. Borrego et al. (2009) tested a rubric (Besterfield-Sacre et al., 2004) to assess engineering students' ability to integrate ID knowledge through concept maps. Here, they had students schematically represent their knowledge of integration by creating a hierarchy of concepts across disciplines, associating sub-groups branching off of each concept, and pairing these ideas with cross-linked arrows to represent relationships. They found that the assessment tool did not produce accurate or reliable results in scoring students' ID knowledge based on variability in interpretation of students' work. Although concept maps are useful in particular environments, they can fall short when 
asking students to exhibit a deeper understanding of why conceptual knowledge is connected across seemingly disparate disciplinary fields (Balgopal et al., 2012).

Several studies have developed assessment tools to score writing activities in specific environments, but these instruments were either targeted for one particular course without additional validation studies from separate populations (Balgopal et al. 2012,2017 ) or focused on integrated learning within one discipline (Besterfield-Sacre et al., 2004, Chan et al., 2010). However, writing activities may be a plausible assessment strategy when tasking students to connect similarities and differences in jargon, methods/methodologies, concepts and ideas across multiple disciplines (Boix Mansilla et al. 2009). Writing can promote reflection and encourage students to be critical of their own understanding while allowing space for affective learning to enhance greater literacy on real-world issues (Connally, 1989, Rivard 1994, Keys, 1999, Balgopal et al., 2012). For example, a pedagogy known as writing-to-learn was adapted to extend students' learning beyond rote memorization and simplified connections (Connally, 1989, Rivard 1994). Writing-to-learn is a constructivist teaching strategy that allows students to construct their own understanding by first thinking and writing about a topic before actually engaging in content-related activities, and has been more recently adopted in the sciences (Carlson, 2007, Balgopal \& Wallace, 2009, Balgopal et al., 2012, Balgopal et al., 2017). Writing-tolearn aligns with work suggesting that students will likely need to think interdisciplinarily before engaging in ID science research (Tripp \& Shortlidge 2019). Yet, it remains relatively unknown if instructors are encouraging ID science thinking, and if so, how they assess this ability in an undergraduate classroom. To address this, the first part of this study examined how instructors assess ID science competencies. 
We then used these results to guide the development of a writing activity to be scored with an ID rubric.

\section{A Theoretical Model and an Interdisciplinary Rubric}

Our previous work outlined a model, the Interdisciplinary Science Framework (IDSF), to guide instructors on factors to consider when developing ID curricula and assessing student understanding of ID science (Tripp \& Shortlidge, 2019). As a step in building this model, we surveyed faculty who teach science courses regarding how they define ID science ( $\mathrm{n}=184)$. By synthesizing these definitions, as well as studying the ID literature, we established five main categories that comprise ID science understanding: 1) disciplinary humility, 2) disciplinary grounding, 3) different research methods, 4) advancement through integration, and 5) collaboration.

The IDSF categories, 'disciplinary grounding' and 'integration', were derived from criteria theorized as pivotal for interdisciplinarity in the social sciences (Boix Mansilla and Duraisingh, 2007). These researchers developed a rubric to score social science and humanities students' understanding of the constructs, along with two additional constructs 'purposefulness' and 'critical awareness' (Boix Mansilla et al., 2009). One study examined the rubric's functionality on grant proposals submitted to the National Science Foundation's former Interdisciplinary Graduate Engineering Research Traineeship (IGERT) program (Borrego et al., 2010). Researchers used the rubric to compare grants submitted to the IGERT solicitation to identify learning outcomes for proposed ID graduate programs. The researchers' findings suggested that the constructs of the rubric, although applicable to the physical sciences, needed amendment to fully capture learning outcomes for graduate students in STEM fields 
(Borrego et al., 2010). Here, we expand this work by testing the same rubric's (Boix Mansilla et al., 2019) ability to measure responses to a situated undergraduate writing assignment.

Although the rubric was developed from faculty feedback across many STEM and non-STEM disciplines, the designers limited validation of the data to students in the social sciences and humanities (Boix Mansilla et al., 2009). Instead of initially modifying this rubric to align with the ID science-focused IDSF, we chose to maintain the integrity of the instrument by using it as published. Had we changed the criteria in the rubric without first testing the validity of the data collected, our findings would be potentially be invalidated (Stangor, 2014). We hypothesized that the results from testing the rubric would not only assist in understanding how students conceptualize ID science, but also test for evidence of validity for the IDSF model.

\section{$\underline{\text { Research Aims }}$}

In this study, we first aimed to reveal how instructors currently assess ID science understanding, and use this information to inform the development of an activity to measure undergraduate ID science understanding. We then scored this activity with a previously developed ID rubric to test if the rubric produced valid data in our population. We examined if the rubric fully captured students' ID understanding by conducting interviews to holistically probe how students perceive ID science. Lastly, we used these interviews to test for evidence of validity for the theoretically-driven IDSF. Specifically, we asked the following research questions:

1) How do instructors typically assess undergraduate students' conceptualization of interdisciplinary science? 
2) In what ways can a previously developed rubric measure undergraduate students' interdisciplinary science understanding?

2a. Which aspects of the rubric are more or less difficult for students to meet, and does this vary by course?

2b. Can the rubric accurately measure undergraduate students' interdisciplinary science understanding?

3) How do undergraduate students perceive interdisciplinary science?

\section{METHODS}

Research Question 1: How do instructors typically assess undergraduate students' conceptualization of interdisciplinary science?

\section{$\underline{\text { Survey Recruitment }}$}

To gauge how science instructors assess ID science understanding, we conducted a web-based search for participants that spanned STEM departments across the United States. We compiled an email list of potential participants and sent individual and listserv emails requesting anonymous participation in a Qualtrics survey regarding ID science. Individuals were invited to participate if they: 1) held a faculty position at an academic institution, and 2) had a position located in a science department. The survey items underwent iterative revision based on feedback from multiple researchers (including authors). 
This portion of the study was conducted under exempt status at Portland State University (IRB \#174219).

\section{$\underline{\text { Data Collection }}$}

The survey asked participants a series of demographic questions, one binary'yes' or 'no'—question: “Do you teach courses that you consider interdisciplinary?", as well as two open-ended questions: "How do you define interdisciplinary science?" (results can be found in Tripp \& Shortlidge, 2019), and “Please explain how you assess learning outcomes related to students' understanding of interdisciplinary science." (presented in this study). We used inductive content analysis (Patton, 1990) to evaluate responses to the latter survey question. Two researchers (including B.T.) compiled responses into a list, which were subsequently organized into categories of similar assessment strategies. Since the survey responses were often provided in an itemized format containing the same or similar words in each response (e.g. Survey Participant 1: quizzes, tests, oral presentations; Survey Participant 2: quizzes, exams, essays, verbal presentations), we categorized associated words into a code resulting in multiple codes with related words per code. Thus, very little interpretation was used in the development of the code list due to the categorizing of exact or associated words. All survey responses were coded to consensus. We then condensed interrelated codes into overarching themes that holistically represented the codes. A researcher uninvolved in the initial coding process (E.E.S.) independently evaluated $20 \%$ of the data at random-checking for accuracy and appropriateness of the coding scheme - as an additional measure to support the validity of our analysis. 


\section{Essay Assignment Development}

Based on results from our faculty survey, we created a writing assignment to collect a sample of science students' abilities to think interdisciplinarily. Additional reasons for developing a writing assignment were three-fold: writing activities are being adopted at a higher rate in science to encourage critical thinking skills (Carlson, 2007, Balgopal \& Wallace, 2009, Balgopal et al., 2012, Balgopal et al., 2017); we sought to engage students in connecting multiple disciplines in a cohesive manner by first thinking through an ID lens (Tripp \& Shortlidge, 2019); and the assignment served as an artefact to measure students' ID understanding using the aforementioned rubric developed by Boix Mansilla et al. (2009).

One way to possibly enhance student ability to meaningfully connect disciplines is through real-world applications of ID science, as ID work is how we truly solve complicated issues in society (Tripp \& Shortlidge, 2019). Therefore in this study, we developed essay prompts that task students to ponder real-world problems that inherently require multiple disciplines to address. Two authors (BT and EES) iteratively developed and revised essay prompts in collaboration with the instructor(s) of each course to ensure that content aligned with the course subject matter. Although the context of the prompt varied between courses, student instructions for completing the assignment remained consistent across courses, and all instructors incorporated the assignment into the grading scheme of the course (see APPENDIX B. for example prompts). We intentionally worded the prompts to encourage students to meet each construct in the rubric (rubric details below). The research team collaboratively discussed different types of student knowledge that 
could potentially satisfy understanding of the rubric's constructs based on the information they were given in the prompt.

Research Question 2: What ways can a previously developed rubric measure undergraduate students' interdisciplinary science understanding?

2a. Which aspects of rubric are more or less difficult for students to meet, and does this vary by course?

\section{$\underline{\text { Data Collection }}$}

We recruited undergraduate students from four upper-division natural and physical science courses at a large northwestern public university in 2017-2018. We targeted students in upper-division courses because ID understanding is partially contingent upon higher order thinking, and students at the beginning of their academic career may not have had the experience or time to fully develop these skills (Tripp \& Shortlidge, 2019).

The essay assignment was given to all students enrolled in each course and scores were incorporated into their overall course grade. One week prior to the assignment, we made a class announcement requesting consent from students to use their essay responses for education research; written consent forms were disseminated and collected in class. The large majority of students consented to their responses being included in the study ( $\mathrm{n}=71,99 \%$ consent rate). Although the assignment was part of their final grade, student involvement in this study was completely voluntary and their participation remained anonymous to the instructor. Students were given one week to complete the individual assignment and were allowed to use any resources 
they chose to complete the essay. The assignment was worth $10-15 \%$ of final course grades.

We recruited students for interviews during the same class announcement and provided a sign-up sheet for students interested in participating. A follow-up email was sent to those who volunteered to participate in interviews. There were no students with dual enrollment in any of the courses.

This portion of the study was conducted under exempt status at Portland State University (IRB \#163998).

\section{The Rubric}

The rubric was designed to reconcile "rhetorical, theoretical, and methodological" differences among disciplines, with an aim of discerning student competencies of ID understanding (Boix Mansilla et al., 2009). It was intended to be an adaptable assessment tool to guide instructors in qualities of students' understanding of interdisciplinarity based on four constructs: purposefulness, disciplinary grounding, integration, and critical awareness (Table 1).

We performed a pilot test of the assignment on a group of students from the same population as our study, and subsequently scored essay responses with the rubric $(n=13)$. We were unable to discern whether the authors of the rubric provided students with this tool; thus, we initially withheld the rubric from students as it was intended for practitioners' use. However, based on verbal feedback and analysis of scores on assignments, it was evident that students needed more guidance in writing an essay that demonstrated how they conceptualize ID connections. The full rubric 
intended for instructors had guiding questions within the document (see APPENDIX

C. PRACTIONERS VERSION OF RUBRIC for full rubric). We decided to include

these guiding questions alongside the essay prompts for our subsequent research to

help students in meeting expectations (Table 1).

Table 1. Shortened rubric* provided to students.

\begin{tabular}{|c|c|c|}
\hline Rubric Elements & Criteria & Guiding Questions \\
\hline \multirow[t]{2}{*}{ Purposefulness } & 1.1 & $\begin{array}{l}\text { Is there a clearly stated purpose that calls for an } \\
\text { integrative approach and a clear rationale or } \\
\text { justification for taking this approach? }\end{array}$ \\
\hline & 1.2 & $\begin{array}{l}\text { Does the paper use the writing genre effectively to } \\
\text { communicate with its intended audience? }\end{array}$ \\
\hline \multirow[t]{2}{*}{$\begin{array}{l}\text { Disciplinary } \\
\text { Grounding }\end{array}$} & 2.1 & $\begin{array}{l}\text { Does the paper use disciplinary knowledge accurately } \\
\text { and effectively (e.g. concepts, perspectives, findings, } \\
\text { examples, relevant and credible sources)? }\end{array}$ \\
\hline & 2.2 & $\begin{array}{l}\text { Does the paper use disciplinary methods accurately and } \\
\text { effectively (e.g. experimental design)? }\end{array}$ \\
\hline \multirow[t]{4}{*}{ Integration } & 3.1 & $\begin{array}{l}\text { Does the paper include selected disciplinary } \\
\text { perspectives and insights from two or more disciplinary } \\
\text { traditions presented in the course or from elsewhere } \\
\text { that are relevant to the paper's purpose? }\end{array}$ \\
\hline & $3.2 * *$ & $\begin{array}{l}\text { Is there an integrative device or strategy (i.e. metaphor } \\
\text { or analogy)? }\end{array}$ \\
\hline & 3.3 & $\begin{array}{l}\text { Is there a sense of balance in the overall composition of } \\
\text { the piece with regard to how disciplinary perspectives } \\
\text { are brought together to advance the purpose of the } \\
\text { piece? }\end{array}$ \\
\hline & 3.4 & $\begin{array}{l}\text { Do the conclusions drawn by the paper indicate that } \\
\text { understanding has been advanced by the integration of } \\
\text { disciplinary views (e.g. the paper takes full advantage } \\
\text { of the opportunities presented by the integration of } \\
\text { disciplinary insights to advance its intended purpose } \\
\text { both effectively and efficiently. The integration may } \\
\text { result in novel or unexpected insights)? }\end{array}$ \\
\hline \multirow[t]{2}{*}{ Critical Awareness } & $4.1+$ & $\begin{array}{l}\text { Does the paper exhibit awareness of the limitations and } \\
\text { benefits of the contributing disciplines? }\end{array}$ \\
\hline & $4.2+$ & $\begin{array}{l}\text { Does the paper exhibit self-reflection (e.g. } \\
\text { metacognition)? }\end{array}$ \\
\hline
\end{tabular}

*Adapted from Boix-Mansilla et al. 2009.

**Excluded from scoring

+ Merged 
Next, we aimed to establish evidence of validity of data collected in our population by applying the rubric to the essay assignment in the four courses described in this study (Barbera \& VandenPlas, 2011, American Educational Research Association et al., 2014). To ensure fidelity of implementation, the conceptual foundations and core elements of the rubric were strictly followed, with minimal adaptations to the four constructs and scoring metrics. However, there were two criteria-3.2: Is there an integrative device or strategy (i.e. metaphor, or analogy)? and 4.2: Does the paper exhibit self-reflection (e.g. metacognition)?"- that did not fit the context of this study based on the responses from students in the pilot test. We tasked students with writing an essay to governmental bodies or scientific enterprises, thus, usage of analogies and metaphors in criteria 3.2 would not be appropriate for this population. Criterion 4.2 was extremely similar to criterion 4.1 and we had a difficult time disaggregating their meaning, as did students in the pilot study. Therefore, criterion 3.2 was excluded from scoring the essays and 4.2 was merged with 4.1 (Table 1).

\section{$\underline{\text { Rubric Scoring }}$}

Each construct (purposefulness, disciplinary grounding, integration, and critical awareness) was scored on a four-point scale as outlined by the designers of the rubric: naïve (1), novice (2), apprentice (3), and mastery (4). There were also several detailed criteria associated with the four constructs to aid instructors in assessing students' understanding of interdisciplinarity (Table 1). However, it was unclear if these criteria were supposed to be scored on the 1-4 scale individually, or if 
that scoring metric was exclusively reserved for the construct as a whole. Thus, we decided to score each criterion on the 1-4 scale, and then calculate the average of all criteria within one construct, resulting in one score per construct. An average of criteria scores was necessary because there were different numbers of criteria under each construct, and we wanted to ensure they were weighted the same (e.g. having two criteria in 'critical awareness' does not make that construct less important than the 'integration' construct containing four criteria). There were some criteria that the coding researchers were not able to assess on the 1-4 whole-number scale, thus resorting to a rational (decimal) number scores (i.e. 1.5, 2.5, 3.5). For example, a student could have received a sub-score of 1.5 due to the fact that they were exhibiting knowledge in between a naïve (1) and novice (2) understanding. After each construct score was calculated, we added these numbers together for a total score out of 16 possible points for the assignment.

Two researchers (B.T. and S.A.V.) randomly selected and scored a subset of student essays from each of the four courses based on the above scoring method until there was consistency in the scoring of students' work. A second subset of essays were independently scored by both researchers, who then reconvened and discussed each construct and associated criteria until consensus was reached. We continued this iterative process with $63 \%$ of all essays. A final subset of essays was scored and an interrater reliability was obtained using R Studio $(\kappa=0.77)$ (R Studio Team, 2019). B.T independently scored the remaining essays, occasionally having S.A.V. check for accuracy in scores from essays that were difficult to score.

$\underline{\text { Statistical Analysis }}$ 
Statistical analyses were performed to explore differences in student performance on the essay based on the rubric constructs and the course they were enrolled in. One-way ANOVAs were used to identify any statistically significant differences in student performance based on construct and total essay scores. Welch's one-way test for unequal variance was used to account for a significant Levene's test for overall mean construct scores. A one-way ANOVA was also used to detect statistically significant differences among student performance based on each construct by course. Welch's one-way test for unequal variance was used on constructs integration and critical awareness due to a significant Levene's test. Tukey's HSD post-hoc analyses were conducted on each statistical measurement to further identify significance between groups $(\mathrm{p}<0.05)$. Effect sizes were calculated with eta-squared () and interpreted according to Maher et al. (2013): small effect $=0.01$, medium effect $=0.06$, large effect $=0.14$. All statistical tests were performed in R Studio (R Studio Team, 2019).

Research Question 2b. Can the rubric accurately measure undergraduate students' interdisciplinary science understanding?

\section{$\underline{\text { Interviews }}$}

To explore the breadth of students' understanding of ID science, a researcher (B.T.) conducted semi-structured interviews. The interview questions were formulated to organically investigate student understanding of interdisciplinarity unrelated to the rubric or essay assignment (see APPENDIX D. for interview 
questions). We asked participants about their general perceptions of the course in which the required writing assignment was embedded. We also inquired about students' experiences with research, how they viewed scientific disciplines and ID science, and the value they placed on both. The questions were first piloted on a group of eight education researchers (ranging from undergraduates to faculty) to assess the quality, accuracy, and intent of each question. After thorough discussion and deliberation, 20 questions were selected for this study. All questions remained consistent across the semi-structured interviews. Each interview was recorded and transcribed verbatim with interviews lasting an average of 30 minutes. For simplicity in reporting and protection of participant identities, all interviewees were given pseudonyms with gender neutral pronouns.

\section{Evidence of Convergent Validity through Matched Data}

When initially reading through interviews, we noticed similarities and differences between student essay responses and how they articulated ID science in their interviews. As there was a subset of students who participated in both the writing assignment and an interview, we were able to better understand how these students were interpreting disciplinary grounding, integration, and critical awareness constructs and the associated criteria from the rubric. Thus, we examined the data for evidence of convergent validity. Convergent evidence is one type of validity that evaluates relationships between test scores and other external variables to assess the same or similar constructs (American Educational Research Association et al., 2014). We hypothesized that the rubric constructs should be related to how students 
articulate ID science understanding in their interviews, if the constructs were operating as the designers intended.

As interview questions were not specifically designed to address the rubric constructs, we did not have comparable matched data for the purposefulness construct in the interview responses. The criteria for purposefulness were very specific to essays - framing the problem and using a writing genre to communicate to an appropriate audience - and would likely not add to our understanding of how students conceptualize ID science. Thus, we omitted purposefulness from our matched writing assignment and interview data analysis.

\section{$\underline{\text { Scoring Interviews with Rubric }}$}

We identified responses in the interviews that aligned with each of the constructs in the rubric, ultimately scoring the interviews binarily (e.g. 'Yes' the student exhibited the rubric construct disciplinary grounding in the interview (unprompted) or 'No' they did not) (Table 7). We hypothesized that students who scored high on a particular rubric construct would also communicate an advanced level of understanding in their interviews regarding that construct. Likewise, we expected that low essay scores on a construct would be mirrored by little or no expression of the concept in the interviews. This method uniquely allowed us to examine evidence of convergent validity of data from two different measurements designed to assess the same concept of ID science understanding. Research Question 3: How do undergraduate students perceive interdisciplinary science? 
To hone in on student perceptions of ID science that fell outside of the rubric constructs, we reanalyzed the interview data, both inductively and deductively.

\section{$\underline{\text { Inductive Analysis }}$}

Using holistic coding (Saldana, 2016) — a method that applies a single code to each large unit of data to capture an overall sense of emergent content—-three researchers (including B.T., S.A.V) performed inductive content analysis (Patton, 1990) - an analysis that uses the data to derive the structure of investigation — by systematically listing all emergent categories from $30 \%$ of the interviews. We reorganized and condensed similar categories into general codes. Once the final code list was complete, researchers independently coded a new subset of interviews with the codebook (20\%) and reconvened to discuss new codes and reach consensus on coding interpretation. This process of iteratively coding and revising the codebook was repeated until we reached data saturation (Fusch \& Ness, 2015). Next, a new subset of the remaining interviews (20\%) were independently coded and analyzed with a Fleiss' kappa coefficient >.60 ( $\kappa=0.63)$ using R Studio (R Studio Team, 2019). The remaining interviews were coded to consensus.

\section{Deductive Analysis}

After we completed the matched data and inductive interview analyses for this study, our work on the IDSF came to completion and was published (Tripp \& Shortlidge 2019). This provided an opportunity to learn more from the student interviews and test the robustness of the IDSF by recoding the interviews based on the five pillars of ID science understanding: disciplinary grounding, different research 
methods, integration, collaboration, and disciplinary humility (Tripp \& Shortlidge). As the IDSF was partially developed through faculty perspectives of ID science, we could test for evidence of convergent validity of data for the model through student perspectives of this competency. Three researchers (including B.T. and S.A.V) performed deductive content analysis (Patton, 1990) — a method that tests existing categories or theories in a novel context—by reviewing all student interviews and applying codes to the responses that aligned with the five criteria in the IDSF. All interviews were coded to consensus and coding analyses were conducted in MAXQDA (VERBI software, Berlin, Germany).

\section{RESULTS}

Research Question 1: How do instructors typically assess undergraduate students' conceptualization of interdisciplinary science?

\section{$\underline{\text { Survey }}$}

From the survey recruitment effort, 186 individual faculty members completed all survey questions. We excluded responses that were incomplete or were written in a way that indicated participants did not understand the question as intended. In response to the question, "Do you teach courses that you consider interdisciplinary?”, 45\% $(\mathrm{n}=84)$ selected 'yes'. Of these 84 participants, $81 \%(\mathrm{n}=68)$ also responded to the follow-up question, "Please explain how you assess these learning outcomes related to students' understanding of the interdisciplinary nature of science." (see APPENDIX E. for demographics and APPENDIX F. for survey questions). 
The top three themes reported by faculty were coded as Writing Activities (e.g. essays, journal reflections; 69\%), Traditional (e.g. quizzes, exams, and homework that were not described by the survey respondent as completed individually or in a group; 34\%), and Group Work (e.g. group presentations, group projects; 34\%) (Table 2). Many faculty members listed assessment strategies that fell into more than one theme, hence the percentages sum to greater than $100 \%$.

Table 2. Coding rubric for survey question: Please explain how you assess learning outcomes related to students' understanding of interdisciplinary science $(n=68)$.

\begin{tabular}{clc}
\hline Themes & Examples & $\begin{array}{c}\text { Participants } \\
\%(\mathrm{n}=68)\end{array}$ \\
\hline 1. Writing Activities & & $69 \%(47)$ \\
a. Writing assignments & Essays/papers & $51(35)$ \\
b. Self-reflection & Journals & $6(4)$ \\
& Reflection assignments & $34(23)$ \\
2. Traditional & Unspecified as individual or group: \\
& $\begin{array}{l}\text { Exams } \\
\text { Quizzes }\end{array}$ & \\
& Homework assignments & $34(23)$ \\
& \\
& \\
& 2+ students: \\
& Communication/Discussion & \\
& Group research/Projects \\
& Problem-Based Learning \\
& Group Presentation
\end{tabular}

*Percentages are greater than $100 \%$ due to responses coded into multiple themes

Research Question 2: What ways can a previously developed rubric measure undergraduate students' interdisciplinary science understanding?

2a. Which aspects of rubric are more or less difficult for students to meet, and does this vary by course? 


\section{$\underline{\text { Student Performance Based on Rubric Construct Scores }}$}

To evaluate which constructs in the rubric were more or less difficult for students to communicate in their essay responses, we compared student performance (by construct) using the 1-4 scoring metric $(n=71)$ (Table 3) (Figure 1). There was a significant difference between students' scores by construct $(\mathrm{F}(3,280)=6.149$, $p=0.00057, \eta^{2}=0.062$ ). Pairwise comparisons revealed that overall, students scored significantly higher in the purposefulness construct than on integration or critical awareness ( $p=0.0025, p=0.0139$, respectively), and on average, scored significantly higher on the disciplinary grounding construct than on integration $(p=0.0185)$.

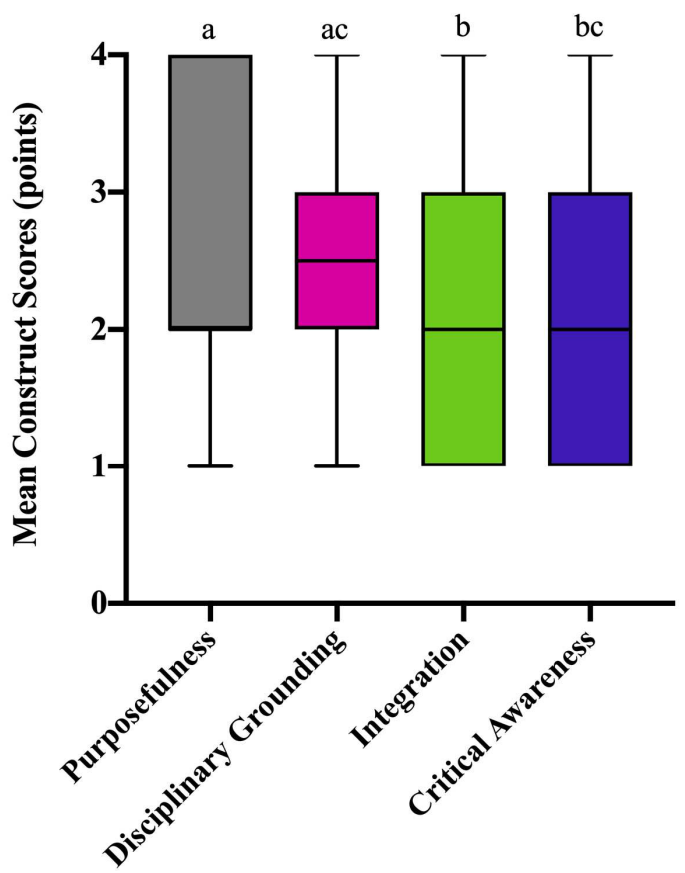

Rubric Constructs 
Figure 1. Box plots compare student performance on overall mean construct scores $(n=71)$. Nonidentical letters above bars represent significant $(p<0.05)$ differences among construct scores (as determined by ANOVA and post hoc pairwise comparisons using Tukey's HSD). A one-way Welch's ANOVA detected a significant difference between mean construct scores $(\mathrm{F}(3,280)=6.149$, $p=0.00057, \eta^{2}=0.062$ ). Tukey's post-hoc analyses reveal that students scored significantly higher on purposefulness than integration and critical awareness ( $p=0.0025, \mathrm{p}=0.0139$, respectively), with no significant differences between the latter two constructs. Students performed significantly better on disciplinary grounding than integration ( $p=0.0185$ ), with no significant differences between disciplinary grounding and purposefulness. $\mathrm{Box}=25$ th to 75 th percentile; bars $=\min$ and $\max$ values. The error bars represent standard error of the mean.

\section{Student Performance Based on Course}

To disaggregate differences between student ID science understanding by course, we first compared total average essay scores of students from each course (Figure 2). There was a significant difference between student scores by course $(\mathrm{F}(3$, $67)=3.69, p=0.016, \eta^{2}=0.142$ ). Pairwise comparisons indicated that mean essay scores of students in Chemical Ecology were significantly higher than in Environmental Restoration ( $p=0.0187)$, with no significant differences between other courses. 


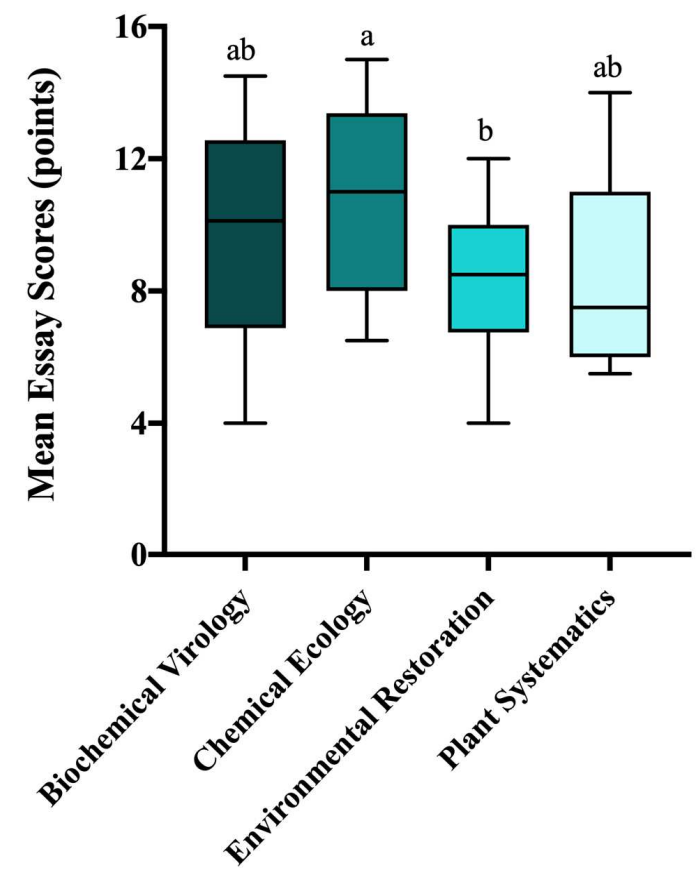

Course

Figure 2. Box plots compare student performance students' mean essay scores across four upperdivision courses $(\mathrm{n}=71)$. Non-identical letters above bars represent significant $(p<0.05)$ differences among courses (as determined by ANOVA and post hoc pairwise comparisons using Tukey's HSD). One-way ANOVA revealed a significant difference between mean construct scores $(\mathrm{F}(3,67)=3.691$, $\left.p=0.016, \eta^{2}=0.142\right)$. A Tukey's post hoc test indicated a significant difference in mean essay scores between Chemical Ecology and Environmental Ecology $(p=0.0187)$, with no significant differences between other courses. Box $=25$ th to 75 th percentile; bars $=$ min and $\max$ values.

\section{Student Performance Based on Construct by Course}

Next, we analyzed average student performance on each rubric construct by course, illustrating an overall significant difference between courses in disciplinary grounding $\left(\mathrm{F}(3,68)=14.5, p<0.0001, \eta^{2}=0.329\right)$, integration $(\mathrm{F}(3,68)=19.2$, $\left.p<0.0001, \eta^{2}=0.401\right)$, and critical awareness $\left(\mathrm{F}(3,68)=8.38, p=0.0003, \eta^{2}=0.187\right)$, with no significant differences between courses in purposefulness (Figure 3A). For disciplinary grounding, pairwise comparisons revealed students enrolled in the Chemical Ecology $(p<0.0001)$, Biochemical Virology $(p=0.002)$, and Plant Systematics $(p=0.044)$ scored significantly higher than students in Environmental 
Restoration, with no significant differences between the former three courses (Figure 3B). For integration, students enrolled in Biochemical Virology and Chemical Ecology significantly outperformed students in Plant Systematics $(p=0.0207$ and $p=0.0138$, respectively), as well as those enrolled in Environmental Restoration $(p<0.0001$ for both courses) (Figure 3C). For critical awareness, students enrolled in Chemical Ecology and Environmental Restoration scored significantly higher than those enrolled in Plant Systematics ( $p=0.006$ and $p=0.016$, respectively) (Figure 3D). Overall, students enrolled in the Chemical Ecology course scored significantly higher in every construct (except purposefulness) compared to at least one other course. 
A. Purposefulness

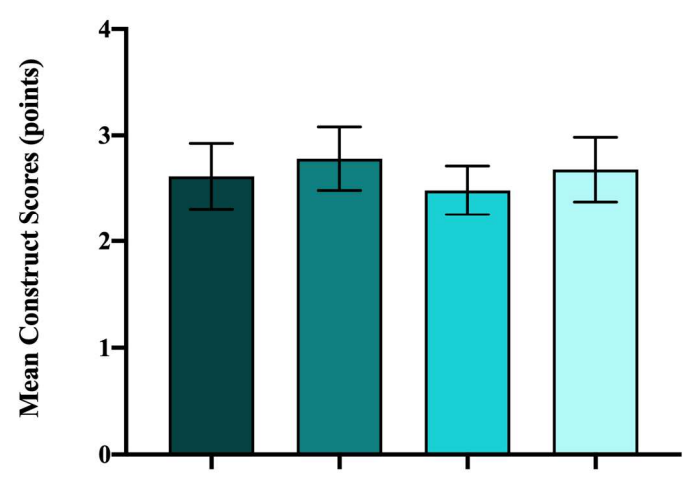

\section{B. Disciplinary Grounding}

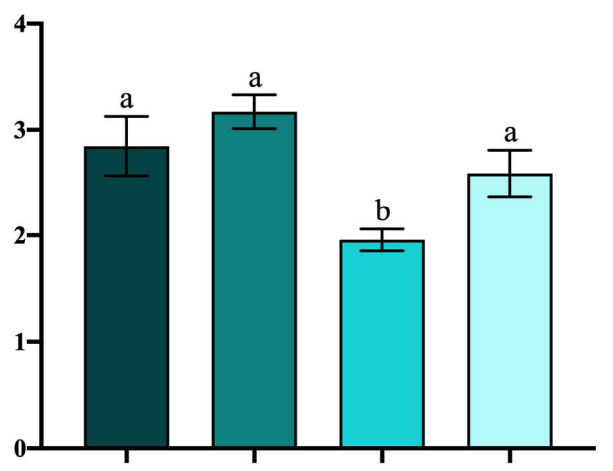

\section{Critical Awareness}

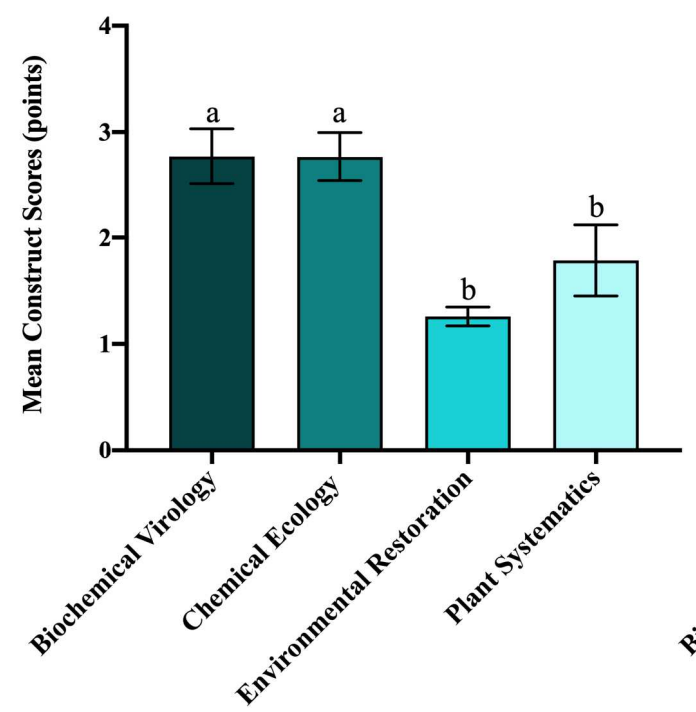

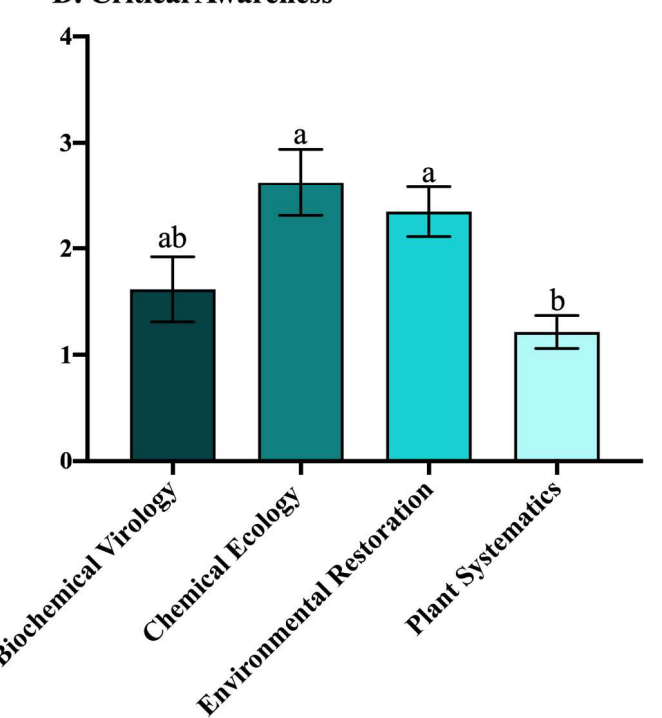

Figure 3. Comparison of mean construct scores for students enrolled in four courses $(n=71)$. Nonidentical letters above bars represent significant $(p<0.05)$ differences among courses within each construct (as determined by ANOVA and post hoc pairwise comparisons using Tukey's HSD). Oneway ANOVA indicated a significant difference between course scores based on constructs disciplinary grounding $\left.\mathrm{F}(3,68)=14.5, p<0.0001, \eta^{2}=0.329\right)$, integration $\left(\mathrm{F}(3,68)=19.2, p<0.0001, \eta^{2}=0.401\right)$, and critical awareness $\left(\mathrm{F}(3,68)=8.38, p=0.0003, \eta^{2}=0.187\right.$ ) (Welch's ANOVA for unequal variances reported based on significant Levene's test for integration and critical awareness). Tukey's posthoc tests: A) Construct Purposefulness: No significant differences in student scores across courses; B) Construct Disciplinary Grounding: Students in Chemical Ecology, Biochemical Virology, and Plant Systematics score significantly higher than students in Environmental Restoration $(p<0.0001$, $p=0.0024, p=0.0435$, respectively); C) Construct Integration: Students enrolled in Biochemical Virology and Chemical Ecology significantly outperformed students in Plant Systematics $(p=0.0207$ and $p=0.0138$, respectively) and in Environmental Restoration ( $p<0.0001$ for both courses); D) Construct Critical Awareness: Students in Chemical Ecology and Environmental Restoration score significantly higher than students in Plant Systematics ( $p=0.006$ and $p=0.016$, respectively). 
Research Question 2b. Can the rubric accurately measure undergraduate students' interdisciplinary science understanding?

\section{$\underline{\text { Interviews }}$}

We interviewed a subset of students from each course who had completed the essay assignment to test if the rubric accurately and adequately captured ID science understanding in our population. In total, 25 of the 71 students participated in an interview (Table 3). Our first round of interview analyses were restricted to scoring the interviews binarily — students either articulated each construct as defined by the rubric (yes), or it was absent or scantly addressed (no).

Table 3. Course characterization of four upper-division natural and physical science courses.

\begin{tabular}{|c|c|c|c|c|c|c|}
\hline Course & Format & Credits & $\begin{array}{c}\text { Total \# of } \\
\text { essay } \\
\text { participants }\end{array}$ & $\begin{array}{l}\text { Total \# of } \\
\text { interview } \\
\text { participants }\end{array}$ & $\begin{array}{l}\text { Disciplinary or } \\
\text { ID; } \\
\text { Course-Listed } \\
\text { Departments }\end{array}$ & Instructors \\
\hline $\begin{array}{l}\text { Biochemical } \\
\text { Virology }\end{array}$ & Lecture & 1 & 11 & 4 & $\begin{array}{c}\text { ID; } \\
\text { Biology and } \\
\text { Chemistry }\end{array}$ & $\begin{array}{c}1 \\
\text { Biochemist } \\
1 \text { Biologist }\end{array}$ \\
\hline $\begin{array}{l}\text { Chemical } \\
\text { Ecology }\end{array}$ & $\begin{array}{l}\text { Lecture + } \\
\text { Research- } \\
\text { based Lab }\end{array}$ & 3 & 13 & 8 & $\begin{array}{c}\text { ID; } \\
\text { Biology and } \\
\text { Chemistry }\end{array}$ & $\begin{array}{l}1 \text { Chemist } \\
1 \text { Biologist }\end{array}$ \\
\hline $\begin{array}{l}\text { Environmental } \\
\text { Restoration }\end{array}$ & Lecture & 3 & 32 & 6 & $\begin{array}{c}\text { ID; } \\
\text { Environmental } \\
\text { Sciences }\end{array}$ & 1 Ecologist \\
\hline $\begin{array}{c}\text { Plant } \\
\text { Systematics }\end{array}$ & $\begin{array}{l}\text { Lecture }+ \\
\text { Traditiona } \\
1 \text { Lab }\end{array}$ & 4 & 15 & 7 & $\begin{array}{c}\text { Disciplinary; } \\
\text { Biology }\end{array}$ & 1 Biologist \\
\hline
\end{tabular}

\section{$\underline{\text { Evidence of Convergent Validity through Matched Data }}$}

To better understand the data collected from the rubric, we compared samestudent scores across essays and interviews $(n=25)$ (Figure 4). Students' 
understanding of disciplinary grounding was relatively consistent across their essays and interviews, with $64 \%(n=16)$ of the population scoring high or low across both measurements. Overall, 11 students received high scores on their essay (apprentice to mastery) and exhibited this same level of understanding in their interview; 5 students scored low (naïve to novice) on their essay, while also unable to articulate disciplinary grounding in their interview) (Figure 4A). The construct integration had a much smaller proportion of matched understanding between essays and interviews $(n=11,33 \%)$ (Figure 4B). For critical awareness, the highest proportion of students $(\mathrm{n}=17,68 \%)$ had matched understanding between measurements (Figure 4C). However, of these 17 students, the majority $(n=13,76 \%)$ scored low on critical awareness across both measurements, receiving between naïve (1) and novice (2) scores on their essay and binarily scored a 'no' for their interview. This accounts for over half of the entire population (52\%) who were not meeting the requirements for critical awareness set forth by the rubric across both measurements.

Many essay scores fell in-between levels of understanding, (e.g. receiving a score of 3.5; see Table 4A2 for example). Reasons for this are two-fold: 1) researchers were often unable to cleanly identify if a student was exhibiting a mastery or apprentice, apprentice or novice, and/or novice or naïve levels of understanding across the three constructs, and 2) averaging criteria scores often resulted in nonintegers. 

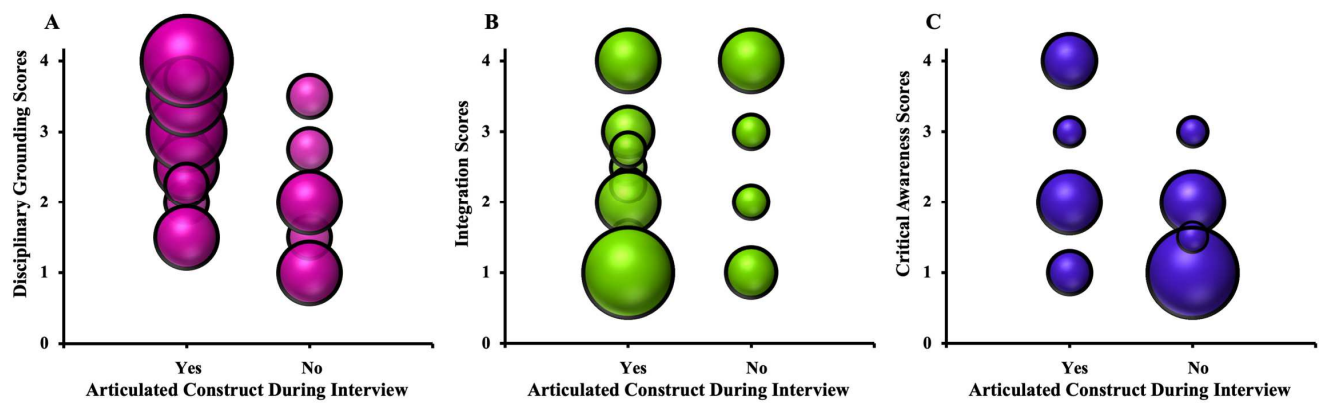

Figure 4. Numeric construct scores ((1) Naïve (2) Novice (3) Apprentice (4) Mastery) matched with same-student binary interview score (Yes, No); A) Disciplinary Grounding, B) Integration, C) Critical Awareness. Size of the bubbles correspond to the number of students who obtained a given construct and interview score (e.g. larger bubbles indicate a larger number of students who received a particular matched score).

\section{Disciplinary Grounding}

Examples of students' matched and mismatched scores for disciplinary grounding are provided in Table 4A1. Chemical Ecology student, Willow, exhibits a mastery level of understanding in their essay and mirrors an adequate articulation of disciplinary grounding in their interview. Oppositely, Birch from Chemical Ecology demonstrates a mismatched understanding of disciplinary grounding between their essay and interview. Birch's essay exhibits high understanding of disciplinary knowledge (score of 3), but provides scant disciplinary methods (score of 1.5), thus receiving an average score of 2.25 for the construct. However, in Willow's interview, they identify the exact methods to use when addressing a problem similar to the essay prompt.

\section{Integration}


The integration construct had the largest difference between essay and interview scores, with over half of the population $(n=14,56 \%)$ exhibiting integration knowledge in their interviews but unable to display this same understanding in their essay, receiving naïve or novice scores (Figure 4B).

Table 4B1 demonstrates Plant Systematics student, Cedar's mastery level of understanding across both measurements in the construct integration, using two or more disciplines in an integrated fashion to advance the solution to the problem (meeting criteria requirements 3.1, 3.3, and 3.4). Cedar provides deep explanation of integrating biology (phylogenetic methods, using microsatellites, etc.) and chemistry (measuring alkaloids, glucosinolates) while connecting how each discipline is necessary. Similarly in Cedar's interview, they describe how chemistry, biology, geology, and history are used in understanding each discipline, as well as how they build off of one another to yield a holistic understanding of the issue.

In Table 4B2, Magnolia from Environmental Restoration displays a disconnected understanding of the construct integration. In this essay, no disciplines are included to support their approach to the essay prompt. Magnolia repeatedly poses questions throughout the essay but never attempts to provide an answer. But in the interview, they provide clear evidence of their understanding of integration through the identification of multiple disciplines and the connection between them (biogeochemistry, systems science, history) to yield a more well-rounded view of restoration, while relying on experts in other fields (hydrologist, geologist, biologist, chemist) to advance the solution toward a direction with the most successful outcome. 
Student scores for the critical awareness construct conveyed a pervasive mismatched understanding across both measurements, with more than half of the population unable to display critical awareness as defined by the rubric in the essay or interview (Figure 4C).

In Table 4C1, Maple from Plant Systematics received a mastery level score for critical awareness, including a description of benefits and limitations of integrating biology and chemistry methods, and a metacognitive checkpoint for dealing with unexpected results. This level of awareness is paralleled in Maple's interview as they discuss the all-angled thinking involved in biology research.

Hazel from Biochemical Virology, however, provides a grandiose outlook on the proposed solution to the essay prompt Table $4 \mathrm{C} 2$. They provide no awareness of limitations and place extensive weight on benefits that are unfeasible given their approach in the essay. However, Hazel articulates an analytical critical awareness in their interview by explaining the limitations of research (experimental design, variables, parameters) and the usefulness of alternative routes when an approach fails.

Table 4. Examples of matched and mismatched understanding of ID of same -student essay and interview responses. 


\begin{tabular}{|c|c|c|}
\hline Construct & Essay Responses & Interview Quotes \\
\hline \multirow{5}{*}{ 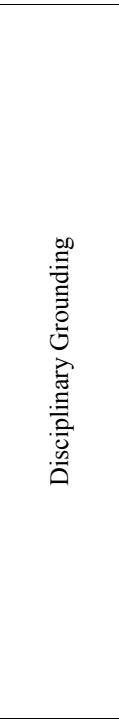 } & \multicolumn{2}{|c|}{ A1. Willow, Chemical Ecology } \\
\hline & $\begin{array}{l}\text { "The unknown plant bears fruits that appear } \\
\text { healthy and edible, but without analysis of their } \\
\text { nutritional content nothing can be said for certain. } \\
\text { We intend on determining the mineral content of } \\
\text { the fruit using near-infrared reflectance } \\
\text { spectroscopy, as well as measuring secondary- } \\
\text { metabolites to deter herbivory. Assessing floral } \\
\text { morphology will provide insight into its } \\
\text { pollination syndrome, and, consequently, its } \\
\text { method of pollination." }\end{array}$ & $\begin{array}{l}\text { "I think about how plants use compounds, there's } \\
\text { all sorts of ecological relationships between plants, } \\
\text { and different organisms, and pollinators, and the } \\
\text { idea of plants producing nectar has a lot to do with } \\
\text { chemistry. Then plants producing all sorts of } \\
\text { volatile compounds that attract predatory } \\
\text { organisms for defences." }\end{array}$ \\
\hline & & Matched Understanding: YES \\
\hline & \multicolumn{2}{|c|}{ A2. Birch, Chemical Ecology } \\
\hline & $\begin{array}{l}\text { "The morphological character of the flower also does } \\
\text { not indicate bee pollination. The inflorescence consists } \\
\text { of a single yellow-orange tubular corolla with a deep } \\
\text { nectar reserve, which suggests pollination by } \\
\text { Lepidoptera or possibly hummingbirds. Further tests } \\
\text { need to be conducted to figure out which one." } \\
\text { Avg. Construct Score: Novice (2.25) }\end{array}$ & $\begin{array}{l}\text { "We talked about compounds and secondary } \\
\text { compounds of plants. There's even, when you go } \\
\text { down to systematics you're talking about how } \\
\text { things are related. To find out how things are } \\
\text { related you look at the DNA of plants the } \\
\text { molecular level through DNA sequencing and } \\
\text { GenBank as well as they work morphologically." } \\
\text { Matched Understanding: NO }\end{array}$ \\
\hline \multirow{6}{*}{ 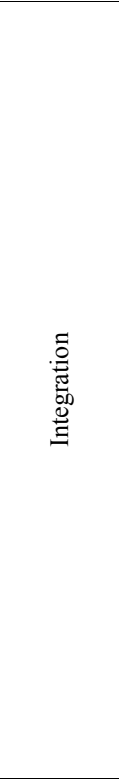 } & \multicolumn{2}{|c|}{ B1. Cedar, Plant Systematics } \\
\hline & $\begin{array}{l}\text { "We will perform a phylogenetic analysis using } \\
\text { microsatellites to find out what species of fruit or } \\
\text { vegetable this plant is most closely related to. We will } \\
\text { use microsatellites since this new species must have } \\
\text { recently diverged from an extant crop plant species. } \\
\text { We can then contact chemists to analyze the chemical } \\
\text { compounds present and correlate this with related } \\
\text { species from the phytogenic analysis." }\end{array}$ & $\begin{array}{l}\text { "It's important to know how things are actually } \\
\text { working, requiring the knowledge of chemistry and } \\
\text { viewing biological systems in a chemistry sort of } \\
\text { lens. Learning about geology and chemistry would } \\
\text { really help in phylogenetic projects, just because } \\
\text { understanding the history of the earth and the } \\
\text { geography can help us interpret trends in the } \\
\text { genotypes of organisms. The moulding of these } \\
\text { knowledge sets ends in a greater understanding of } \\
\text { plants holistically." }\end{array}$ \\
\hline & Avg. Construct Score: Mastery (4) & Matched Understanding: YES \\
\hline & \multicolumn{2}{|c|}{ B2. Magnolia, Environmental Science } \\
\hline & $\begin{array}{c}\text { "How the park will be restored mostly comes down to } \\
\text { the project goals. This is a public park after all }[. . .] \text { not } \\
\text { a far out wilderness ecosystem. So, what does the } \\
\text { public want?" }\end{array}$ & $\begin{array}{l}\text { "[Environmental restoration] means using systems } \\
\text { science and science of cycles in biogeochemistry. } \\
\text { It's trying to bring back a previous state using } \\
\text { history to look back at reference sites. Restoration } \\
\text { requires collaborating between experts, having a } \\
\text { more well-rounded view, because you're bring in } \\
\text { hydrologist to geologist, a biologist, a chemist. } \\
\text { You're thinking about all the different aspects of } \\
\text { something instead of being one sided." }\end{array}$ \\
\hline & Avg. Construct Score: Naïve (1) & Matched Understanding: NO \\
\hline \multirow{3}{*}{ 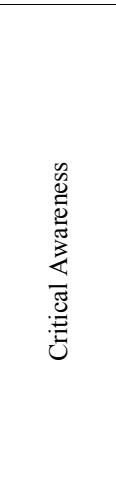 } & \multicolumn{2}{|c|}{ C1. Maple, Plant Systematics } \\
\hline & $\begin{array}{l}\text { "If the species is determined to be a self-pollinator and } \\
\text { we determined the origin of its evolution through } \\
\text { genetic sequencing there is a possibility that we could } \\
\text { use cross pollination. However, as many self- } \\
\text { pollinators use wind or rain as transportation modes } \\
\text { for pollen, this could ultimately lead to an uncontrolled } \\
\text { spread of the plants' genes to other species, thus } \\
\text { having a negative effect [on] the ecosystem. } \\
\text { Alternatively, we could assess pollination through the } \\
\text { measurement of volatile organic compounds. If all else } \\
\text { fails, I would reassess my methodological approach." }\end{array}$ & $\begin{array}{l}\text { "I like the, 'it may or may not happen this way', in } \\
\text { biology. I love going out into nature and } \\
\text { [wondering], "Why is it that way?" It is very } \\
\text { important to set it up beforehand, like my bee } \\
\text { pollination experimental design, and map it out and } \\
\text { it may not go as planned. A big part of science is } \\
\text { just recognizing why you failed or how you can do } \\
\text { things better the next time around. Why didn't they } \\
\text { pollinate? Why did the plants not sprout? Why did } \\
\text { we not get the results that we wanted? You need to } \\
\text { go need back and check your experimental } \\
\text { process!" }\end{array}$ \\
\hline & Avg. Construct Score: Mastery (4) & Matched Understanding: YES \\
\hline
\end{tabular}


C2. Hazel, Biochemical Virology

"We can live in a better world, and this better world must inherently include all people on the planet earth By providing a sustainable, high nutrient food source, we can [achieve] this dream thereby halting human starvation."
"Learning about how to deal with experiments not turning out how you want them to turn out-what's possibly good data when addressing the behemoth issue of food insecurity. Learning to take a step back- which variable or parameters are we going to change here to make this still useful, even though it didn't turn out how we wanted it to turn out.

Avg. Construct Score: Naïve (1) Matched Understanding: NO

The Emergent Theme of Collaboration

Although there was no requirement to include a collaboration component in the essay submission or rubric, many students included language that indicated the necessity of collaboration. Of the larger population that completed the essay $(n=71)$, $34 \%$ included the importance of collaborating with other scientists or community members in their essay; in the matched data set, $51 \%$ of students discussed elements of collaboration. Below is an example of collaboration language from an essay of a student:

"Regardless of the fire severity, including the public in the decision-making process should be a key component in the restoration program. The land is also built on indigenous grounds and it is critical to involve tribal members." - Acacia, Environmental Restoration

Research Question 3: How do undergraduate students perceive interdisciplinary science?

Deductive Analysis

Our first aim with the interview data was to code passages that aligned with constructs of the rubric, yet clearly students discussed ideas unrelated to the rubric. 
To capture these themes, we performed additional rounds of interview analysis using both inductive and deductive approaches. The codes that emerged from the initial inductive analysis mapped almost directly onto the subsequent, IDSF-derived, deductive codebook. Therefore, we chose to include the results and discussion from the deductive analysis only. This analysis allowed us to test the robustness of the IDSF criteria: disciplinary grounding, different research methods, integration, collaboration, and disciplinary humility. Examples of student interviews that reflected these criteria are outlined in this section.

\section{Perceptions of Disciplinary Grounding}

Disciplinary grounding is a shared construct between the rubric and IDSF. Of the 25 interview participants, $76 \%$ articulated disciplinary grounding:

"I did well [in this course] because of my larger knowledge in both chemistry and biology, like when we had to isolate cyanide. We had to specifically look at the plants and then we isolated the cyanide from various leaves. I guess our experimental process was a lot of biology. Then from there, we moved into the chemistry aspect. If I didn't have both of those backgrounds, it would have made it hard for me to see the relevance or actually just get through the entire process." -Elm, Chemical Ecology

"I think it would be a lot more helpful to learn disciplines by themselves in order to connect them. There's always going to be some chemistry when you talk about biology and vice versa. It would be a lot more helpful to have a good background in those disciplines first." -Hazel, Biochemical Virology 
Interestingly, although many students understood the value of deep knowledge in one discipline, they often coupled this appreciation with a clause endorsing integration as the essential next steps:

"I think there are some benefits to learning a discipline by itself... if you're only a chemist, and you only focus on chemistry you can be a really good expert at that, but I think that it's more important to also see how it connects to other fields. If someone is really into just researching DNA, and only doing that one thing, there is some benefit to that, like you'll be the expert in that one specific thing. But if you want to have more relevance to the world it's probably better to have some background of what else is going on." -Hemlock, Environmental Restoration

"I think that there's a reason that we make these arbitrary, or not so arbitrary distinctions between chemistry and biology, and physics. I think that they are so full of information, and concepts that it make sense to separate them, but it also makes equal sense to unify them, and to show that they're not separate. That they are all the same system.” -Cedar, Plant Systematics

In expressing the value of disciplinary knowledge, many students exhibited the need for collaboration, and in doing so, were displaying disciplinary humility - an openness and respect for other disciplines and value of collaboration in ID science: 
"You can't be an expert in everything. Depending on who you are, how you learn, what you're passionate about, it may be better for some people to just focus on one discipline and they can become an expert in that. But they then should work with others with specialties in other areas to accomplish these heavier issues in society." Aspen, Plant Systematics

\section{Different Research Methods}

The inclusion of different research methods from multiple disciplines was overwhelmingly absent from student responses when describing ID science. Only $12 \%(n=3)$ of students included aspects of different disciplinary research methods in their conceptualization of ID science:

"Interdisciplinary science is combining chemistry, biology and ecology all together. I'm thinking, specifically, of tomato plants and the insects, the insects they interact with. They produce those alkaloids, which is a compound, a chemical compound. The caterpillars then, use that like a defense in an ecological system for predators." Willow, Chemical Ecology

\section{$\underline{\text { Advancement through Integration }}$}

The idea of integration as an integral piece to ID science was represented in all student interviews ( $\mathrm{n}=25,100 \%)$ as they discussed the meaning of ID science:

"I think [interdisciplinary science is] kind of combining the different aspects of science, meaning that link between chemistry and ecology, biology. I think even 
physics can be thrown in there, and geology. Just kind of bringing it all together." Cherry, Plant Systematics

"I just think it's important to know how things are actually working, which, a lot of the time, requires the knowledge of chemistry and viewing biological systems in a chemistry sort of lens. To get that full picture, you really need to look at the big thing. " -Sycamore, Biochemical Virology

Most students were not only juxtaposing multiple disciplines in their understanding (as displayed in the two quotes above), but they often expressed integration through the leveraging of different knowledge and methods from separate disciplines to understand a phenomena or advance knowledge $(92 \%, \mathrm{n}=23)$ - a critical component that separates interdisciplinarity from cross- and multi-disciplinarity:

"Interdisciplinary science is important, like, learning geology would really help in phylogenetic projects, just because understanding the history of the earth and the geography can help us interpret trends in the genotypes of organisms. "-Spruce, Plant Systematics

"I think [interdisciplinary science] means the soft and hard sciences working together and building off each other's knowledge. Understanding the human components. Bringing those together to understand how systems don't work in a vacuum, and human components are kind of always at work in natural science systems." Magnolia, Environmental Restoration 
"I really appreciate the interdisciplinary connections in science and I think that reflects a lot of true science. You might start out with one question but by the time you meet with other people who have knowledge in other regions, you may be able to ask more profound question and integrate your knowledge with their knowledge into the project. Integrating knowledge helps me learn how to deal with experiments not turning out how I want them to turn out, you know, how ca we rethink this-what's possibly good data. So learning to take a step back and lean on others methods and such." -Larch, Chemical Ecology

\section{Integration through Collaboration}

Students spoke of collaborative efforts often in conjunction with integration language, as these two criteria are intricately entwined. When individuals collaborate, they bring their expertise to a team with hopes of successfully integrating pieces of knowledge with their collaborators to advance a field, create a discovery, or inform gaps in knowledge. This interconnection was expressed by $64 \%(n=16)$ of students:

"When you study something you know [it] really well, you do that one thing super well, but you may you fail to take into account other factors that may be present or influencing it. You have to take it all into account and think about bigger pictures while at the same time looking at the small picture and the context. That's hard for just one person to do when you're thinking about a study which is why collaborating with a lot of different folks is important. I think that's more important than focusing on details that aren't seen in day-to-day life." -Oak, Environmental Restoration 
"It's like in economic theory, this whole idea that if you have everybody doing everything, then you have a net loss. Meaning, if you have a person who's a farmer and a doctor and trying to do everything at once, then you're going be much less productive in everything. Then if you have one person specializing as a farmer, and that's all he does, and one person who's a doctor and specialize in that, then you can be more specialized in that field and you can share your information and everybody gains.” -Elm, Biochemical Virology

Many students touched on aspects of common ground $(28 \%, n=7)$ - a key contributor to successful collaborations as noted in the IDSF - and its importance in learning ID science:

"In this class, you never knew who you were going to end up talking to, where they were at as far as, like, conceptualizing what you are saying, or conceptualizing your project. So kind of having to adapt to that and make sure, you know you get so used to talking to people in your specific discipline, it was kind of nice to talk to other people and be like, oh that's not even a thing in their world. Let me explain it. Or like same thing for me. I had to learn a lot about chemistry and different applications of that in biology." -Pine, Chemical Ecology

"[Interdisciplinary science is] just trying to bridge the gap. Science is just trying to bring everything together, the whole because basically each discipline has similar things, but they're from very different perspectives. So, if you can create a common 
language, it'd bring everybody together. You'd think it would be very beneficial, especially for medicine. If you're trying to create drugs, you need to have crosstalk between different professors, etc., it's how you bring that work together." -Ash, Biochemical Virology

Expression of Disciplinary Humility

As we read and coded student interview transcripts, it was evident that students were expressing high levels of disciplinary humility (as defined in the IDSF) when verbalizing the meaning of ID science and its value in the larger context of society. Evidence of how the IDSF defines this criterion-openness and respect for other disciplinary perspectives and expertise — was riddled throughout the aforementioned themes. We also identified interview responses that specifically capitalized on this humility $(60 \%, n=15)$, and to a much lesser degree $(12 \%, n=3)$, responses that connected the importance of leveraging STEM and non-STEM disciplines:

"I don't think that you can have one [discipline] without the other when you're talking about any type of science and that includes social sciences. Unless you want to just stick yourself in the lab all day and never talk to anyone else, which is totally fine, but you're going to have to know what your research is doing and how it connects with others' research in order to, kind of, elevate the importance." -Olive, Environmental Restoration 
"I think we lose a lot of knowledge when we ignore that someone else might have a different way to interpret things especially given their background. For instance, I think it is important to get different data interpretations. Everybody has a different way to interpret things." -Juniper, Chemical Ecology

"I think [interdisciplinary science] can help further research and improve it, and also help solve real world science problems. I think with restoration ecology in particular, you need combination of different scientists, including those from the soft sciences, so if they already have that knowledge of other fields, it will improve their problem solving abilities.” -Sassafras, Environmental Restoration

\section{DISCUSSION}

The necessity of ID science as a critical factor in solving real-world problems is undeniable. Yet, little has been done to assess if future scientists are equipped with the resources to address this competency as an undergraduate science student. Here, we identified that instructors typically assess ID science understanding through writing assignments, and therefore developed an essay assignment as a platform for students to exhibit their ID science knowledge. We then tested for evidence of convergent validity of data collected from a pre-existing ID rubric to evaluate undergraduate students' understanding of this competency. Lastly, we used our results to inform the robustness of the Interdisciplinary Science Framework through a similar validity analysis. 


\section{Instructors Assess ID Science Understanding through Writing}

Faculty that we surveyed predominantly identified writing activities as the main way they assess ID understanding in a classroom setting (69\%) (Table 2).

Within this category, more than half of our participants identified writing assignments through essays and papers as the preferred method of assessment (51\%). This finding is consistent with a wealth of literature that suggests students must be given the opportunity to problem-solve and think critically through writing when addressing the complexities involved in ID science (Boix-Mansilla et al., 2009, Chan et al. 2010, Gouvea et al., 2013, Balgopal et al., 2012, 2017, Cooper \& Stowe, 2017, Tripp \& Shortlidge, 2019). Thus, we support that instructors use writing-intensive activities as a mechanism to measure ID science understanding in an undergraduate setting.

Traditional assessments (34\%) through exams and quizzes were chosen as the second most frequently utilized evaluation, followed by group work (34\%). Although

group work is being championed through active learning models (Johnson \& Johnson, 2009, Haak et al., 2011, Lamm et al., 2012, Wilson \& Brame, 2018), and importantly, is how ID work is actually accomplished, this was not well reflected by science faculty. Such results suggest that experts rely on students being able to demonstrate that they can think interdisciplinarily before actually participating in a collaborative ID project (Tripp \& Shortlidge, 2019). We recommend that as we consciously move students through a progression from thinking to acting interdisciplinarily, we should thoughtfully consider the appropriateness of the assessment method.

$\underline{\text { Rubric can Differentiate Performance Based on Constructs among Students and }}$ Courses 
The rubric was able to detect differences in student construct performance based on the rubric scores from the essay (Figures 1-3) as defined by the designers (Boix Mansilla et al., 2009). Overall, students struggled to meet the requirements for integration and critical awareness understanding as evidenced by the significantly lower scores in these constructs compared to purposefulness and disciplinary grounding across our entire population (Figure 1). This is unsurprising as integration and critical awareness are much more nebulous and are not well-defined for the natural and physical sciences (Borrego et al., 2010). These statistical analyses support findings from the matched data of essay scores and interviews (discussed more thoroughly below) — students are conceptualizing disciplinary grounding similarly to the rubric, and thus have higher scores in this construct reflecting this understanding. The significantly lower student scores for integration and critical awareness are also reflected in the matched data—students are operationalizing these constructs differently than the rubric, and perhaps more similarly to the IDSF. Although there was no matched data for purposefulness, students scored well on this construct, providing evidence that this may be an important piece in helping students' framing their writing in an appropriate context.

When comparing differences in overall student performance in essays by course and rubric constructs, the students enrolled in Chemical Ecology, which was a course-based undergraduate research experience (CURE), had higher scores than students in Biochemical Virology, Environmental Restoration, and Plant Systematics across all rubric constructs (Figure $2 \& 3$ ). This high performance may be a result of students exposure to ID science as they worked on a chemical ecology research question with a biologist and a chemist. Students taking a research-based course have 
the chance to "do" science as opposed to learn about science, which in practice, is often an inherently ID endeavor. Additionally, students enrolled in courses taught by two instructors from different disciplines (Chemical Ecology and Biochemical Virology- see Table 3 for information on instructors) tended to score higher on total average essay scores than students taught by one disciplinary instructor (data not shown in this study). This may reinforce that students need exposure to deep disciplinary knowledge from separate disciplines in order to effectively integrate knowledge to address real-world issues.

\section{$\underline{\text { Rubric Did Not Fully Measure up to Validity Tests across Data Measurements }}$}

Our matched data between essays and interviews reveal several inconsistencies between students' written and verbal communication of the integration and critical awareness constructs, while less so in disciplinary grounding. In disciplinary grounding (Figure 4A), there was high variability in matched scores across students but overall, this construct is operating as expected—individual students received similar scores in both their interview and essay measurements (e.g. same-student high scores on interviews and essays or same-student low scores across both). In interviews, students also expressed an appreciation for disciplinary knowledge, which supports the IDSF's disciplinary grounding category and provides further evidence that this construct is likely a fundamental component to ID science understanding.

Integration (Figure 4B) had the largest amount of mismatched understanding between same-student measurements, with many students meeting this benchmark in their interviews but completely missing this understanding in their essays $(n=12$, 
measured as scores below 2.5 in the rubric). This could be attributed to certain criteria within this construct being unsuitable for our population. If students are able to articulate integration in interviews but miss this mark entirely in their written responses, this could suggest that natural and physical science students may operationalize integration differently from the social sciences. This point is further substantiated in our deductive analysis of interviews using the IDSF — students are indeed understanding integration through the leveraging of disciplines to advance solutions to problems. Thus, it is likely that elements of the rubric are either stifling students' from incorporating integration or misleading them toward more simplified connections between disciplines. We also fully recognize that students' abilities vary between written and oral assessments, perhaps partially contributing to this discrepancy. However, it is unlikely that this is the case for over half of our population. Redefining and setting clear expectations for accomplishing integration as defined in the IDSF could potentially provide an outlet for students to apply their integrative knowledge to real-world issues.

Critical awareness (Figure 4C) scores were perhaps the most perplexing of the constructs, with over half of our population completely missing or poorly meeting this construct across both essays and interviews ( $n=13$, measured as scores below 2.5 in the rubric). A potential reason for this may be similar to integration-the operationalization of critical awareness may differ between the natural and social sciences (Borrego et al., 2010). Another possibility is that critical awareness may be out of a student's capability at the undergraduate level, or perhaps, this construct is not suitable for the natural and physical sciences altogether. However, we posit that students should absolutely be critically aware in science, including the benefits and 
limitations of their study/approach, but perhaps being proficient of all the caveats of each discipline involved, as the rubric suggests, is infeasible. Instead, it may be highly beneficial to restructure critical awareness to more closely align with the IDSF's criteria of disciplinary humility. Students overwhelmingly expressed an awareness of, and respect for, other disciplinary expertise and perspectives during their interviews by frequently expressing their lack of knowledge in other disciplinary domains. This humility and consciousness of their own limitations is critical in ID science work and are characteristics of conscientious scientists. To nurture this humble mindset on a larger scale, students may need to be led through a more explicit pathway, such as the IDSF, to develop a greater ability to demonstrate open-mindedness and inclusivity in ID collaborations (particularly with non-STEM disciplines-discussed below).

Furthermore, we propose that a lack of understanding in both integration and critical awareness may not be the onus of students, but instead, instructors need to be more intentional in helping students integrate knowledge, concepts, and methods/methodologies across disciplines and provide opportunities for students to enhance their critical awareness by thinking 'outside-the-box'.

\section{Exclusion of non-STEM disciplines}

A common trend in the matched interview and writing assignment data sets was the absence of non-STEM disciplines in students' essay responses. According to the IDSF, 'disciplinary humility' is the thread that connects all other aspects of ID science understanding with a component to consider non-STEM contributions to realworld problems (Tripp \& Shortlidge, 2019). We developed essay prompts that we believed would elicit students integrating the humanities and social sciences (i.e. 
topics included declining honeybee populations, environmental restoration, and infectious viral outbreaks) for a complete, thoughtful response. However, only $25 \%$ of students mentioned disciplines outside of STEM fields in their essays. The rubric may not have the necessary elements or may be too specific for students to consider including fields outside of STEM. Further, specific courses had a stricter focus on STEM, and thus, it is possible that other fields were overlooked or students perceived that non-STEM disciplines would not be appropriate for these writing activities. This pervasive lack of non-STEM inclusion was also reflected in student interviews, with only $12 \%$ of students speaking to the importance of non-STEM disciplines. This is alarming as mitigating real-world issues, such as food insecurity, will undoubtedly involve non-STEM fields to fully address. In addition, research suggests that undergraduate STEM students have historically been less mindful of societal issues and how science can impact equity and the human good (Garibay, 2015). In order to train STEM students to be more civically responsible and socially aware of the impact of science, instructors should make intentional efforts to incorporate connections between science and society into curricula and assessments (NRC, 2009, AAAS, 2011, Garibay, 2015).

The Importance of Collaboration

Lastly, the theme of collaboration emerged in both essays and interviews, with percentages appreciably high considering there was no specific collaboration requirement in the rubric (34\% entire essay data set, $64 \%$ in interviews, $51 \%$ across matched data set). These findings corroborate Borrego et al.'s work (2010), stating that the natural and physical sciences rely on collaboration at higher rates than other 
disciplines. The inclusion of this theme is also strongly supported by the IDSF (Tripp \& Shortlidge, 2019) highlighting the importance of interacting across disciplines and suggesting this as a fundamental cornerstone of ID science understanding.

$\underline{\text { Students Conceptualize Interdisciplinary Science in Ways that Align with the IDSF }}$

The majority of students discussed ideas that closely align with our previous work on science faculty's perceptions of ID science and the IDSF (Tripp \& Shortlidge, 2019). Students' perceptions of ID science reflect almost all of the criteria in the IDSF as evidenced through interviews in this study. Many students exhibited the essence of disciplinary humility, acknowledging and respecting the importance of other disciplines within STEM during interviews (60\%). Moreover, students often described attributes of ID science as the application of these different disciplines to solve larger societal problems. This result closely ties to elements of faculty's description of ID science and supports the notion that real-world problems inherently require the application of multiple disciplines in order to advance the problem at hand (Tripp \& Shortlidge, 2019). Students spoke to the importance of being grounded in disciplinary knowledge before integrating different disciplines (74\%), often describing integration as the leveraging of disciplinary knowledge, methods, or ideas into a cohesive whole $(92 \%)$. The majority of students included collaboration as a hallmark of ID science (64\%), and to a lesser extent, the necessity of common ground and/or language amongst ID collaborators (28\%). This idea of common ground in ID work is emphasized by Tripp \& Shortlidge (2019), as well as many ID experts, as a necessary component for effective ID collaboration (Boix Mansilla \& Gardner, 2003, Thompson, 2005, Öberg, 2008). 
One pillar of understanding ID science according to the IDSF, that was severely lacking recognition in student interviews, is the inclusion of 'different research methods' from other disciplines. However, students effectively met a similar criterion (2.2: Does the paper use disciplinary methods accurately and effectively (e.g. experimental design)?) in their essays evidenced by their high scores in disciplinary grounding. Students inexperience with research at the undergraduate level possibly explains this exclusion in their interviews. We contend that as students start to engage in more ID science research and collaborations, this awareness of different research methods will likely increase.

Given the above alignment and considerations, student perceptions and conceptualization of ID science increase the validity of the IDSF as an accurate model to design curricula that capture students' understanding of ID science.

\section{LIMITATIONS}

We acknowledge that we only used one non-ID course resulting in the absence of statistical analyses of student scores based on ID course format (ID v. non-ID), difference in demographics, and prior ID science exposure. Trends in our data indicated that, rather than focus on differences between ID and non-ID course format, individual student scores based on demographics, or prior ID experience, efforts should first be centralized around developing a functional tool that effectively captures student understanding of ID science across disciplines on a larger scale, regardless of student background or classroom environment. Although our effect sizes were large, the significant differences that were observed in scores between the 
research-based course and the other courses represent a small sample size and more essays should be analysed from multiple research- and non-research-based courses to provide further evidence on the instrument functionality. We also recognize that these data were collected from students from only one institution across four upper-division courses, and thus may not be representative of other student populations.

Additionally, we did not prompt students in interviews to specifically verbalize ideas related to each rubric construct, as we wanted another means of gathering students' understanding and perceptions of ID science outside of the rubric - this allowed us to gain evidence of convergent validity. However, because of this, our interview results may not be fully inclusive of student perceptions and knowledge specifically related to constructs defined in the rubric. Lastly, the rubric constructs were not necessarily linked to learning outcomes and/or focal points of course material, as we did not consult with instructors about embedding the constructs or related ideas into the course prior to the assignment.

\section{CONCLUSION AND NEXT STEPS}

In order to meet the interdisciplinary requirements set forth by initiatives such as Vision and Change, conceptualizing how ID science understanding is currently met and finding ways to assess undergraduate students' ID understanding is imperative. The development of writing activities is one potential platform for students to express their understanding of ID science in a creative, yet constructive way. Providing evidence of validity of data collected from pre-existing instruments and frameworks can inform the selection and/or development of instruments to assess ID science understanding through these activities. 
The results of this study do not provide sufficient evidence that valid data was collected from using the pre-existing rubric, yet largely support the criteria outlined in the IDSF (disciplinary grounding, different research methods, integration, collaboration, and disciplinary humility). We aim to develop and test an instrument based on factors that functioned well with the rubric and constructs that align with the IDSF. Future efforts will focus on gathering a larger sample of essay responses across student populations and conducting student/faculty interviews to further develop an instrument that provides valid data on students' understanding of ID science. This research is a step towards being able to use best practices in measuring undergraduate science students' ability to "tap into the interdisciplinary nature of science" as described by Vision and Change (2011).

\section{ACKNOWLEDGEMENTS}

We would like to thank the instructors who worked with us to embed the essay in their classes, and the student participants for their generous contributions and participation in this study. We thank undergraduate researchers Analee Pham and Megan Thran for their help with data analysis. We also thank the Biology and Chemistry Education Research Group at Portland State University for providing thoughtful feedback on interview questions. 


\section{REFERENCES}

American Association for the Advancement of Science. (2011). Vision and change: A call to Action, Final Report. Washington, DC. Retrieved July 22, 2019, from http://visionandchange.org/finalreport.

American Educational Research Association, American Psychological Association, \& National Council on Measurement in Education. (2013). Standards for educational and psychological testing. American Educational Research Association.

Balgopal, M. M., \& Wallace, A. M. (2009). Decisions and dilemmas: Using writing to learn activities to increase ecological literacy. The Journal of Environmental Education, 40(3), 13-26.

Balgopal, M. M., Wallace, A. M., \& Dahlberg, S. (2012). Writing to learn ecology: a study of three populations of college students. Environmental Education Research, 18(1), 67-90.

Balgopal, M. M., Wallace, A. M., \& Dahlberg, S. (2017). Writing from different cultural contexts: How college students frame an environmental SSI through written arguments. Journal of Research in Science Teaching, 54(2), 195-218.

Barbera, J., \& VandenPlas, J. R. (2011). All Assessment Materials Are Not Created Equal: The Myths about Instrument Development, Validity, and Reliability.

Investigating Classroom Myths through Reseach on Teaching and Learning, 1074, 177-193. https://doi.org/doi:10.1021/bk-2011-1074.ch011

Besterfield-Sacre, M., Gerchak, J., Lyons, M. R., Shuman, L. J., \& Wolfe, H. (2004). Scoring Concept Maps: An Integrated Rubric for Assessing Engineering Education. Journal of Engineering Education, 93(2), 105-115. https://doi.org/10.1002/j.21689830.2004.tb00795.x

Boix Mansilla, V., \& Gardner, H. (2003). Assessing interdisciplinary work at the frontier. An empirical exploration of 'symptoms of quality. Interdisciplinary Studies Project, Project Zero. Harvard Graduate School of Education publications.

Boix Mansilla, V., \& Duraisingh, E. D. (2007). Targeted assessment of students' interdisciplinary work: An empirically grounded framework proposed. Journal of Higher Education, 78(2), 215-237.

Boix Mansilla, V., Duraisingh, E. D., Wolfe, C. R., \& Haynes, C. (2009). Targeted Assessment Rubric: An Empirically Grounded Rubric for Interdisciplinary Writing. Journal of Higher Education, 80(3), 334-353. doi:10.1353/jhe.0.0044.

Borrego, M., Newswander, C. B., McNair, L. D., McGinnis, S., \& Paretti, M. C. (2009). Using Concept Maps to Assess Interdisciplinary Integration of Green Engineering Knowledge. Advances in Engineering Education, 1(3), n3. 
Borrego, M. \& Newswander, L. K. (2010). Definitions of Interdisciplinary Research: Toward Graduate-Level Interdisciplinary Learning Outcomes. The Review of Higher Education 34(1), 61-84. Johns Hopkins University Press. Retrieved August 17, 2019, from Project MUSE database.

Carlson, C. A. (2007). A simple approach to improving student writing. Journal of College Science Teaching, 36(6), 48.

Chan, Y.-Y., Yu, A. C. H., \& Chan, C. K. K. (2010). Assessing students' integrative learning in biomedical engineering from the perspectives of structure, behavior, and function. 2010 IEEE Frontiers in Education Conference (FIE), S1G-1-S1G-6. https://doi.org/10.1109/FIE.2010.5673660

Cohen, J. (1960). A coefficient of agreement for nominal scales. Educational and psychological measurement, 20(1), 37-46.

Connolly, P., \& Vilardi, T. (1989). Writing to learn mathematics and science. Teachers College Press, New York, NY 10027.

Cooper, M. M., \& Stowe, R. L. (2018). Chemistry Education Research-From Personal Empiricism to Evidence, Theory, and Informed Practice. Chemical Reviews, 118(12), 6053-6087. https://doi.org/10.1021/acs.chemrev.8b00020

Full, R. J., Dudley, R., Koehl, M. A. R., Libby, T., \& Schwab, C. (2015). Interdisciplinary laboratory course facilitating knowledge integration, mutualistic teaming, and original discovery. Integrative and Comparative Biology, 55(5), 1-14.

Fusch, P. I., \& Ness, L. R. (2015). Are we there yet? Data saturation in qualitative research. The Qualitative Report, 20(9), 1408.

Garibay, J. C. (2015). STEM students' social agency and views on working for social change: Are STEM disciplines developing socially and civically responsible students? Journal of Research in Science Teaching, 52(5), 610-632. https://doi.org/10.1002/tea.21203

Gouvea, J. S., Sawtelle, V., Geller, B. D., \& Turpen, C. (2013). A framework for analyzing interdisciplinary tasks: Implications for student learning and curricular design. CBE-Life Sciences Education, 12(2), 187-205.

Haak, D. C., HilleRisLambers, J., Pitre, E., \& Freeman, S.(2011). Increased structure and active learning reduce the achievement gap in introductory biology. Science, 332(6034), 1213-1216. 
Johnson, D. W., \& Johnson, R. T. (2009). An educational psychology success story: Social interdependence theory and cooperative learning. Educational Researcher, 38, 365-379.

Keys, C. W. (1999). Revitalizing instruction in scientific genres: Connecting knowledge production with writing to learn in science. Science education, 83(2), 115130.

Lamm, A. J., Shoulders, C., Roberts, T. G., Irani, T. A., Snyder, J. L., \& Brendemuhl, B. J. (2012). The influence of cognitive diversity on group problem solving strategy. Journal of Agricultural Education, 53, 18-30.

Lattuca, L. R. (2001). Creating interdisciplinarity: Interdisciplinary research and teaching among college and University faculty. Nashville, TN: Vanderbilt University Press.

Maher, J. M., Markey, J. C., \& Ebert-May, D. (2013). The Other Half of the Story: Effect Size Analysis in Quantitative Research. CBE-Life Sciences Education, 12(3), 345-351. https://doi.org/10.1187/cbe.13-04-0082

National Academy of Sciences, National Academy of Engineering, and Institute of Medicine. (2005). Facilitating interdisciplinary research, Washington, DC: National Academies Press.

National Research Council. (2003). BIO2010: Transforming undergraduate education for future research biologists. Washington, D.C.: National Academies Press.

National Research Council. (2009). A new biology for the 21st century. Washington, D.C.: National Academies Press.

Öberg, G. (2009). Facilitating interdisciplinary work: Using quality assessment to create common ground. Higher Education, 57(4), 405-415.

Patton, M. Q. (1990). Qualitative evaluation and research methods. Newbury Park, CA: SAGE Publications.

President's Council of Advisors on Science and Technology. (2012). Engage to excel: Producing one million additional college graduates with degrees in science, technology, engineering, and mathematics. Washington, DC: U.S. Government Office of Science and Technology.

R Studio Team. (2019). RStudio: Integrated Development for R. Boston, MA: RStudio. Retrieved 2019 from www.rstudio.com.

Rivard, L. O. P. (1994). A review of writing to learn in science: Implications for practice and research. Journal of Research in Science Teaching, 31(9), 969-983. 
Stangor, C. (2014). Research methods for the behavioral sciences ( $5^{\text {th }}$ ed). New York: Houghton Mifflin.

Thompson Klein, J. (2005). Interdisciplinary team work. The dynamics of collaboration and integration. In S. Derry, J. C. Schunn, \& D. M. A. Gernsbacher (Eds.), Interdisciplinary collaboration. An emerging cognitive science (pp. 23-50). Mahwah, NJ: Lawrence Erlbaum Associates, Inc.

Thompson, K. V., Chmielewski, J., Gaines, M. S., Hrycyna, C. A., \& LaCourse, W. R. (2013). Competency-based reforms of the undergraduate biology curriculum: Integrating the physical and biological sciences. CBE-Life Sciences Education, 12(2), 162-169.

Tripp, B., \& Shortlidge, E. E. (2019). A Framework to Guide Undergraduate Education in Interdisciplinary Science. CBE-Life Sciences Education, 18(2), es3. https://doi.org/10.1187/cbe.18-11-0226

Wilson, K. J., Brickman, P., \& Brame, C. J. (2018). Group work. CBE-Life Sciences Education, 17(1), fe1. 


\title{
CHAPTER 4: INTERDISCIPLINARY SCIENCE RUBRIC
}

\section{In Revision}

Tripp, B. \& Shortlidge, E.E.S. (2020). From Theory to Practice: Gathering Evidence for the Validity of Data Collected with the Interdisciplinary Science Rubric (IDSR). CBE-Life Sciences Education, in revision.

\begin{abstract}
In a world of burgeoning societal issues, future scientists must be equipped to work interdisciplinarily to address real-world problems. To train undergraduate students toward this end, practitioners must also have quality assessment tools to measure students' ability to think within an interdisciplinary system. There is however, a dearth of instruments that accurately measure this competency. Using a theoretically- and empirically-based model, we developed an instrument, the Interdisciplinary Science Rubric (IDSR), to measure undergraduate students' interdisciplinary science understanding. An essay assignment was administered to 102 students across five courses at three different institutions. Students work was scored with the newly developed rubric. Evidence of construct validity was established through novice and expert response processes via semi-structured, think-aloud interviews with 29 students and 4 instructors to ensure the constructs and criteria within the instrument were operating as intended. Interrater reliability of essay scores were collected with the instructors of record $(\kappa=0.67)$. An expert panel of discipline-based education researchers $(n=11)$ were consulted to further refine the scoring metric of the rubric. Results indicate that the IDSR produces valid data to measure undergraduate students' ability to think about the interdisciplinary nature of science.
\end{abstract}




\section{INTRODUCTION}

The acceleration in scientific advancement over the past few decades has been aided by scientists working collaboratively across a wide range of disciplines.

Multilayer science initiatives have been launched to further support innovative workspaces that develop and promote interdisciplinary (ID) programs and collaborative research. The National Science Foundation (NSF), National Institutes of Health (NIH), and National Institute of General Medical Sciences have led various joint initiatives and specific grant proposal solicitations that encourage or require ID science collaborations to promote behavioral biomedicine, computational neuroscience, and mathematical biology research (National Research Council, 2003). The National Institute on Drug Abuse has funded research and development projects that leverage cognitive science, neurobiology, and sociology, to evaluate drug addiction and its impacts on society (NIH, 2019). Given the complexity of environmental, social, and public health problems, this surge of interest in ID collaborations is not only timely but also necessary for ameliorating these issues. Several funding agencies and stakeholders have called for ID science exposure at the undergraduate level (NRC, 2003, 2009, American Association for the Advancement of Science [AAAS], 2011), such that we can train future scientists to think and work interdisciplinarily to tackle these real-world challenges. One prominent recommendation for ID science at the undergraduate level is in Vision and Change in Undergraduate Biology Education: A Call for Action (AAAS, 2011). This report identifies that undergraduate biology students should understand the ID nature of science, the role of science in society, and the ability to communicate and collaborate with other disciplines. Presumably, if undergraduate science students become adept at 
thinking and working interdisciplinarily, as these skills outlined in Vision and Change require, they will be better positioned to solve complex problems (NRC 2003, 2009; AAAS 2011).

Although the aforementioned initiatives play a key role in catalyzing ID science reform goals, they lack guidelines on how to create ID curricula and do not provide mechanisms by which to assess if students are meeting these objectives. Thus, questions arise from educators such as: what does ID science mean? How do I foster an ID science environment in my classroom? Are students truly gaining ID science thinking skills, and if so, what tools are available to measure this competency? Our previous work made progress towards answering these questions through the development of a theoretical model, the Interdisciplinary Science Framework (IDSF) (Figure 1). The IDSF is intended to guide instructors in thinking about what ID science looks like at the undergraduate level, and ideally provide a platform to create ID curricula and assessments (Tripp \& Shortlidge, 2019). The IDSF was developed through expert feedback from 184 science faculty and literature related to ID science understanding (Newell 1990; Klein 1990, 1996, 2000, 2005, 2015; Boix Mansilla \& Duraisingh 2007; Borrego and Newswander 2010; Öberg 2009, Byrne et al. 2016). This model then underwent testing for evidence of convergent validity in Tripp et al. (2020), establishing the IDSF as a valid framework by which to design curricula and inform instrument development. 


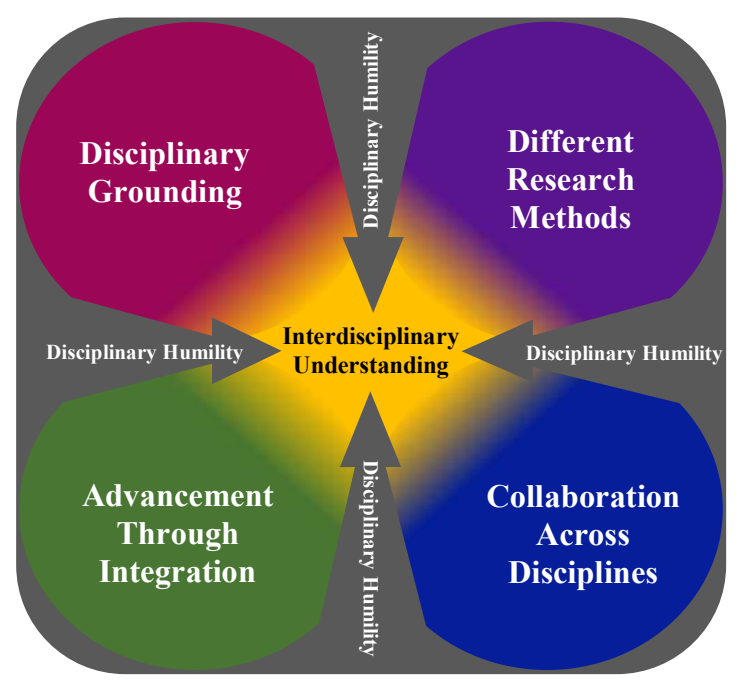

Figure 1. Interdisciplinary Science Framework (IDSF) redrawn from Tripp \& Shortlidge 2019.

To begin the process of assessing ID science comprehension, we first surveyed science faculty nationwide $(n=68)$ and asked how they assess this competency (Tripp et al. 2020). We identified that writing assignments were the most common way that instructors assessed if their students were meeting ID science learning goals. Thus, we tested one published rubric designed to measure students' ability to understand interdisciplinarity in the social sciences through a writing assignment (Boix Mansilla et al., 2009). This rubric contained two constructsdisciplinary grounding and integration — that loosely aligned with the IDSF. These components of the rubric alongside its capability to assess students writing provided justification for examining its functionality on science student populations. Therefore, we tested this tool's ability to produce valid data when implemented in natural and physical science courses. Results revealed that parts of the rubric were not operating on our population as the original designers intended, but rather, students 
conceptualized ID science more similarly to the constructs outlined in the IDSF (Tripp et al. 2020). This called for the development of a new assessment tool guided by the evidence-based IDSF. Herein, we extend this work by gathering evidence from several sources of validity and reliability to develop an instrument based on the IDSF, the Interdisciplinary Science Rubric (IDSR), to measure students' ID science thinking in the context of real-world issues.

\section{Learning Interdisciplinarity through Real-World Contexts}

As science is conducted in a societal context, one purpose for "doing" science is to add knowledge to scientific (and non-scientific) domains that can be applied to real-world issues. When students can grasp and intertwine different pieces of knowledge from diverse disciplines to develop solutions to unresolved issues in society, they will likely be more prepared to enter the scientific workforce. A specific action item in Vision and Change states that instructors ought to "relate abstract concepts in biology to real-world examples on a regular basis, and make biology content relevant by presenting problems in a real-life context” (AAAS, 2011, p. 18).

As new areas of research expand, future scientists will undoubtedly "need to contribute their expertise to research questions as they collaborate with people from other disciplines to address complex and increasingly interdisciplinary problems," (AAAS 2011, p. 3). This call can be actualized by instructors implementing relevant activities in the classroom for students to apply their ID science knowledge and skills to unresolved issues.

There are several lines of evidence that support student writing as a means to generate greater literacy on current real-world problems (Connolly and Vilardi, 1989, 
Rivard 1994, Keys, 1999, Balgopal \& Wallace, 2009, Balgopal et al., 2012, Balgopal et al., 2017). A pedagogy known as writing-to-learn was adapted to move students from fact-based memorization and simplified connections to metacognitive skill development and scientific understanding through real-world applications (Connolly and Vilardi, 1989, Rivard 1994). Writing activities guide students to reflect on what they know, what information they will need to gather, and their understanding of themselves in relation to the task and the strategies available to accomplish the task. Metacognitive theorists refer to these kinds of learning situations as "problemsolving" situations (Flavell 1979). The ability to problem-solve and make these connections is increasingly important when students are tasked with not only grasping deep disciplinary understanding but also integrating knowledge from multiple disciplines into a cohesive whole. Through this lens, writing in science can provide an outlet for students to compare and contrast methods, concepts, and ideas across disciplines toward novel resolutions (Boix Mansilla et al., 2009, Balgopal et al., 2017).

Given our previous work revealing that writing assessments were the most prevalent way that science instructors assess this competency in undergraduate classrooms (Tripp et al. 2020), and the wealth of literature supporting writing in science, we decided to develop a quality instrument that assesses students' written work in relation to real-world issues.

\section{The Role of Validity and Reliability in Instrument Development}

Attention to assessment in higher education has increased since the 1980s, with a surge in research studies aimed at designing assessment tools to evaluate 
student learning gains, inform instruction practices, and improve curriculum (Boix Mansilla \& Duraisingh, 2007). With the growing array of assessment tools being designed by researchers, it is incumbent on instrument developers to ensure that the quality of these tools meet appropriate validity standards. The Standards for Educational and Psychological Testing (hereafter referred to as the Standards) describes validity as "the degree to which evidence and theory support the interpretations of test scores for proposed uses of tests," and is therefore, "the most fundamental consideration in developing and evaluating tests," (American Educational Research Association, American Psychological Association, National Council on Measurement in Education, Joint Committee on Standards for Educational, \& Psychological Testing, 2014 [AERA]; p.11). In other words, validity is the centerpiece that assists developers in determining whether the instrument is measuring what it is intended to measure.

Research articles often refer to validity as the "validity of an instrument" which is inaccurate nomenclature according to psychometricians (Barbera \& VandenPlas 2011, Arjoon et al., 2013, Barbera \& Wren, 2013, AERA, 2014, Knekta et al., 2019). An instrument cannot be valid or invalid, but rather it is the interpretation of the data collected from the tool that can be validated. These important interpretations are often in reference to specific concepts or theory-derived constructs that the instrument is designed to measure. The Standards use a contemporary view of construct validity as an overarching validity trait which all other validities could be used to establish (AERA, 2014). This conceptualization of construct validity has five main sources of evidence: test content, response process, internal structure, association with other variables, and consequence of use (Figure 2). 
A combination of these quantitative and qualitative sources is used in instrument development to increase the validity of the interpretations of data collected.

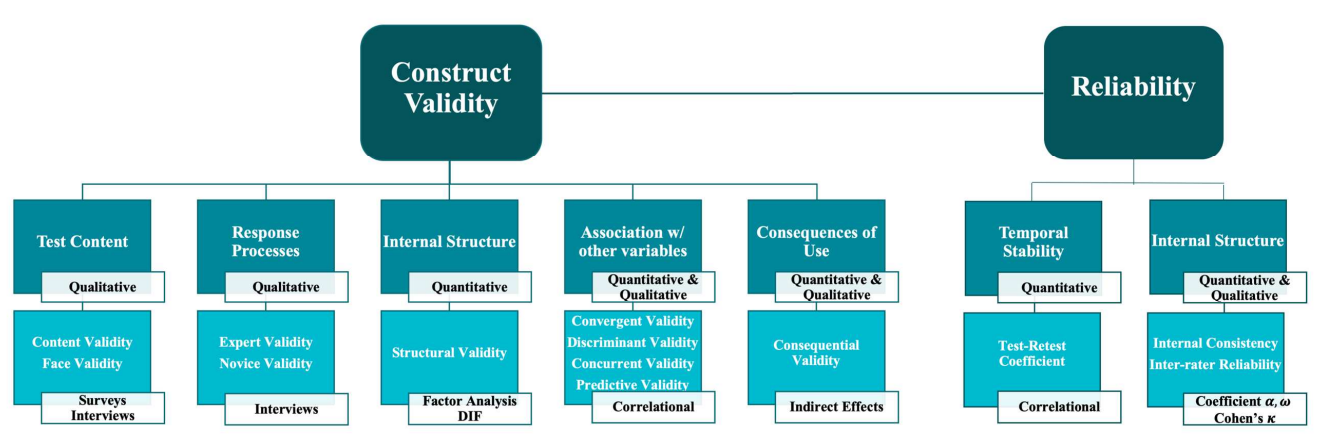

Figure 2. Schematic representation of the multiple sources of evidence for validity and reliability.

\section{Evidence of Validity Based on Novice and Expert Response Processes}

It can be informative for researchers to gain evidence based on the cognitive processes students use to answer criteria or items within an instrument, as observed scores are inseparably linked to how students respond (Wren \& Barbera, 2013). This process can assist instrument developers in ensuring that students are interpreting the criteria as intended, as well as provide a deeper lens into the cognitive processes that formulate a student's answer. This is formally known as novice response process validity (Arjoon et al., 2013, AERA, 2014). Additional evidence can be collected from subject-matter experts on the appropriateness of the scoring scale, the accuracy of criteria within the constructs, and the extent to which the scorers are able to interpret the scores as intended (Wren \& Barbera, 2013, AERA, 2014). These professional insights are referred to as expert response processes. 


\section{Evidence of Reliability}

Reliability measurements are often obtained alongside validity to buttress the quality of an instrument. Reliability of a measure refers to consistency in the instruments' items and the extent to which it is free from error (Stangor, 2011, Arjoon et al., 2013). The Standards describe two sources of reliability: temporal stability and internal consistency (Figure 2). These sources are discussed in the Standards strictly based on quantitative self-report scales (i.e. surveys). It is common practice, however, to apply the internal consistency approach to more qualitative sources of reliability such as inter-rater reliability (IRR) (Stangor, 2011). IRR measures the extent to which multiple judges' ratings on criteria correlate with each other, thus demonstrating that the judges are all measuring the true scores (or the same variables) rather than random error. Stangor (2011) provides a useful justification for taking this approach on work that is more interpretive (such as students writing): "Just as any single item on [an instrument] is expected to have error, so the ratings of any one judge are more likely to contain error than the average rating across a group of raters," (p. 95). Hence, obtaining this form of reliability through the scoring of students' work (i.e. writing assignments) strengthens the precision of an instrument.

\section{OVERVIEW OF STUDY}

This research study focuses on testing for evidence of construct validity from novice and expert response processes to develop and iteratively revise a new instrument, the Interdisciplinary Science Rubric (IDSR). We additionally provide evidence of reliability through internal consistency (via IRR) of researchers and instructors scoring students' written work based on the constructs in the instrument. 
The intention of the IDSR is to accurately assess students' ID science thinking related to real-world problems. Herein, we address the following research question through pilot testing of the IDSR and semi-structured student and faculty interviews:

What evidence supports the constructs and criteria in the Interdisciplinary Science Rubric as a quality assessment tool?

We have divided the evolution and development of the IDSR into three sequential phases: Phase 1- rubric development, Phase 2- first pilot of rubric, and Phase 3- second pilot of rubric (Figure 3) and report the methods and results to each phase sequentially.

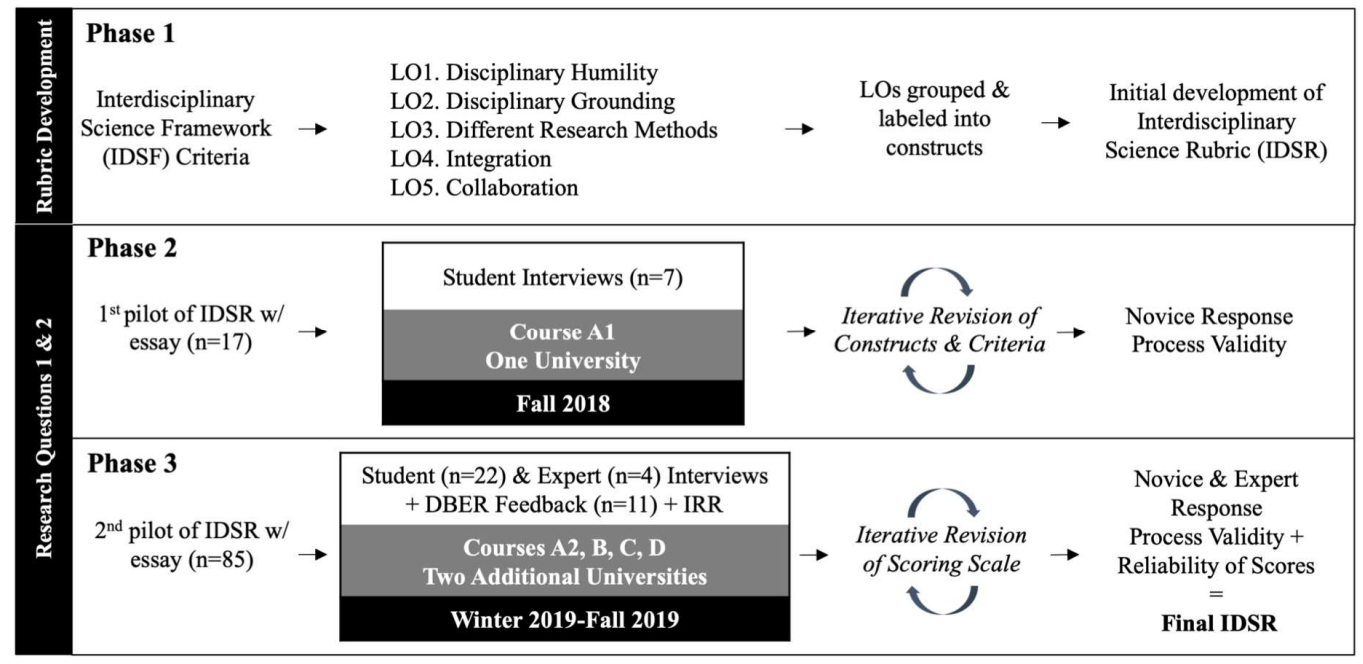

Figure 3. A three-phase outline for the development (Phase 1) and testing (Phases $2 \& 3$ ) of the Interdisciplinary Science Rubric. $\mathrm{LO}=$ learning outcomes; DBER= Discipline-Based Education Researchers. 
METHODS: PHASE 1

Rubric Development

In our previous work, we tested if a preexisting social science rubric (Boix Mansilla et al., 2009), developed to score student essays related to ID understanding in the humanities, could effectively measure the ability of natural and physical science students to communicate ID science understanding (Tripp et al. 2020). We established evidence of convergent validity for one of the original constructs, disciplinary grounding, while the remaining constructs, integration and critical awareness, failed validity tests (Tripp et al., 2020). Therefore, we worked to revise the original rubric into a new, evidence-based rubric for natural science students, the IDSR. The five core criteria of the IDSF (Tripp \& Shortlidge, 2019), disciplinary humility, disciplinary grounding, different research methods, integration, and collaboration, became the blueprint for the IDSR. We subsequently tested the IDSF for evidence of convergent validity and established that the constructs accurately represented students' and expert understanding of this competency (Tripp et al., 2020).

We would like to differentiate the use of the term 'ID understanding' from that of 'ID thinking: 'ID understanding' was the phase used in the preexisting rubric (Boix Mansilla et al. 2009) that we tested (Tripp et al. 2020) and was also used in the development of IDSF (Tripp \& Shortlidge 2019). But in terms of assessment, "understanding" is a nebulous term that is extremely difficult, if impossible, to measure. We also posit that several constructs (i.e. objective and broader awareness) in the IDSR do not necessarily measure a student's ID understanding, but rather their ability to think in an interdisciplinary way when considering how to address real- 
world problems. Thus, the measure of 'students' thinking' is more accurate in describing the purpose of the IDSR.

In developing the initial dimensions of the IDSR, we followed Stevens and Levi’s (2013) four basic stages for constructing rubrics: reflecting, listing learning objectives (LOs), grouping and labeling, and application (Figure 3). In the reflection stage, we took time to reflect on what we wanted from our students and what happened when we previously administered the original rubric published by BoixMansilla et al. (2009). Using this knowledge, we stepped into stage two: listing LOs for the assignment. We developed LOs to closely align with intended outcomes and criteria in the IDSF and labeled these as objectives for our rubric. In stage three, we grouped and labeled similar objectives together (e.g. "different research methods" (LO 3) can be categorized under the larger construct "disciplinary grounding" (LO 2)) and identified the sub-categories, or criteria, that would define each construct. Lastly, stage four involved the application of the constructs and associated criteria from stage three into a grid format.

Scale

To measure how students address dimensions of a rubric, Stevens \& Levi (2013) suggest confining rubrics to three levels of performance in the initial stage of construction, as it becomes more difficult to differentiate between student understanding on scales greater than five. Based on our previous findings (Tripp et al., 2020), in which raters often found it challenging to clearly differentiate between the four discrete levels of understanding from the social science rubric (naïve, novice, apprentice, and mastery) four researchers (including B.T. and E.E.S) created three 
levels to evaluate students' ID science thinking ability in the IDSR. We selected similar terms that were positive, active verb descriptions to mitigate potential distress of low scores if instructors decided to share the full rubric with students: novice, intermediate, and mastery (Stevens \& Levi, 2013). We iteratively revised these levels of understanding to provide succinct and direct instructions that practitioners can follow when scoring each construct. We then outlined specific criteria that would constitute students' ability to think interdisciplinarily in science for each construct domain, guided by the IDSF. Some constructs had more criteria than other constructs but were not meant to be interpreted as more or less important. Thus, we designed the rubric such that instructors average the scores from the criteria within each construct, resulting in one score per construct. Instructors then add the construct scores to provide the total earned point value for the assignment.

\section{Writing Assignment}

To pilot the IDSR, we collected samples of students work that allowed them to exhibit ID knowledge. In our previous work we developed course-specific essay assignments tasking students with integrating knowledge from multiple disciplines to effectively address a challenging real-world issue (Tripp et al. 2020). Here we used the same essay structure to create new, relevant prompts that we developed in conjunction with each course instructor represented in this study. Students were provided a 'student version' of the rubric that outlined the expectations for the assignment. This version was identical to the full 'practitioner version' provided in Table 2, minus the levels by which to score students (mastery, intermediate, novice) (Table 2) (see APPENDIX G. for example prompts and shortened 'student version' 
of the rubric). For a more detailed explanation and guidance on how to develop useful real-world prompts for this assignment, please see Tripp et al. 2020 (p. 3).

RESULTS AND DISCUSSION: PHASE 1

$\underline{\text { Rubric Development }}$

We infused elements of the IDSF into five learning outcomes for the writing assignment; students should: 1) display foundational understanding of one discipline while expressing provisional knowledge in other disciplines, 2) describe methods from multiple fields to accomplish said task, 3) integrate disciplines in a manner that results in a new discovery or idea, 4) display disciplinary humility through the inclusion and respect for teamwork and/or fields outside of STEM 5) describe how and why there is a need to create a collaborative team to accomplish the task. These LOs were transferred into constructs with several criteria aimed at measuring students' thinking in ID science through the lens of the IDSF. This resulted in five constructs—objective, disciplinary grounding, integration, disciplinary humility, collaboration. We created an objective construct to guide students with framing the issue and outlining an approach to tackle the problem in the essay prompt. Although this construct is not included in the IDSF, it is an essential component in essay development (Boix Mansilla et al., 2009). Within this construct we included criteria designed to assess students' ability to synthesize background information through credible sources and to evaluate the quality of students' approach to the essay prompt. The next step in students thinking interdisciplinarily is the acquisition of deep disciplinary knowledge. The IDSF outlines disciplinary grounding and different research methods as exhibiting disciplinary knowledge through the inclusion of information, concepts, and research methods from each contributing discipline. Thus, 
we determined disciplinary grounding would be a construct, and embedded disciplinary reasoning and different research methods as criteria within the construct.

After students grasped the foundational pieces within disciplines, we tasked students with integrating their knowledge from different fields. In developing the integration construct, we paid close attention to the organization and wording of its criteria, as there is evidence that integration of knowledge across disciplines as the central factor separating interdisciplinarity from cross- and multi-disciplinarity (Boix Mansilla et al., 2009, Borrego et al., 2009, Repko, 2009). Furthermore, this construct as defined in a social science rubric (Boix Mansilla et al., 2009) from our previous work did not accurately represent how students operationalized ID science integration (Tripp et al., 2020). The IDSF alternatively defines integration as "not only collecting the appropriate disciplinary pieces of information and placing them in a central repository, but also proficiency in integrating - mixing, connecting, and applying them to discover new insights or ideas," (Tripp \& Shortlidge, 2019; p. 6). Thus, we initially created criteria within this construct to assess students' ability to integrate different disciplines to further the project/solution in a way that one discipline could not.

Disciplinary humility was a criterion in the IDSF that was particularly challenging to initially develop. The IDSF describes this criterion as an affective measure that calls for respect, appreciation, and acknowledgement of other disciplinary perspectives and epistemologies, as well as the inclusion of science and non-science disciplines (Tripp \& Shortlidge, 2019). We contemplated ways for students to not only understand this construct, but also how to measure this affective dimension in a writing sample. We started with a disciplinary humility criterion 
embedded within the integration construct that required students to explain why they must rely on disciplines/experts to address the problem.

Lastly, a collaboration construct was developed to encourage criteria such as the creation of common ground among team players and the inclusion of diverse disciplinary perspectives. This remained congruent with how the IDSF describes collaboration across disciplines.

\section{Scoring and Scale}

We scored students' ability to think interdisciplinarily in science on a threepoint scale: (0) novice, (1) intermediate, and (2) mastery. We used a '0' value to represent novice thinking skills based on our previous findings where ' 1 ' was overcrediting students that did not address any aspects of a particular criteria. We assigned values of ' 1 ' and ' 2 ' to intermediate and mastery, respectively, as we did not want there to be ambiguity between levels of thinking. For instance, if intermediate thinking had a value of ' 5 ' and mastery a value of ' 10 ', there would be a large range of numbers in between levels with no description of how to apply those values to students' essay responses. (Table 2).

\section{METHODS: PHASE 2 AND 3}

Phase 2: First Pilot of Rubric

\section{Recruitment and Data Collection}

We recruited students from one upper-division ID science course at a large, urban, public, research-intensive university in the United States in Fall 2018. The instructor of record (author E.E.S.) announced the assignment to the class. Students in 
this course had consented to any course work being used for research purposes, thereby allowing us to use their responses to the essay assignment for this study.

The instructor administered the essay assignment to students at the end of the course, which included the shortened student version of the rubric. Students were given approximately 7 days to complete the individual assignment using any outside resources available to them. The assignment was attached to course points and factored into their overall course grade. Following completion of the assignment, we emailed students enrolled in the course for a follow-up interview and scheduled interviews with respondents. Before the interview commenced, students provided written consent for their interview responses to be used for research purposes. The students were provided \$20 gift cards for participating in interviews. Student participation in this study remained anonymous from the instructor and each student received a unique numerical identifier. Audio files were transcribed verbatim (Rev.com).

\section{Student Think-Aloud Interviews}

To establish evidence of novice response process validity, we conducted semistructured think-aloud interviews with students to better understand how they were interpreting each construct and associated criteria in the IDSR. Interview questions were designed and iteratively revised by three researchers (including B.T. and E.E.S.) to 1) investigate how wording of the constructs and criteria affected student responses and if students understood them as we had intended, 2) identify other ways in which students may understand ID science outside the rubric, and 3) gain insight on students' perceptions of the value of the assignment and rubric (see APPENDIX H. H 
for student interview questions). We analyzed interview transcripts deductively (Patton, 1990) for evidence that students understood the criteria in the IDSR as it was intended. We did not interview the instructor of this course for feedback on the rubric and assignment, as E.E.S. is an author of the paper, and was fully involved in the development and revision of the IDSR.

\section{Scoring and Interrater Reliability}

Two researchers (including B.T.) scored essays to consensus with the IDSR. E.E.S. independently graded $100 \%$ of the essays with the rubric and compared scores with these researchers (interrater reliability $\kappa=.83$ ). We then collaboratively discussed and revised aspects of the rubric based on essay responses and student interviews to better reflect the intentions of each criteria and provide clarity to areas that were confusing and/or misleading students. English is not the first language of one of the researchers involved in this work, therefore they were able to provide a unique perspective on the syntax and word choice of the rubric. This is especially important regarding students in courses whose first language is also not English. This provided an additional element of inclusivity in the development of this instrument. This study was conducted under exempt status at Portland State University (IRB \#163998).

\section{Phase 3: Second Pilot of Rubric}

\section{Recruitment and Data Collection}

We administered the essay assignment and revised 'student version' of the IDSR in four upper-division courses at three different universities in the next academic year (Winter 2018-Fall 2019). Instructors showed a recruitment video that 
requested students' consent for their responses to the essay assignment to be used for research purposes. The instructors then provided students with an online (Qualtrics) link to accept or decline for their essay responses to be used in this study. The survey also asked students if they would be interested in participating in a follow-up interview. Students that agreed to participate in an interview received another link requesting their consent for their interview responses to be used in this study. We conducted interviews via an online service. The students were provided \$20 gift cards for participating in interviews. We followed the same semi-structured thinkaloud student interview process and used the same interview questions as in Phase 2.

\section{Faculty Interviews}

After the courses concluded, we obtained evidence of expert response process validity through semi-structured interviews with the instructors of record to gather insight and feedback on the rubric and assignment. We emailed the instructors requesting their participation and obtained consent for their interview responses to be used in this study through a survey in Qualtrics. Instructors were given a $\$ 50$ gift card for their participation. Interviews were held in-person or via Skype depending on the instructor's location. Interview questions were designed and iteratively revised by two researchers (B.T and E.E.S) to solicit information on the functionality of the instructor version of the rubric and to gain knowledge on the accuracy of each construct and criteria (see APPENDIX I. for instructor interview questions). Audio files from instructor interviews were transcribed by Rev.com.

\section{Scoring and Interrater Reliability}


To obtain evidence of reliability, B.T. emailed each instructor one week prior to the interview and had them score $20 \%$ of essays from their course with the IDSR; B.T. independently scored the same $20 \%$ of essays. During each instructor's interview, the participant and B.T. obtained IRR on these documents. These analyses were conducted in R Studio (R Studio Team, 2019).

\section{Discipline-Based Education Research Panel Feedback}

To collect additional expert feedback on the IDSR, we consulted a group of discipline-based education researchers (DBER) at a research-intensive university unrelated to the institutions in this study. The researchers collectively read one essay assignment and then split into three groups to evaluate constructs and associated criteria in the IDSR, as well as the three levels of thinking in the 'full practitioner' version. We then reconvened to discuss the researchers' perspectives and gain insight into the usability and clarity of the rubric. We subsequently modified the levels of understanding of the IDSR based on the feedback.

\section{Statistical Analyses}

To assess the utility of the rubric across different populations, we conducted a one-way ANOVA to detect differences in mean student essay scores across Courses A2-D. A Levene test for unequal variances and Kruskal Wallis nonparametric test for normality were ran to confirm that ANOVA assumptions were met. We hypothesized that there would be no difference in overall essay scores between courses, as we iteratively revised the rubric to be broadly applicable to any discipline and real-world problem. ANOVAs were performed in R studio (R Studio Team, 2019). 


\section{RESULTS AND DISCUSSION: PHASES 2 AND 3}

We have combined the results and discussion from Phases 2 and 3 to illuminate our process and decision-making for changes between the two versions of the IDSR.

\section{$\underline{\text { Recruitment and Data Collection }}$}

Courses examined in this study were at three different institutions, and varied in their course format (disciplinary to ID). We piloted the first version of the IDSR and associated assignment to an upper-division ID science course, which was largely small-group and project-based (Course A1) at a public research-intensive Northwestern university in Fall 2018 (Table 1). After revising the rubric based on Phase 2 results, we piloted the IDSR on four additional upper-division courses at varying institutions to examine the utility of the rubric on different populations: two courses from the same university in Phase 2 (Courses A2 and B) and two courses from two separate universities (Courses C and D). Courses A1 and A2 were the same course (taught in Fall 2018 and 2019), which allowed for us to examine if our revisions to the IDSR from Phase 2 had an effect on a very similar student population in Phase 3. Course B was an upper-division, non-ID, lecture-based science course from the same university (Winter 2019). Course C was an ID science, lecture-based course located at a public Northwestern Master's granting university. Course D was an ID small group-based course located at an Eastern research-intensive university (Table 1). A schematic outline of dissemination of the rubric across phases and institutions is visualized in Figure 3. 
Most courses across the universities were listed under a biology department except for Course D - it was listed as an upper-division ID honors course that was not assigned to any specific discipline and was open to all upper-division majors (Table 1). However, the instructor was a biology faculty member and science content was covered throughout the course, with the majority of enrolled students declaring science majors (77\%). The administration of the IDSR on an array of disciplinary to ID formats from varying institution types allowed us to examine the functionality of the IDSR regardless of course content, format, student major, and/or population.

Table 1. Summary of three universities and five associated upper-division course formats (ID=interdisciplinary; $\mathrm{D}=$ disciplinary) and sample sizes of essays and interviews collected over the course of two academic calendar years.

\begin{tabular}{|c|c|c|c|c|}
\hline $\begin{array}{l}\text { University: Carnegie } \\
\text { Classification }\end{array}$ & $\begin{array}{c}\text { Course } \\
\text { Department } \\
\text { Listing: Format }\end{array}$ & Essays (n) & $\begin{array}{c}\text { Student } \\
\text { Interviews (n) }\end{array}$ & $\begin{array}{c}\text { Instructor } \\
\text { Interviews (n) }\end{array}$ \\
\hline $\begin{array}{l}{ }^{*+} \text { A1: Public High } \\
\text { Research Activity }\end{array}$ & Biology: ID & 17 & 7 & N/A \\
\hline $\begin{array}{l}{ }^{*+} \text { A2: Public High } \\
\text { Research Activity }\end{array}$ & Biology: ID & 15 & 7 & 1 \\
\hline $\begin{array}{l}\text { *B: Public High Research } \\
\text { Activity }\end{array}$ & Biology: D & 23 & 5 & 1 \\
\hline $\begin{array}{l}\text { C: Public Master's } \\
\text { Colleges and } \\
\text { Universities: Small } \\
\text { Programs }\end{array}$ & Biology: ID & 34 & 6 & 1 \\
\hline $\begin{array}{l}\text { D: Public High Research } \\
\text { Activity }\end{array}$ & Honors: ID & 13 & 4 & 1 \\
\hline Total & & 102 & 29 & 4 \\
\hline
\end{tabular}

Examining interview transcripts from students $(n=25)$ in Phase 2 resulted in the final rubric containing four constructs and associated criteria by which to measure students' ID science thinking related to real-world issues: objective, disciplinary 
grounding, integration, and broader awareness (Table 2). Thus, the rubric was modified from five constructs in Phase 2 to four constructs in Phase 3, containing rearrangement and revisions to many dimensions of the rubric. We have labeled these constructs as 'categories' in Table 2 so instructors that are unfamiliar with the word 'construct' have a better understanding of this particular dimension of the rubric. A 'format' category was included as an optional element for instructors to score basic requirements they deem necessary for complete written assignments (e.g. APA format, spelling, grammar). To reduce construct irrelevance variance (AERA 2014) the inclusion of extraneous and/or confounding variables that skew assessment outcomes - we did not include the scores from this 'format' category when scoring essay assignments for research purposes.

Table 2. The instructor version of Interdisciplinary Science Rubric (IDSR) to measure students' understanding of ID science. The 'category' and 'criteria' columns were provided to students in essay assignments (i.e. student version of rubric). 


\begin{tabular}{|c|c|c|c|c|c|c|}
\hline $\begin{array}{l}\text { Constr- } \\
\text { ucts }\end{array}$ & Criteria & Mastery (3) & Intermediate (2) & Novice (1) & Naïve (0) & 总 * \\
\hline \multirow{4}{*}{$\sum_{\substack{E \\
0}}^{1}$} & $\begin{array}{l}\text { 1.1 Purpose: What is the } \\
\text { problem and task? } \\
\text { Provide background } \\
\text { information to introduce } \\
\text { and frame the problem/ } \\
\text { task. }\end{array}$ & $\begin{array}{l}\text { Includes } \\
\text { background } \\
\text { information that } \\
\text { sufficiently } \\
\text { reviews the } \\
\text { subject matter and } \\
\text { accurately reports } \\
\text { any historical } \\
\text { and/or current } \\
\text { material to frame } \\
\text { the problem }\end{array}$ & $\begin{array}{l}\text { Includes background } \\
\text { information that } \\
\text { moderately reviews the } \\
\text { subject matter and } \\
\text { accurately reports any } \\
\text { historical and/or } \\
\text { current material to } \\
\text { frame the problem }\end{array}$ & $\begin{array}{l}\text { Includes } \\
\text { background } \\
\text { information that } \\
\text { moderately reviews } \\
\text { the subject but } \\
\text { inaccurately reports } \\
\text { material } \\
\text { OR includes } \\
\text { minimal } \\
\text { background } \\
\text { information but } \\
\text { accurately reports } \\
\text { any historical } \\
\text { and/or current } \\
\text { material to frame } \\
\text { the problem }\end{array}$ & $\begin{array}{l}\text { Does not } \\
\text { include } \\
\text { background } \\
\text { information }\end{array}$ & $/ 3$ \\
\hline & $\begin{array}{l}1.2 \text { Approach: How will } \\
\text { you approach the } \\
\text { problem/task? Formulate } \\
\text { a plan that clearly } \\
\text { outlines your approach } \\
\text { (steps/procedures). }\end{array}$ & $\begin{array}{l}\text { Includes a plan } \\
\text { that clearly } \\
\text { outlines } \\
\text { steps/procedures } \\
\text { that will be } \\
\text { accomplished to } \\
\text { address the } \\
\text { problem/ at hand }\end{array}$ & $\begin{array}{l}\text { Includes a plan that } \\
\text { moderately outlines } \\
\text { steps/procedures that } \\
\text { will be accomplished } \\
\text { but excludes } \\
\text { steps/procedures that } \\
\text { are discussed further in } \\
\text { essay }\end{array}$ & $\begin{array}{l}\text { Includes a plan that } \\
\text { unclearly and/or } \\
\text { insufficiently } \\
\text { addresses the } \\
\text { problem/task at } \\
\text { hand }\end{array}$ & $\begin{array}{l}\text { Does not } \\
\text { include a } \\
\text { plan }\end{array}$ & 3 \\
\hline & $\begin{array}{l}\text { 1.3 Credibility: What } \\
\text { sources will you include? } \\
\text { Use peer-reviewed } \\
\text { articles and/or other } \\
\text { supporting information } \\
\text { that are relevant to the } \\
\text { problem/task. }\end{array}$ & $\begin{array}{l}\text { Includes peer- } \\
\text { reviewed articles } \\
\text { and/or information } \\
\text { that are relevant to } \\
\text { the problem }\end{array}$ & $\begin{array}{l}\text { Includes peer-reviewed } \\
\text { articles and/or } \\
\text { information that are } \\
\text { tangential to the } \\
\text { problem }\end{array}$ & $\begin{array}{l}\text { Includes peer- } \\
\text { reviewed articles } \\
\text { and/or information } \\
\text { but are irrelevant to } \\
\text { the problem }\end{array}$ & $\begin{array}{l}\text { Does not } \\
\text { include } \\
\text { peer- } \\
\text { reviewed } \\
\text { articles } \\
\text { and/or } \\
\text { information }\end{array}$ & $/ 3$ \\
\hline & \multicolumn{5}{|c|}{ Average Objective Score } & $/ 3$ \\
\hline \multirow{4}{*}{ 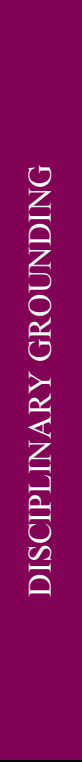 } & $\begin{array}{l}\text { 2.1 Disciplines/Experts: } \\
\text { What disciplines and/or } \\
\text { experts will be involved? } \\
\text { Include } \text { two or more } \\
\text { disciplines and/or } \\
\text { experts in your approach } \\
\text { to the problem/task. }\end{array}$ & $\begin{array}{l}\text { Includes two or } \\
\text { more disciplines } \\
\text { and/or experts } \\
\text { relevant to } \\
\text { student's approach }\end{array}$ & $\begin{array}{l}\text { Includes two or more } \\
\text { disciplines and/or } \\
\text { experts but some are } \\
\text { irrelevant to student's } \\
\text { approach. }\end{array}$ & $\begin{array}{l}\text { Includes only one } \\
\text { discipline and/or } \\
\text { expert relevant to } \\
\text { student's approach. }\end{array}$ & $\begin{array}{l}\text { Does not } \\
\text { include } \\
\text { disciplines } \\
\text { and/or } \\
\text { experts }\end{array}$ & $/ 3$ \\
\hline & $\begin{array}{l}2.2 \text { Disciplinary } \\
\text { Reasoning: Why are you } \\
\text { including each discipline } \\
\text { and/or expert? } \\
\text { Meaningfully explain the } \\
\text { reasoning behind the use } \\
\text { of each discipline and/or } \\
\text { expert. }\end{array}$ & $\begin{array}{l}\text { Includes accurate, } \\
\text { informed } \\
\text { reasoning behind } \\
\text { all contributing } \\
\text { disciplines and/or } \\
\text { experts }\end{array}$ & $\begin{array}{l}\text { Includes accurate, } \\
\text { informed reasoning } \\
\text { behind one or multiple } \\
\text { but } \text { not all contributing } \\
\text { disciplines and/or } \\
\text { experts }\end{array}$ & $\begin{array}{l}\text { Includes inaccurate } \\
\text { or oversimplified } \\
\text { reasoning for all } \\
\text { contributing } \\
\text { disciplines and/or } \\
\text { experts }\end{array}$ & $\begin{array}{l}\text { Does not } \\
\text { include } \\
\text { reasoning } \\
\text { behind using } \\
\text { disciplines } \\
\text { and/or } \\
\text { experts }\end{array}$ & $/ 3$ \\
\hline & $\begin{array}{l}\text { 2.3 Methods \& Tools: } \\
\text { What methods will each } \\
\text { discipline and/or expert } \\
\text { use? Include } \\
\text { techniques/procedures/to } \\
\text { ols from contributing } \\
\text { disciplines and/or } \\
\text { experts. }\end{array}$ & $\begin{array}{l}\text { Includes accurate } \\
\text { methods } \\
\text { (techniques/proce } \\
\text { dures/tools) from } \\
\text { all contributing } \\
\text { disciplines }\end{array}$ & $\begin{array}{l}\text { Includes accurate } \\
\text { methods } \\
\text { (techniques/procedures } \\
\text { /tools) from one or } \\
\text { multiple but not all } \\
\text { contributing } \\
\text { disciplines and/or } \\
\text { experts }\end{array}$ & $\begin{array}{l}\text { Includes inaccurate } \\
\text { methods } \\
\text { (techniques/procedu } \\
\text { res/tools) for all } \\
\text { contributing } \\
\text { disciplines and/or } \\
\text { experts }\end{array}$ & $\begin{array}{l}\text { Does not } \\
\text { include } \\
\text { methods } \\
\text { (techniques/ } \\
\text { procedures/t } \\
\text { ools) }\end{array}$ & $/ 3$ \\
\hline & & & & verage Disciplinary & unding Score & 13 \\
\hline
\end{tabular}




\begin{tabular}{|c|c|c|c|c|c|c|}
\hline \multirow{3}{*}{ 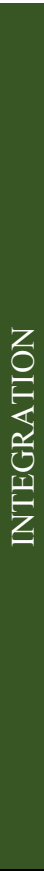 } & $\begin{array}{l}\text { 3.1 Leveraging } \\
\text { Disciplines/Experts: } \\
\text { How will each } \\
\text { contributing discipline } \\
\text { and/or expert build off } \\
\text { one another to } \\
\text { effectively address the } \\
\text { problem/task in a way } \\
\text { that one contributor } \\
\text { cannot? Specifically } \\
\text { address how each } \\
\text { discipline's and/or } \\
\text { expert's contribution } \\
\text { (knowledge/methods) } \\
\text { will be useful for the } \\
\text { other disciplines and/or } \\
\text { experts. }\end{array}$ & $\begin{array}{l}\text { Leverages } \\
\text { contributing } \\
\text { disciplines and/or } \\
\text { experts by } \\
\text { building off } \\
\text { knowledge/metho } \\
\text { ds to effectively } \\
\text { address the } \\
\text { problem/task in a } \\
\text { way that one } \\
\text { contributor cannot }\end{array}$ & $\begin{array}{l}\text { Leverages contributing } \\
\text { disciplines and/or } \\
\text { experts by building off } \\
\text { knowledge/methods to } \\
\text { effectively address the } \\
\text { problem/task in a way } \\
\text { that one contributor } \\
\text { cannot but does not } \\
\text { consider all disciplines } \\
\text { involved }\end{array}$ & $\begin{array}{l}\text { Lists } \\
\text { disciplines/experts } \\
\text { knowledge/methods } \\
\text { contribution without } \\
\text { building off the } \\
\text { knowledge/methods } \\
\text { from each } \\
\text { contributor }\end{array}$ & $\begin{array}{l}\text { Does not } \\
\text { include } \\
\text { ways to } \\
\text { leverage the } \\
\text { disciplines } \\
\text { and/or } \\
\text { experts }\end{array}$ & $/ 3$ \\
\hline & $\begin{array}{l}3.2 \text { Collaboration: How } \\
\text { will you foster successful } \\
\text { partnerships? Include } \\
\text { and explain two or more } \\
\text { ways to build community } \\
\text { and respect among } \\
\text { different disciplinary } \\
\text { team members (e.g. } \\
\text { establishing common } \\
\text { ground and language, } \\
\text { overcoming different } \\
\text { perspectives, etc.). }\end{array}$ & $\begin{array}{l}\text { Includes and } \\
\text { sufficiently } \\
\text { explains two or } \\
\text { more logical ways } \\
\text { to build } \\
\text { community and } \\
\text { respect among } \\
\text { different } \\
\text { disciplinary team } \\
\text { members }\end{array}$ & $\begin{array}{l}\text { Includes and } \\
\text { sufficiently explains } \\
\text { one logical way to } \\
\text { build community and } \\
\text { respect among } \\
\text { different disciplinary } \\
\text { team members }\end{array}$ & $\begin{array}{l}\text { Lists two or more } \\
\text { logical ways but } \\
\text { does not explain } \\
\text { how to build } \\
\text { community and } \\
\text { respect among } \\
\text { different } \\
\text { disciplinary team } \\
\text { members }\end{array}$ & $\begin{array}{l}\text { Does not } \\
\text { include } \text { nor } \\
\text { explain } \\
\text { ways to } \\
\text { build } \\
\text { community } \\
\text { and respect } \\
\text { among } \\
\text { different } \\
\text { disciplinary } \\
\text { team } \\
\text { members }\end{array}$ & $/ 3$ \\
\hline & \multicolumn{5}{|c|}{ Average Integration Score } & $/ 3$ \\
\hline \multirow{3}{*}{ 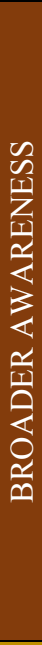 } & $\begin{array}{l}\text { 4.1 Societal Impact: } \\
\text { How does your proposed } \\
\text { solution impact society? } \\
\text { Include why your } \\
\text { solution is locally and } \\
\text { more broadly relevant to } \\
\text { society and what/who } \\
\text { will be affected (e.g. } \\
\text { economics, politics, } \\
\text { social, health, etc.). }\end{array}$ & $\begin{array}{l}\text { Includes local and } \\
\text { broader societal } \\
\text { impacts and } \\
\text { sufficiently } \\
\text { explains what/who } \\
\text { will be affected }\end{array}$ & $\begin{array}{l}\text { Includes local and } \\
\text { broader societal } \\
\text { impacts and } \\
\text { moderately explains } \\
\text { what/who will be } \\
\text { affected } \\
\text { OR Sufficiently } \\
\text { explains what/who will } \\
\text { be affected but } \\
\text { includes only local or } \\
\text { broader (not both) } \\
\text { societal impacts }\end{array}$ & $\begin{array}{l}\text { Includes only local } \\
\text { or broader (not } \\
\text { both) societal } \\
\text { impacts and does } \\
\text { not } \text { sufficiently } \\
\text { explain what/who } \\
\text { will be affected }\end{array}$ & $\begin{array}{l}\text { Does not } \\
\text { include local } \\
\text { or broader } \\
\text { societal } \\
\text { impacts nor } \\
\text { (what/who) } \\
\text { will be } \\
\text { affected }\end{array}$ & $/ 3$ \\
\hline & $\begin{array}{l}\text { 4.2 Limitations: What } \\
\text { are the potential } \\
\text { limitations to your plan } \\
\text { and how will you } \\
\text { overcome these barriers? } \\
\text { Forecast possible } \\
\text { limitations of your plan } \\
\text { and provide resolutions. }\end{array}$ & $\begin{array}{l}\text { Includes potential } \\
\text { limitations of plan } \\
\text { and sufficiently } \\
\text { explains } \\
\text { resolutions to } \\
\text { overcome these } \\
\text { barriers }\end{array}$ & $\begin{array}{l}\text { Includes potential } \\
\text { limitations of plan and } \\
\text { moderately explains } \\
\text { resolutions to } \\
\text { overcome these } \\
\text { barriers }\end{array}$ & $\begin{array}{l}\text { Includes potential } \\
\text { limitations but does } \\
\text { not } \text { explains } \\
\text { resolutions to } \\
\text { overcome these } \\
\text { barriers }\end{array}$ & $\begin{array}{l}\text { Does } n o t \\
\text { include } \\
\text { limitations } \\
\text { nor } \\
\text { resolutions }\end{array}$ & $/ 3$ \\
\hline & \multicolumn{5}{|c|}{ Average Broader Awareness Score } & 13 \\
\hline 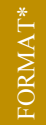 & \multicolumn{5}{|c|}{$\begin{array}{l}\text { 4.1 Format, Grammar, Structure: Have you followed all formatting guidelines? Does your proposal have an } \\
\text { introduction, body, and conclusion? }\end{array}$} & $/ 3$ \\
\hline & & & & & Total Score** & $/ 15$ \\
\hline
\end{tabular}

* Optional construct

**Adjust each category's score to align with your course's point needs (i.e. if course assignment is worth 50 points, adjust category criteria accordingly. Average each category's criteria to obtain a category score. Keep each criteria equal in value to not weight one criteria and/or category over another.

\section{Evidence of Novice and Expert Response Process Validity}

\section{We have provided student essay and interview responses and faculty interview}


consistency between novice and expert understanding of the rubric. Below, we outline additional evidence for the inclusion or exclusion of each criteria in the piloting of our

instrument.

Table 3. Examples of student essay and interview responses and faculty interview responses supporting the criteria in the IDSR.

\begin{tabular}{|c|c|c|c|c|}
\hline Construct & Criteria & $\begin{array}{l}\text { Example of Student Essays from } \\
\text { Course C }\end{array}$ & $\begin{array}{l}\text { Student Interviews from all five } \\
\text { courses }\end{array}$ & Instructor Interviews \\
\hline \multirow{3}{*}{ 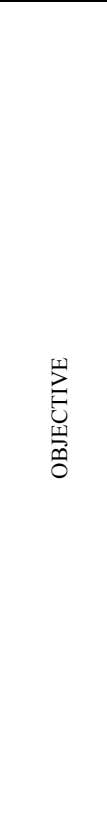 } & $\begin{array}{l}\text { 1.1 Purpose: Provide } \\
\text { background information } \\
\text { to introduce and frame } \\
\text { the problem. }\end{array}$ & $\begin{array}{l}\text { Louisiana wishes to build a park } \\
\text { w/ a garden for human } \\
\text { consumption, but the soil is filled } \\
\text { w/ hydrocarbons \& alkyl halides } \\
\text { from a BP oil spill. }\end{array}$ & $\begin{array}{l}\text { "General scope of research in the } \\
\text { current field, what's going on-the } \\
\text { problem. So, with that I focused on } \\
\text { Department of Education information } \\
\text { and statistics... how many people is this } \\
\text { currently affecting." } \\
\text {-Course A2 }\end{array}$ & $\begin{array}{l}\text { "What I see students } \\
\text { answering for } \\
\text { purpose is what the } \\
\text { state of things are \& } \\
\text { how to address the } \\
\text { problem." }\end{array}$ \\
\hline & $\begin{array}{l}\text { 1.2 Approach: } \\
\text { Formulate a plan that } \\
\text { clearly outlines your } \\
\text { approach. }\end{array}$ & $\begin{array}{l}\text { The best solution for reducing } \\
\text { contaminates in the soil would be } \\
\text { to use bioremediation methods } \\
\text { with bacterial species that have } \\
\text { the ability to use hydrocarbons as } \\
\text { their source of energy by } \\
\text { inoculating the soil on a mineral } \\
\text { medium in the presence of sweet } \\
\text { crude oil. Subsequent bacterial } \\
\text { colonies would then be grown to } \\
\text { produce more bacteria and } \\
\text { reintroduced back into the } \\
\text { contaminated site. }\end{array}$ & $\begin{array}{l}\text { "How you go about solving the } \\
\text { problem \& the different necessary } \\
\text { steps; explain what you're going to do } \\
\text { about the problem." } \\
\text {-Course D }\end{array}$ & $\begin{array}{l}\text { "This will help } \\
\text { students organize } \\
\text { how to attack the } \\
\text { issue and give step- } \\
\text { wise direction." }\end{array}$ \\
\hline & $\begin{array}{l}\text { 1.3 Credibility: Use } \\
\text { peer-reviewed articles } \\
\text { and other supporting } \\
\text { information that are } \\
\text { relevant to the } \\
\text { problem/task. }\end{array}$ & $\begin{array}{l}\text { Our team will use data collected } \\
\text { from this project to craft an } \\
\text { application to the Environmental } \\
\text { Protection Agency's brownfields, } \\
\text { superfund, or emergency response } \\
\text { cleanup programs, in order to } \\
\text { offset the economic burden the } \\
\text { Remediation Plan will place on } \\
\text { the local communities (EPA, } \\
\text { 2013). }\end{array}$ & $\begin{array}{l}\text { I just tried to include as many articles } \\
\text { from peer-reviewed journals as } \\
\text { possible. I also looked for previous } \\
\text { credible authors who had multiple } \\
\text { articles under the same subject. I tried } \\
\text { to avoid Wikipedia too. } \\
\text {-Course B }\end{array}$ & $\begin{array}{l}\text { This is a given ... } \\
\text { always have students } \\
\text { use credible sources. }\end{array}$ \\
\hline \multirow{3}{*}{ 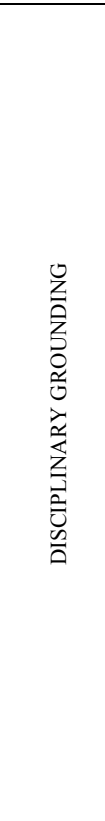 } & $\begin{array}{l}\text { 2.1 Disciplines/Experts: } \\
\text { Include two or more } \\
\text { disciplines and/or } \\
\text { experts in your } \\
\text { approach to the } \\
\text { problem/task. }\end{array}$ & $\begin{array}{l}\text { An important role in the recovery } \\
\text { process is that of a public policy } \\
\text { administrator, as well as a grant } \\
\text { writer, a chemist, and a } \\
\text { microbiologist. }\end{array}$ & $\begin{array}{l}\text { For me, when I was looking at } \\
\text { disciplines and experts, how I interpret } \\
\text { it is needing people from very } \\
\text { specialized fields. The sheer } \\
\text { complexity of the problem requires } \\
\text { people with various specific skillsets } \\
\text { coming together. } \\
\text {-Course D }\end{array}$ & $\begin{array}{l}2.1 \text { means "I'm } \\
\text { going to use these } \\
\text { disciplinarians and } \\
\text { experts to do } X, Y \text {, } \\
\text { and } Z \text { ". }\end{array}$ \\
\hline & $\begin{array}{l}2.2 \text { Disciplinary } \\
\text { Reasoning: } \\
\text { Meaningfully explain } \\
\text { the reasoning behind } \\
\text { the use of each } \\
\text { discipline and/or expert. }\end{array}$ & $\begin{array}{l}\text { The policy administrator will } \\
\text { ensure that the community is } \\
\text { aware of all of the steps taken by } \\
\text { scientific experts to restore the } \\
\text { land while the grant writer } \\
\text { familiar with the U.S. } \\
\text { Environmental Protection Agency } \\
\text { and its guidelines will be } \\
\text { necessary to offset the costs of the } \\
\text { cleanup and request more funds to } \\
\text { sustain the newly developed } \\
\text { garden. The microbiologist will } \\
\text { take soil and water samples while } \\
\text { the analytical chemist assesses the } \\
\text { level of toxicity in these samples. }\end{array}$ & $\begin{array}{l}\text { An immunologist may not have the } \\
\text { background or experience to address } \\
\text { public opinion. Someone in public } \\
\text { health may have a better } \\
\text { tool set to do so. } \\
\text {-Course B }\end{array}$ & $\begin{array}{l}\text { And then } 2.2 \text { builds } \\
\text { off of } 2.1 \text { by having } \\
\text { students go on to } \\
\text { explain what those } \\
\text { things are. }\end{array}$ \\
\hline & $\begin{array}{l}2.3 \text { Methods \& Tools: } \\
\text { Include } \\
\text { techniques/procedures/t } \\
\text { ools from contributing } \\
\text { disciplines and/or } \\
\text { experts. }\end{array}$ & $\begin{array}{l}\text { Organic \& inorganic chemists will } \\
\text { extract, separate, \& examine the } \\
\text { pollutants w/ GC, NMR imaging, } \\
\& \text { Mass Spec. }\end{array}$ & $\begin{array}{l}\text { What is the direct action of what your } \\
\text { experts will be doing and how they will } \\
\text { accomplish that-what tools. } \\
\text {-Course A2 }\end{array}$ & $\begin{array}{l}\text { "What techniques } \\
\text { will be implemented } \\
\text { from each discipline } \\
\text { to accomplish the } \\
\text { task." }\end{array}$ \\
\hline
\end{tabular}




\begin{tabular}{|c|c|c|c|c|}
\hline \multirow[t]{2}{*}{ Z } & $\begin{array}{l}\text { 3.1 Leveraging } \\
\text { Disciplines/Experts: } \\
\text { Address how each } \\
\text { discipline's and/or } \\
\text { expert's contribution } \\
\text { (knowledge/methods) } \\
\text { will be useful for the } \\
\text { other disciplines and/or } \\
\text { experts. }\end{array}$ & $\begin{array}{l}\text { It would vastly benefit the } \\
\text { Remediation Plan to consult with } \\
\text { local Department of Health agents } \\
\text { and medical personnel in order to } \\
\text { craft a Public Health bulletin to } \\
\text { address community and health } \\
\text { concerns about introducing a } \\
\text { robust bacterial species to local } \\
\text { properties. Assuming that we are } \\
\text { not violating policies and can } \\
\text { abate community concerns, the } \\
\text { remediation strategy to remove } \\
\text { the alkyl halides depends } \\
\text { chemists' toxicity analysis and on } \\
\text { the microbiologists' soil samples. }\end{array}$ & $\begin{array}{l}\text { "The idea that even when you break } \\
\text { the problem up into chunks, it's not } \\
\text { independent chunks, each chunk } \\
\text { contributing to a whole, so they need } \\
\text { to really work together. So, this gets at } \\
\text { the idea that one part has to feed into } \\
\text { another." } \\
\text {-Course C }\end{array}$ & $\begin{array}{l}\text { This is providing } \\
\text { logic behind how } \\
\text { each puzzle piece fits } \\
\text { into the whole \& } \\
\text { formulating a } \\
\text { solution that is not } \\
\text { possible without } \\
\text { them. }\end{array}$ \\
\hline & $\begin{array}{l}\text { 3.2 Collaboration: } \\
\text { Include two or more } \\
\text { ways to build } \\
\text { community and respect } \\
\text { among different } \\
\text { disciplinary team } \\
\text { members. }\end{array}$ & $\begin{array}{l}\text { Regular public meetings and } \\
\text { private team building activities } \\
\text { between participating parties } \\
\text { should be facilitated through the } \\
\text { entire process in order to maintain } \\
\text { regular communication, active } \\
\text { community involvement, } \\
\text { accessible public education, and } \\
\text { trust building. }\end{array}$ & $\begin{array}{l}\text { Going through typical municipal } \\
\text { processes of community involvement, } \\
\text { having team building exercises, being } \\
\text { transparent. } \\
\text {-Course D }\end{array}$ & $\begin{array}{l}\text { This is requiring } \\
\text { [students] to think } \\
\text { about collaborating } \\
\text { in effective ways. } \\
\text { More of a social skill } \\
\text { to prepare them for } \\
\text { real life problem- } \\
\text { solving. }\end{array}$ \\
\hline \multirow{2}{*}{ 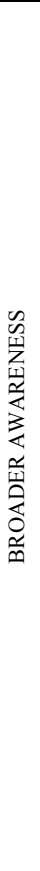 } & $\begin{array}{l}\text { 4.1 Societal Impact: } \\
\text { Include what/who will } \\
\text { be affected (e.g. } \\
\text { economics, politics, } \\
\text { social, health, etc.). }\end{array}$ & $\begin{array}{l}\text { The clean-up of this area and } \\
\text { creation of a community garden } \\
\text { would create a social, common } \\
\text { space accessible } \\
\text { to local people, as well as } \\
\text { a source of healthy food } \\
\text { for low income families. Phase } \\
\text { four will require significant } \\
\text { community input, and will be } \\
\text { most successful if the } \\
\text { Remediation Team supports local } \\
\text { leadership rather than } \\
\text { spearheading the restoration. This } \\
\text { park belongs to the city and its } \\
\text { people and should be treated as } \\
\text { such. }\end{array}$ & $\begin{array}{l}\text { "At the end of the day I'm doing this } \\
\text { because if this pipeline does fail, it's } \\
\text { going to lead to massive water } \\
\text { contamination and potential illness } \\
\text { and death among our communities. But } \\
\text { if we succeed, our communities are } \\
\text { going to have a better quality of life } \\
\text { because they're water will be safe." } \\
\text {-Course Al }\end{array}$ & $\begin{array}{l}\text { "Possible outcomes } \\
\text { in the event of not } \\
\text { receiving a vaccine- } \\
\text { implications on } \\
\text { public health, health } \\
\text { insurance, economy, } \\
\text { etc." }\end{array}$ \\
\hline & $\begin{array}{l}\text { 4.2 Limitations: } \\
\text { Forecast possible } \\
\text { limitations of your plan } \\
\text { and provide resolutions. }\end{array}$ & $\begin{array}{l}\text { A limitation of this plan is the } \\
\text { timeline-completely renovating } \\
\text { this area will take longer than the } \\
\text { projected opening of the } \\
\text { community garden date. This is } \\
\text { due to the high toxicity of PAH } \\
\text { compounds and alkyl halide } \\
\text { waste. We recommend waiting at } \\
\text { least fifteen years after } \\
\text { remediation to develop an in- } \\
\text { ground vegetable garden, pending } \\
\text { toxicity reports from the analytical } \\
\text { and organic chemistry teams and } \\
\text { EPA guidelines. In the interim, } \\
\text { the Remediation Plan suggests the } \\
\text { use of above-ground planter beds } \\
\text { as community garden plots. }\end{array}$ & $\begin{array}{l}\text { "Limitations... that just means if my } \\
\text { plan failed, people may get sick. There } \\
\text { would be detectable levels of alkaloids } \\
\text { \& bromine in the squash and oil } \\
\text { saturating the food." } \\
\text {-Course C }\end{array}$ & $\begin{array}{l}\text { "This is great } \\
\text { because it will force } \\
\text { students to be } \\
\text { metacognitive and } \\
\text { see inherent holes in } \\
\text { their plan. Also how } \\
\text { to mitigate those } \\
\text { potential issues } \\
\text { ahead of time." }\end{array}$ \\
\hline
\end{tabular}

\section{Objective Construct}

\section{There were several constructs that were relatively straightforward to both} students and faculty in Phases 2 and 3, including the objective construct (Table 3).

\section{Students expressed that this construct assisted them in collecting pertinent}


information and structuring their essay by providing a launch point to start the writing process:

"The requirements for [objective] just sounds like a lead in, understanding what you're supposed to be doing, and then how you're going to apply that. It is design, think, build, or whatever the engineering workflow will be for the paper." -Student Interview, Course A1

Faculty similarly attested to the accuracy of the objective construct in helping students frame big issues:

"[Objective] feels like a really, really important step. So, how someone frames a problem determines everything else, right? And one of the things that I try to do in this class is really focus on framing the problem earlier on and how you go about framing that problem- the approach. Because if framing is narrow then so are the solutions. " -Faculty Interview, Course B

\section{Disciplinary Grounding Construct}

Within the disciplinary grounding construct, most criteria were clear to students throughout Phases 2 and 3 (Table 3), however, several students in both phases found disciplinary research methods (criterion 2.3) to be challenging based on their lack of knowledge across disciplines: 
"I found talking about the specific methodology of each discipline to be really difficult, because I mean, even if you were a PhD Microbiologist, it would be difficult to understand the depth of knowledge that you need for each of these issues." -Student Interview, Course A1

This mirrors ideas from the IDSF in that students may need to focus on methods from one particular discipline in which they have developed knowledge, while providing provisional knowledge of methods from other disciplines (Tripp \& Shortlidge, 2019). Faculty assisted in providing justification for why students were typically providing laundry lists of methods:

“Because [students have] never solved big problems literally like this, they're just thinking. They're not actually getting to the nuts and bolts [of methods]. It's interdisciplinary thinking versus execution. [Methods] is important though and in my opinion, since I've been probably doing interdisciplinary type teaching for about 20 years, I would say that methods are often removed from interdisciplinary thinking. So I agree the next step is how well can they execute a plan and potentially be a project manager by explicitly stating what they're mode of action is and what methods they'll use to do it." -Faculty Interview, Course C

Given that students were not misinterpreting this criterion and faculty saw the importance in students including methods from more unfamiliar disciplines, we changed the language in the levels of thinking to more explicitly help instructors score 
this criterion and better reflect the tiered thinking skills that students commonly expressed (Table 2).

\section{Integration and Collaboration Constructs}

We initially had several criteria within integration that led many students to list disciplines needed without an intentional effort to integrate knowledge in their essays in Phase 2:

"I recommend a team of surveyors to monitor the erosion in the immediate area, soil specialists and engineers to make an updated survey of the immediate topography, as well as researchers to study innovative erosion remediation techniques." -Student Essay, Course A1

To assist students in the rather advanced task of truly integrating different disciplinary pieces of information, we reworked this construct to include specific instructions to leverage each discipline's knowledge/methods in a way that will be useful to the other disciplines involved (criterion 3.1). Rewording integration in this manner also inherently required a collaboration component for students to address (Table 2). This resulted in essays with much richer integration between disciplines evidenced by students providing ways to synthesize information into a cohesive whole through involvement and reliance on other disciplinary fields or expertise (Table 3).

With this inherent interplay between integration and collaboration, we chose to collapse the collaboration construct into a criterion within integration (Table 3). 
Several students in Phase 3 then reflected on the integration construct as the heart of what makes the assignment 'interdisciplinary science', such as this student from Course A2:

Student: The integration construct helped me use interdisciplinary science to tackle this problem on this assignment.

Interviewer: So this specific construct [integration] was the one that made you realize that you have to be interdisciplinary in answering the essay?

Student: Yeah. Because you needed to have your group work together and build the different areas in their respective fields to solve this problem better.

Conversely, a different proportion of our data from Phase 3 reflected a difficulty for students to address collaboration in their essays but for reasons that were quite unexpected; students were not misinterpreting this criterion but rather, were afraid to include evidence of collaboration in fear of the instructor's stringent grading on such a requirement:

"I did not include anything about collaboration because [this essay] is going to be a thing that I'm graded on by my professor. They're pretty far down the rabbit hole of, "You're in a science class. You are not in an intentional community class." I felt like any attention I gave to this would be counted against me." -Student Interview, Course $C$

"[Collaboration] is just difficult to address because then you get into the whole discipline of psychology and sociology and that's not a part of science, or this class... 
definitely not. I think the structuring, the whole information gathering, that's kind of how I addressed it; information gathering aspect; that everybody played a critical role. Yeah. I mean it's a clear question. It's just hard to answer because of personality differences, personality disorders, and this class subject isn't about people." -Student Interview, Course C

Since we only observed this kind of feedback from Course C, we suspect that the nature of instruction and/or more purely disciplinary content had an impact on if and how students addressed collaboration. Given the fundamental importance of collaboration in ID science work expressed by content experts in this study (Table 3) and a multitude of literature (NRC, 2003, 2009, Borrego \& Newswander 2010, AAAS, 2011), we posit that this criterion is foundational in acquiring real-world problem-solving skills. This serves as an important lesson for science instructors to embed ID activities and assessments that span beyond STEM disciplines. This also feeds into disciplinary humility and the necessity to foster respect, appreciation, and inclusion of social sciences and humanities into science courses, as collaboration within these fields is how real-world problems are best addressed. We are not arguing that deep disciplinary knowledge in scientific content is unimportant, but rather, it should be accompanied with an application aspect to help students broaden their awareness outside of science.

To help mold students' ID thinking toward these ends, in Phase 3 we created a broader awareness construct with a criterion of 'social impacts' (4.1), as our previous study revealed a deficit of students including disciplines outside of STEM (e.g. politics, business, economics, sociology, etc.) (Tripp et al., 2020). We also decided to 
change language in the rubric from 'disciplines' in Phase 2 to 'disciplines and/or experts' in Phase 3 (Table 2) to broaden students' ability to include individuals who may or may not be strictly within a discipline (e.g. native peoples, community groups). This simple rephrasing resulted in an overwhelming shift in students incorporation of 'non-traditional' disciplines and individuals as part of their equation to address the problem.

Despite the hesitation from some students in Course $\mathrm{C}$ to incorporate collaboration, a few students from this class were able to extend their thinking not only to address collaboration, but also incorporated non-traditional and non-STEM fields:

"The most crucial but often overlooked step towards the remediation of such a level of contamination is clear and accessible communication with the local community. This includes not only the locals, but the indigenous community and tribal leaders. Indigenous people are often the most severely affected by such disasters, as they are more connected to and reliant on the environment; an environmental disaster such as the BP oil spill proves mentally, physically and spiritually harmful to those people. The Louisiana coast is traditionally the land of the Houma and Choctaw Nations. Therefore, it is crucial to communicate with the tribal council of these nations the nature and magnitude of the contamination. This is mutually beneficial, as indigenous people are holders of traditional ecological knowledge, a vast but often untapped body of knowledge developed and refined over the course of centuries. " Student Essay, Course C 
When we asked this student about how they crafted their essay in this manner, they indicated the 'social impacts' criterion:

"In my own essay, I talked about the safety of doing a community garden with, the uptake problems of toxins like heavy metal toxins in a former industrial area. And you have to think about the people that it will impact. So I think that 'social impacts' is a good thing to have in the rubric and I think that it's a ... social awareness thing. All of these [criteria] are weighted equally, but that one's pretty important in my opinion." Student Interview, Course $C$

This indicates that regardless of the content taught in courses, the 'social impacts' criterion may help students broaden their approach to the issue by exhibiting disciplinary humility and collaboration through the inclusion of STEM and nonSTEM disciplines, and community members.

\section{Disciplinary Humility Mindset}

Disciplinary humility posits that students will likely need to gain respect and open-mindedness of other disciplinary perspectives, both within and outside of STEM disciplines (Tripp \& Shortlidge, 2019). We included it as a criterion for students to meet in Phase 2 of our rubric development. However, it became clear that the majority of students were exhibiting levels of disciplinary humility by addressing criterion 2.2 - disciplinary reasoning: 
'I guess ['disciplinary reasoning' and 'disciplinary humility'] seem like the same thing to a large extent. Because they are both just pressing for the need to explain why it is necessary to have an interdisciplinary approach - they are similar in context. And you can't have successful collaboration without disciplinary humility so you really have to have humility to even answer a question like this." -Student Interview, Course A1

The IDSF also reflects this sentiment by stating disciplinary humility is the thread that runs throughout ID science understanding and will likely increase as students have an opportunity to think and work interdisciplinarily (Tripp \& Shortlidge, 2019). It logically follows that as students go through the process of thinking in this way, they will inherently gain a level of disciplinary humility without having to describe the process of acquiring this mindset in their essay. As such, we excluded this requirement from the final rubric provided in this paper.

\section{Modifications for Broad Use in STEM and non-STEM Disciplines}

The final, fundamental aspect of disciplinary humility, and arguably at the core of ID science, is one of inclusion - the IDSF specifically highlights the importance of integration and collaboration across a spectrum of STEM, social sciences, arts, and humanities fields (Tripp \& Shortlidge, 2019). Throughout the development of IDSR, we deliberately modified the rubric to be broadly useful across disciplines, both within and outside STEM fields. As mentioned, students in our study ranged in major, background, course, and institution. Thus, amendments were made to the IDSR between Phases 2 and 3 to be more inclusive of the spectrum of 
undergraduate populations that may be scored with this instrument. For instance, the word 'hypothesis' was initially used in tasking students to formulate a plan. Based on novice and expert feedback, we removed language such as this, as students may have felt they must stay confined to the natural and physical science fields. To be civic leaders and contributors to the challenging world problems we continually face, students will undoubtedly interface with disciplines outside STEM and may need to act as stewards to lower the hierarchical barriers between competing ideologies across disciplines (Garibay, 2015, Tripp and Shortlidge 2019). This assignment and rubric may be a small step toward cultivating a mindset that prepares them for these challenges.

\section{Scoring and Scale}

We analyzed the levels of ID science thinking (i.e. scale) for the IDSR through instructor interviews across the four courses, as well as a panel of discipline-based education researchers (DBER) $(n=11)$ in Phase 3 (Figure 3). Three instructors suggested expanding the 3-point scale, as they found some students' responses falling in between the three levels of understanding (e.g. students were exhibiting thinking skills that fell between mastery and apprentice). Similarly, the DBER group suggested adding a fourth level to more fully represent the array of knowledge that students were directly exhibiting in their essays. For instance, we observed that some students communicated leveraging disciplines/expert contributions, but did not specifically address how to leverage the knowledge and/or methods from these individuals in a way that would be useful to the project (criterion 3.1). However, the initial 3-point scale did not include this as scoring option. Thus, we added another level to the IDSR 
as well as redefined the existing levels based on what students were actually exhibiting in their essays. We ensured that the spectrum of ways students described (or did not describe) each aspect of the rubric was represented in these tiers of thinking. This resulted in the measurement of ID science thinking across a 4-point spectrum: mastery (3), intermediate (2), novice (1), and naïve (0) (Table 2). The numerical values assigned to these levels can be changed based on assignment point value and instructor preference.

\section{Interrater Reliability and Statistical Findings}

The instructors of the courses who were previously unfamiliar with our instrument and had no training in using it—scored essays from their courses with high reliability in score interpretations with one of the rubric designers (B.T) $(\kappa=0.67)$. This indicates that practitioners can use the IDSR without being trained in how to interpret or grade students' work, and additionally attests to the reliability of data collected from the IDSR.

In examining differences in students' thinking across populations, we found no significant differences between essay scores in Phase 3 across Courses A2, B, C, and $\mathrm{D}(F=0.72, p=0.79, \mathrm{n}=85$; see APPENDIX $\mathrm{J}$ for descriptive statistics $)$. We did not include Course A1 in our statistical analysis as this group received the unrevised version of the IDSR (in Phase 2), and thus, is statistically incompatible with the other courses. As mentioned previously, we did not include scores from the 'format' category as this element is not directly related to ID science thinking, and would likely skew the data based on construct irrelevance variance (AERA 2014). 
Based on the low sample sizes at the course level (Table 1. Summary of three universities and five associated upper-division course formats (ID=interdisciplinary; $D=$ disciplinary) and sample sizes of essays and interviews collected over the course of two academic calendar years.), we performed a post-hoc power analysis (R Studio Team, 2020), which indicated the need for larger sample sizes to effectively make claims about differences in students' ID science thinking across populations and institutions. Nonetheless, as evidenced through the validity and reliability tests, the IDSR can indeed accurately and reliably detect science students' ability to think interdisciplinarily in a variety of course environments.

\section{$\underline{\text { Student Perceptions of Rubric and Assignment }}$}

One way to measure the outcomes of an activity is to gauge student perceptions of the activity, and how it impacts their interest and learning of the subject (Shortlidge et al. 2018). To evaluate if the rubric and assignment were assisting students in thinking interdisciplinarily in a valuable way, we inquired about student perceptions of both of these tools in student interviews in Phases 2 and 3. Many students expressed that the rubric helped narrow the scope and expectations of the assignment, and moreover, the combination of the assignment and rubric together significantly improved students' perceptions and ability to think interdisciplinarily in science:

"I felt like in a way, there was so much freedom at first in the prompt. That's where I was having a little bit of a hard time, just looking at the prompt. I guess the rubric 
helped me to narrow the scope. At first, it was hard just looking off the prompt itself. But the rubric really helped for me to be like, "This is how I develop an interdisciplinary approach." So yeah, I think having the rubric there and using it as a checklist. It helped to answer a lot of questions. "-Student Interview, Course A1

"I think this assignment was kind of profound. When you're tasked with something that is as far reaching as this is, it's really... It's taxing. It makes you think outside the box. It makes you take a step back and figure out what you actually know is effective for approaching the problem, and what sort of things you actually need to do and who to involve to help you get there." -Student Interview, Course B

“[The rubric] was helpful because I think it's hard for, I don't know what you call them, hardcore science students, to pay mind to a lot of these things that seem also focused on social stuff than the hard sciences, but I think that it's important and the rubric is what got me to expand my thinking in that way." -Student Interview, Course $C$

"I think the assignment really helped me understand what it is like to be a real scientist. I don't feel like I'm necessarily there yet obviously, like how to ask the questions or propose how to solve problems. So I guess this assignment forced me to think that way. It's the first real assignment where I've had to think about it from the start and not necessarily guided like I am in labs. " -Student Interview, Course D 
Students also verbalized a greater understanding and necessity for interdisciplinarity to solve real world issues based on the assignment:

"The types of questions that are most interesting don't just stay in one category, as [evidenced] by this assignment. They aren't under a single discipline. They are far reaching, and you need a lot of different background knowledge to understand some of those more critical things. I don't know if I can think of any real question in science that doesn't require that you understand at several different levels what's actually going on. So, interdisciplinary studies really breaks down a lot of walls that are created when we make those boxes for different fields, you know? When we say, "Okay, this is the chemistry ... We're in chemistry class, just open up the chemistry box." Or, "We're in biology, just open up the biology box." Or, "We're in physics, just open up the physics box." Interdisciplinary assignments like this allow for a lot more bridging of those gaps." -Student Interview, Course A2

To measure if an activity "works", collecting student perceptions can uncover important considerations in students' interest and learning (Shortlidge et al., 2018). Overall, students appear to be realizing the significance of ID science based on their experience with the assignment and IDSR. This indicates that these two tools not only measure conceptualization of ID science, but likely foster a more integrated way of knowing. When students can appreciate the value of learning from fields with different perspectives from their own, they may be able to see the benefits gained from working across disciplines. 


\section{LIMITATIONS}

Through the development of this instrument, there have been a few noteworthy limitations. Our decision to include a 'student version' of the rubric may have led students to think about interdisciplinarity in science from a narrower perspective. We based this decision on a pilot study where we withheld the student rubric from the assignment (Tripp et al., 2020). This resulted in diffuse, tangential, and unstructured essay responses. Thus, we resorted to providing students with the student rubric in subsequent pilots. The outcome from this modification revealed that students were still able to think holistically and creatively about how to arrive at plausible solutions to real-world issues, with the rubric actually assisting in the expansion of their mindset and ability to think "outside-the-box".

Another limitation may be related to the context of the real-world problem that instructors chose to embed in the assignment, as well as the content that is taught within the course. Several current real-world problems inherently have higher levels of ID science such as climate change, while others may be more strictly focused on indirect real-world issues. This could potentially change the level of integration or ID thinking that students are able to exhibit. However, the prompts used in this study varied from tasking students to develop an education plan for sexually transmitted infections to mitigating damaging effects from the construction of the Keystone Pipeline. The rubric was applicable to each type of problem regardless of the content covered in the courses. In the event that essay prompts are more specifically focused on indirect current issues, we have also provided evidence that the rubric may help guide students to think outside-the-box by connecting it to a broader relevance. 
Lastly, we were unable to draw conclusions about the usefulness of the IDSR based on certain demographics (e.g. age, gender, race, socioeconomic status, prior ID experience, students who used English as their second language, etc.). We did not obtain IRB approval to collect this type of sensitive data and thus, were unable to examine these important variables. Instead, we initially (and intentionally) wanted to validate data with the rubric by first assessing how it functioned across populations in general.

In addition, our samples sizes at the course level were limited in this study, and therefore we were unable to draw conclusions about the effectiveness of the IDSR in differentiating students' ID science thinking across populations. We highly encourage other practitioners and researchers to extend this work by testing the IDSR on larger populations to examine demographic factors and differences in how students think interdisciplinarily across populations.

\section{CONCLUSION AND FUTURE DIRECTIONS}

Research-based disciplines have a fundamental duty to pose and answer research questions that are often contingent on valid data collected from highly calibrated instruments. In this study, we developed an instrument, the Interdisciplinary Science Rubric, to assess undergraduate students' ID science thinking related to real-world issues. Through an iterative process based on novice and expert response processes and internal consistency of rubric scores, we have provided evidence that the IDSR is a quality assessment tool to measure ID science thinking in undergraduate education. 
Results also revealed that the IDSR and a real-world, problem-based writing assignment can be widely used across institutional and course platforms to measure Vision and Change's ID science competency (AAAS, 2011). We encourage faculty to use these tools to gauge students' ability to think interdisciplinarily and challenge them to broaden their mindset toward more disciplinary inclusion and humility. Furthermore, this activity represents a "low-bar" for instructors to implement in undergraduate courses by encouraging students to create outward-facing solutions to big issues.

There are a number of ways that the IDSR and IDSF could be used in various classrooms. For example, a shortened version of the essay assignment could be used as a pre/post examination of ID science thinking to assess the impact of a course on students' understanding of this competency. The practitioner/researcher must first, however, maintain validity and reliability measures by examining validity and reliability of data on their population both before and after administering a modified version of this instrument. This tool could also potentially be used to inform the development of a survey instrument to quantitatively assess students' ID science thinking; however, researchers would first want to establish evidence of validity and reliability of the data collected with the rubric on their student population.

We do contend that although this assignment and the IDSR have the ability to foster and accurately measure students' ID science thinking skills, this is one small step in the overall picture of interdisciplinary training and assessment. Much more effort must be intentionally infused into curricula and pedagogy to assist students in working across disciplinary fields and collaborating with teams to address unresolved issues. This instrument provides one way to measure this nebulous competency and 
look forward to researchers building on this work. We hope this work inspires science educators to use the IDSF and IDSR as a guide by which to create group activities and research projects that engage students in interdisciplinary collaboration. Through these efforts, we can better prepare students to enter the workforce with tools and skills to optimize a fluctuating world of burgeoning societal issues.

\section{ACKNOWLEDGEMENTS}

This research study would not have been possible without the student and expert interviewee participants, and to the instructors for incorporating the assignment into their courses. We thank the undergraduate researchers who made important contributions to the project, in particular: Sophia A. Vornoff and Analee Pham. We would also like to thank the Biology Education Research Group at University of Washington for providing their insight on this project. Thank you to the reviewers who spent time providing thoughtful and insightful suggestions to improve this manuscript. And lastly, we are grateful to the Biology Leadership Community's Catalytic Grant program for funding this research. 


\section{REFERENCES}

American Educational Research Association, American Psychological Association, National Council on Measurement in Education, Joint Committee on Standards for Educational, \& Psychological Testing (US). (2014). Standards for educational and psychological testing. Washington, DC: American Educational Research Association.

Arjoon, J. A., Xu, X., \& Lewis, J. E. (2013). Understanding the state of the art for measurement in chemistry education research: Examining the psychometric evidence. Journal of Chemical Education, 90(5), 536-545.

Besterfield-Sacre, M., Gerchak, J., Lyons, M. R., Shuman, L. J., \& Wolfe, H. (2004). Scoring Concept Maps: An Integrated Rubric for Assessing Engineering Education. Journal of Engineering Education, 93(2), 105-115. https://doi.org/10.1002/j.21689830.2004.tb00795.x

Boix Mansilla, V., \& Duraisingh, E. D. (2007). Targeted assessment of students' interdisciplinary work: An empirically grounded framework proposed. Journal of Higher Education, 78(2), 215-237.

Borrego, M., \& Newswander, L. K. (2010). Definitions of interdisciplinary research: Toward graduate-level interdisciplinary learning outcomes. Review of Higher Education, 34(1), 61-84.

Byrne, E., Sage, C., \& Mullally, G. (2016). Transdisciplinarity perspectives on transitions to sustainability. Routledge.

Balgopal, M. M., \& Wallace, A. M. (2009). Decisions and dilemmas: Using writing to learn activities to increase ecological literacy. Journal of Environmental Education, 40(3), 13-26.

Balgopal, M. M., Wallace, A. M., \& Dahlberg, S. (2012). Writing to learn ecology: A study of three populations of college students. Environmental Education Research, 18(1), 67-90. https://doi.org/10.1080/13504622.2011.576316

Balgopal, M. M., Wallace, A. M., \& Dahlberg, S. (2017). Writing from different cultural contexts: How college students frame an environmental SSI through written arguments. Journal of Research in Science Teaching, 54(2), 195-218. https://doi.org/10.1002/tea.21342

Barbera, J., \& VandenPlas, J. R. (2011). All Assessment Materials Are Not Created Equal: The Myths about Instrument Development, Validity, and Reliability.

Investigating Classroom Myths through Research on Teaching and Learning, 1074, 177-193. https://doi.org/doi:10.1021/bk-2011-1074.ch011

Boix Mansilla, V., \& Duraisingh, E. D. (2007). Targeted assessment of students' interdisciplinary work: An empirically grounded framework proposed. Journal of Higher Education, 78(2), 215-237. 
Boix Mansilla, V., Duraisingh, E. D., Wolfe, C. R., \& Haynes, C. (2009). Targeted Assessment Rubric: An Empirically Grounded Rubric for Interdisciplinary Writing. Journal of Higher Education, 80(3), 334-353. doi:10.1353/jhe.0.0044.

Borrego, M., Newswander, C. B., McNair, L. D., McGinnis, S., \& Paretti, M. C. (2009). Using concept maps to assess interdisciplinary integration of green engineering knowledge. Advances in Engineering Education, 1(3), n3.

Borrego, M., \& Newswander, L. K. (2010). Definitions of interdisciplinary research: Toward graduate-level interdisciplinary learning outcomes. Review of Higher Education, 34(1), 61-84.

Clabough, E.B.D. and Clabough, S.W. (2016). Using Rubrics as a Scientific Writing Instructional Method in Early Stage Undergraduate Neuroscience Study. The Journal of Undergraduate Neuroscience Education, (15)1:A85-A93.

Connolly, P., \& Vilardi, T. (1989). Writing to learn mathematics and science. New York: Teachers College Press.

Flavell, J.H. (1979). Metacognition and cognitive monitoring: A new era cognitive development inquiry. American Psychologist, 34, 906-911.

Garibay, J. C. (2015). STEM students' social agency and views on working for social change: Are STEM disciplines developing socially and civically responsible students? Journal of Research in Science Teaching, 52(5), 610-632.

https://doi.org/10.1002/tea.21203

National Institute of Health: National Institute on Drug Abuse. Retrieved from https://www.nih.gov/about-nih/what-we-do/nih-almanac/national-institute-drugabuse-nida. September 12, 2019.

National Research Council. (2003). BIO2010: Transforming undergraduate education for future research biologists. Washington, D.C.: National Academies Press.

National Research Council. (2009). A new biology for the 21st century. Washington, D.C.: National Academies Press.

Newell, W. H., \& Green, W. J. (1982). Defining and teaching interdisciplinary studies. Improving College and University Teaching, 30(1), 23-30.

Öberg, G. (2009). Facilitating interdisciplinary work: Using quality assessment to create common ground. Higher Education, 57(4), 405-415. 
Stevens, D. D., \& Levi, A. J. (2013). Introduction to rubrics: An assessment tool to save grading time, convey effective feedback, and promote student learning. Sterling, VA: Stylus Publishing, LLC.

Keys, C. W. (1999). Revitalizing instruction in scientific genres: Connecting knowledge production with writing to learn in science. Science Education, 83(2), 115-130.

Knekta, E., Runyon, C., \& Eddy, S. (2019). One Size Doesn't Fit All: Using Factor Analysis to Gather Validity Evidence When Using Surveys in Your Research. CBELife Sciences Education, 18(1), rm1. https://doi.org/10.1187/cbe.18-04-0064

Reynolds, J. A., Thaiss, C., Katkin, W., \& Thompson, R. J. (2012). Writing-to-Learn in Undergraduate Science Education: A Community-Based, Conceptually Driven Approach. CBE-Life Sciences Education, 11(1), 17-25. https://doi.org/10.1187/cbe.11-08-0064

Rivard, L. O. P. (1994). A review of writing to learn in science: Implications for practice and research. Journal of Research in Science Teaching, 31(9), 969-983.

Shortlidge, E. E.; Rain-Griffith, L., Shelby, C., Barbera, J., Shusterman, G. P. (2018). Despite Similar Perceptions and Attitudes, Postbaccalaureate Students Outperform in Introductory Biology and Chemistry Courses. CBE-Life Sciences Education, 18, 1, doi:10.1187/cbe. $17-12-0289$.

Stangor, C. (2014). Research methods for the behavioral sciences (5th ed.). New York: Houghton Mifflin.

Tripp, B., \& Shortlidge, E. E. (2019). A Framework to Guide Undergraduate Education in Interdisciplinary Science. CBE-Life Sciences Education, 18(2), es3.

Tripp, B., Vornoff, S.A., Shortlidge, E. E. (2020). Crossing Boundaries: Steps Toward Measuring Undergraduate Interdisicplinary Science Understanding, March Edition.

Wren, D., \& Barbera, J. (2013). Gathering Evidence for Validity during the Design, Development, and Qualitative Evaluation of Thermochemistry Concept Inventory Items. Journal of Chemical Education, 90(12), 1590-1601. https://doi.org/10.1021/ed400384g 


\section{CHAPTER 5: BROADER IMPLICATIONS}

In a world that is constantly interfacing with important interdisciplinary (ID) issues, we must provide environments for future scientists to develop their knowledge, perspectives, and curiosity across disciplinary boundaries (NRC, 2003, 2009, AAAS, 2011; PCAST, 2012). Allowing space for this growth may better equip students to enter the scientific workforce and develop innovative solutions to realworld dilemmas. This requires that we alert undergraduate science students to start thinking interdisciplinarily and encourage a mindset inclusive of other disciplines. This includes fields that lie outside of science, as real-world problems are often best addressed by the integration of knowledge from seemingly unrelated fields (NRC, 2003, 2009). To start cultivating these experiences, the onus is on practitioners to create ID science learning opportunities in undergraduate classrooms (NRC, 2003, 2009, AAAS, 2011). The goal of this dissertation is to provide evidence-based resources for instructors to start implementing ID science curricula and assessments that spur students to think within an open-ended, ID system. The following section outlines the implications and broader relevance of my work toward this goal.

\section{CONTRIBUTION OF RESULTS TO EXISTING LITERATURE}

\section{History as a Benchmark for Change}

In order to grasp the complex nature of ID science, I first embarked on a literature review of the history behind interdisciplinarity. Most articles with historical ID relevance were sourced through social science and humanities literature (Frank 1998, Klein 1996, 2000, 2005, 2010, Lattuca, 2001, 2010, Moran, 2002, Repko 2008), as these fields have been studying interdisciplinarity for over a century (Frank 1998). 
I was intrigued by how disciplines themselves came to exist, particularly, the ways in which disciplines were created as a means to substantiate power differentials between classes of people, with science at the top and other disciplines listed in a ranked order of importance toward the bottom, such as social justice, feminism, and cultural studies (Pellmar \& Eisenberg 2000, Moran, 2002; Tripp \& Shortlidge, 2019). The significance of this finding is paramount: to train students to solve real-world problems, as Vision and Change prioritizes (AAAS, 2011), they will undoubtedly need to work with other disciplines outside of STEM to address societal issues (Garibay, 2015, NRC 2003, 2009). Thus, educators should be aware that these discipline-based superiority views exist and make efforts to reverse these inequities in the classroom. Reports and studies have shown that science students may be less likely to engage in civic responsibilities and social justice (AAAS, 2011, Garibay, 2015). This lack of stewardship and humility in science should be contextualized and readily available to practitioners, thereby revealing a path to change the way science is currently taught.

Based on this, I explicitly outline the historical background of how disciplines and ID studies emerged and the role that science has played in reinforcing inequities across disciplines in Chapter 2 (Tripp \& Shortlidge, 2019). This also offers the scientific community an explanation for why existing hierarchies among disciplines currently plague academic culture. Knowing the why may spark additional motivation for science educators to embed inclusive material in their science courses that enumerate the benefits of collaborating with disciplines that lie outside STEM. This ultimately may be one small step toward decreasing the power differentials that exist between STEM and non-STEM disciplines. 
In addition, I outlined other barriers to ID science in academia by reviewing why researching and teaching interdisciplinarily at the university level has been particularly challenging for science fields (Gazzinga, 1998). This included reasons such as prioritizing specialization, lack of funding, and reward processes that often do not incentivize ID science efforts (Gazzinga, 1998, Pellmar \& Eisenberg, 2000, Lattuca, 2001, Tripp \& Shortlidge, 2019). I deliberately highlighted these barriers as a starting place for practitioners to enact change across the academic landscape. As stated throughout this dissertation, undergraduate biology education has been illprepared to train students to think and participate in ID practices (NRC, 2003). Perhaps by characterizing the reasons for this, science educators can be more proactive in changing the role that science plays in inhibiting students' ID science thinking and humility.

\section{$\underline{\text { Defining Interdisciplinary Science }}$}

Adding to the barriers mentioned above, I found little cohesion in the literature on how experts describe interdisciplinarity, particularly in the sciences (Bennington 1999, Moran 2002, Tripp \& Shortlidge, 2019). In addition, these definitions were often sourced from other literature that only provided opinions from one or two authors (Borrego et al. 2009, Borrego \& Newswander 2010, Chan et al. 2010), or pulled from governing bodies that solely focused on research (National Academy of Sciences, 2004). The importance of acquiring a unified definition of ID science from current scientists and science educators working at universities is critical, as it can provide information on what encompasses true ID science understanding at the undergraduate level. These are the individuals researching and teaching ID science 
topics, and thus, can deliver unique and valuable insights into existing and/or new facets of this concept that were previously undocumented.

To give voice to these scholars, I nationally surveyed faculty who work in science departments at universities and asked how they define ID science $(n=184)$. I thematically analyzed their responses into six main themes (Chapter 2, Table 1) and molded these into a definition of ID science (Tripp \& Shortlidge, 2019). By providing this unified definition, practitioners may be better suited to develop curricula that is truly conducive to ID science understanding in undergraduate settings.

\section{From a Definition to a Framework}

An important aspect in creating quality ID curricula involves the use of a theoretical framework that identifies what constitutes ID science understanding. Theoretical frameworks specify key variables influencing a phenomenon or concept under investigation (e.g. ID science understanding) and open up possibilities to examine how those variables might differ and under what conditions (Jadallah, 1996, Kroll \& LaBoskey, 1996, Marsh et al., 2006). However, I found no such model in the STEM literature. To close this gap, I tied theoretical literature from the social sciences (Boix Mansilla \& Durasingh, 2007) with the data-driven definition of ID science (Tripp \& Shortlidge, 2019) to develop the Interdisciplinary Science Framework (IDSF) (Chapter 2, Figure 1). This model defines five main criteria that comprises a students' understanding of ID science: disciplinary humility, disciplinary grounding, different research methods, integration, and collaboration. The IDSF serves as a foundation for instructors to start developing ID science curricula based on these pillars of understanding. 
To further assist practitioners in this process, I outlined eleven existing peerreviewed articles that exhibited criteria in the IDSF as a means to generate evidencebased resources for instructors to develop learning objectives, activities, and assessments (Chapter 2, Table 2). I then provided an example of how to apply the IDSF to a classroom through a 'Deliberative Democracy' activity (Komperda et al., 2018) (Chapter 2, Table 3). Given these multiple resources, I hope that the science education field is better equipped to develop curricula and pedagogy that fosters students' ability to understand the ID nature of science.

\section{Quality Assessment Tools}

In order for practitioners to evaluate if their implemented curriculum is "working", they must have a mechanism to assess if students are truly grasping ID science. To address this, I searched for instruments in the literature that measured this competency for undergraduate science students. However, my efforts were met by a dearth of quality assessment tools in STEM. Thus, I turned to the non-STEM literature and found an instrument (in the form of a rubric) designed to measure social science students' ID understanding (Boix Mansilla et al., 2009). Although the validation process did not include students from STEM disciplines, several constructs in the rubric did align with the theoretical criteria in the IDSF, justifying my reasoning for testing it on a science population.

Before implementing a preexisting instrument on a new population, however, evidence of validity measures must be established (Barbera \& VandenPlas 2011, AERA 2014, Arjoon et al. 2013). Validity is arguably one of the most important aspects of measurement, and "instruments should not be used without sufficient 
evidence of their ability to produce valid scores in a desired context," (Arjoon et al. 2013). To obtain this, I first developed and administered essay assignments to students in upper-division science courses and subsequently scored their work with the rubric. The essay prompts tasked students with addressing a real-world problem relevant to their course content. I conducted semi-structured interviews with a subset of these students and compared same-student essay and interview responses, thereby testing for evidence of convergent validity (AERA, 2014) of the rubric's scores (Chapter 3, Figure 4). The results indicated that certain criteria were not functioning as the designers intended, but instead, students conceptualized ID science more similarly to the IDSF (Tripp et al., 2020). This finding presented an opportunity to similarly test the quality of the IDSF through evidence of convergent validity of data. Although the IDSF is not a survey 'instrument', it still requires validity measures to substantiate its accuracy in describing key variables involved in ID science understanding. I examined this by re-analyzing the interviews with the IDSF criteria, which successfully demonstrated the model's robustness in accurately measuring students' understanding of ID science in our population.

Although validity is not a new concept in biology education research, testing for evidence of convergent validity through matched data (same-student essays and interviews) appears to be a unique form of evidence in the biology education field. The implications of introducing 1) a potentially novel measure for testing validity and 2) an evidence-based model for creating ID science assessments can move science educators toward using and creating quality tools that accurately measure students' understanding of this competency. 
Interdisciplinary Science Rubric

Defining the parameters of ID science, creating a model (IDSF) of key variables contributing to ID science understanding (Chapter 2), and verifying evidence for the validity of data collected from the IDSF (Chapter 3), led to the development of an assessment tool that is theoretically and empirically supported, the Interdisciplinary Science Rubric (IDSR) (Tripp et al., 2020) (Chapter 4, Table 2). Through a series of validity and reliability studies, I provided evidence that this instrument can accurately and reliably capture ID science thinking across varying institutions, course formats (disciplinary to ID), and student majors (STEM and nonSTEM). To accomplish this, I developed and administered another round of essay assignments to students in five courses across three universities and scored their work with the IDSR. I then recruited students from these courses for semi-structured, thinkaloud interviews to ensure that they were understanding the constructs and criteria in the IDSR as intended. I also interviewed the instructors of record to verify the appropriateness and accuracy of the constructs and criteria from a practitioner's perspective. These qualitative measures are formally known as testing for evidence of validity through novice and expert responses processes, and is one of the many sources that contribute to construct validity (AERA, 2013). In addition, I sought feedback from an expert panel of discipline-based researchers, strengthening the validity of the scoring metric and levels of understanding (mastery (3), intermediate (2), novice (1), naïve (0)) in the IDSR.

Lastly, I established evidence of reliability through interrater reliability (IRR) of essay scores with the instructors of record. Reliability through IRR in this study measured the extent to which judges' ratings on criteria correlated with each other, 
thus demonstrating that the judges were all measuring the true scores collected from the IDSR rather than random error (Stangor, 2011). The significance of establishing reliability of scores with instructors that had no prior experience with the rubric verifies that 1) practitioners can more accurately measure students' thinking of ID science as defined by the instrument, and 2) establishes that this tool is being interpreted by practitioners in similar ways, regardless of experience or prior background knowledge. Although data from the IDSR should be reevaluated for evidence of validity and reliability in each new environment it is administered, this tool has evolved through an extensive iterative process to be useful across a wide variety of educational settings and populations.

Through the iterative process of scoring 187 essays and performing 89 interviews across nine courses and three different universities, this work provides the field with a novel, empirically-based instrument to assist instructors in measuring if and how students conceptualize ID science.

\section{Writing Assignments}

The platform that was developed for students' to exhibit their ID science knowledge — 'real-world problem' essay assignments (Chapters 3 and 4)—contributed to students recognizing the value of working across disciplines and served as a space for students to exhibit their growth in disciplinary humility. In essays and interviews, students often reflected on the absolute necessity of disciplines outside of STEM in addressing complex societal issues and repeatedly acknowledged their limitations to "knowing everything" (Tripp et al. 2020; Tripp \& Shortlidge 2020). Students further attributed this recognition to their exposure with the assignment. As disciplinary 
humility is the connecting thread in students understanding ID science (Tripp and Shortlidge 2019), and arguably, a necessary component to successfully working with experts from other fields, the essay assignment provides practitioners with an easily implementable tool by which to guide students in developing an inclusive mindset. This activity also challenges students to "think-outside-the-box" by pulling together knowledge and resources from different fields of study to address challenging societal issues.

\section{FINAL THOUGHTS}

Although it will take additional efforts to move students from thinking interdisciplinarily in science to practicing ID science in the workforce, the expertbased definition, IDSF, and IDSR developed in this dissertation are vital steps toward defining and assessing the parameters of ID science understanding in higher education. Additionally, these resources have the potential to guide practitioners in fostering students' disciplinary humility and cultivating a mindset toward inclusivity within STEM and between non-STEM disciplines. More broadly, and perhaps ambitiously, I hope that this research can pave the way for practitioners and science educators to enact change in academic culture from specialized, hierarchical ways of knowing to integrated and inclusive forms of learning across disciplinary silos. 


\section{REFERENCES}

American Association for the Advancement of Science. (2011). Vision and change: A call to Action, Final Report. Washington, DC. Retrieved July 22, 2019, from http://visionandchange.org/finalreport.

American Educational Research Association, American Psychological Association, \& National Council on Measurement in Education [AERA]. (2013). Standards for educational and psychological testing. American Educational Research Association.

Barbera, J., \& VandenPlas, J. R. (2011). All Assessment Materials Are Not Created Equal: The Myths about Instrument Development, Validity, and Reliability. Investigating Classroom Myths through Reseach on Teaching and Learning, 1074, 177-193. https://doi.org/doi:10.1021/bk-2011-1074.ch011

Boix Mansilla, V., Miller, W. C., \& Gardner, H. (2000). On disciplinary lenses and inter- disciplinary work. In S. Wineburg \& P. Grossman (Eds.), Interdisciplinary curriculum: challenges to implementation. (pp. 17-38). New York: Teachers College Press.

Boix Mansilla, V., \& Duraisingh, E. D. (2007). Targeted assessment of students' interdisciplinary work: An empirically grounded framework proposed. Journal of Higher Education, 78(2), 215-237.

Boix Mansilla, V., Duraisingh, E. D., Wolfe, C. R., \& Haynes, C. (2009). Targeted Assessment Rubric: An Empirically Grounded Rubric for Interdisciplinary Writing. Journal of Higher Education, 80(3), 334-353. doi:10.1353/jhe.0.0044.

Borrego, M. \& Newswander, L. K. (2010). Definitions of Interdisciplinary Research: Toward Graduate-Level Interdisciplinary Learning Outcomes. The Review of Higher Education 34(1), 61-84. Johns Hopkins University Press. Retrieved August 17, 2019, from Project MUSE database.

Cooper, M. M., \& Stowe, R. L. (2018). Chemistry Education Research-From Personal Empiricism to Evidence, Theory, and Informed Practice. Chemical Reviews, 118(12), 6053-6087. https://doi.org/10.1021/acs.chemrev.8b00020

Frank, R. (1988). 'Interdisciplinary’: The First Half Century. Issues in Integrative Studies, 40(6), 139-151.

Garibay, J. C. (2015). STEM students' social agency and views on working for social change: Are STEM disciplines developing socially and civically responsible students? Journal of Research in Science Teaching, 52(5), 610-632. https://doi.org/10.1002/tea.21203

Gazzaniga, M. S. (1998). How to change the university. Science, 282(5387), 237-237. 
Jadallah, E. (1996). Reflective theory and practice: A constructivist process for curriculum and instructional decisions. Action in Teacher Education , 18, 73-85.

Klein, J. T. (1990). Interdisciplinarity: History, theory, and practice. Detroit, MI: Wayne State University Press.

Klein, J. T. (1996). Crossing boundaries: Knowledge, disciplinarities, and interdisciplinarities. Nashville, TN: University of Virginia Press.

Klein, J. T. (2000). A conceptual vocabulary of interdisciplinary science. In Stehr, N \& Weingart, P. (Eds,), Practising interdisciplinarity, 3-24. Toronto, Canada: University of Toronto Press.

Klein, J. T. (2005). Integrative learning and interdisciplinary studies. Peer Review, 7(4), 8-10.

Klein, J. T. (2015). Reprint of "Discourses of transdisciplinarity: Looking back to the future". Futures, 65, 10-16.

Kroll, L. R. \& LaBoskey, V. K. (1996). Practicing what we preach: Constructivism in a teacher education program. Action in Teacher Education . 18 (2), 63-72.

Lattuca, L. R. (2001). Creating interdisciplinarity: Interdisciplinary research and teaching among college and university faculty. Vanderbilt University Press.

Lattuca, L., \& Knight, D. (2010). In the eye of the beholder: Defining and studying interdisciplinarity in engineering education. In American Society for Engineering Education. American Society for Engineering Education.

Marsh, J. et al. (2006) Making sense of data-driven decision making in education. Rand: Occasional Papers.

National Academy of Sciences. (2004). Facilitating Interdisciplinary Research. Washington, DC: National Academy of Engineering, Institute of Medicine, National Academies Press.

National Research Council. (2003). BIO2010: Transforming undergraduate education for future research biologists. Washington, D.C.: National Academies Press.

National Research Council. (2009). A new biology for the 21st century. Washington, D.C.: National Academies Press.

Pellmar, T. C. \& Eisenberg, L. (2000). Bridging Disciplines in the Brain, Behavioral, and Clinical Sciences. Washington, D.C.: National Academies Press.

President's Council of Advisors on Science and Technology [PCAST]. (2012). Engage to excel: Producing one million additional college graduates with 
degrees in science, technology, engineering, and mathematics. Washington, DC: U.S. Government Office of Science and Technology.

Stangor, C. (2011). Research methods for the behavioral sciences $\left(5^{\text {th }}\right.$ ed). New York: Houghton Mifflin.

Tripp, B., \& Shortlidge, E. E. (2019). A Framework to Guide Undergraduate

Education in Interdisciplinary Science. CBE_Life Sciences Education, 18(2), es3.

Tripp, B., Voronoff, S. A., \& Shortlidge, E. E. (2020). Crossing Boundaries: Steps Toward Measuring Undergraduates' Interdisciplinary Science Understanding. $C B E-$ Life Sciences Education, 19(1), ar8.

Tripp, B., \& Shortlidge, E. E. (2020). From Theory to Practice: Development of an Instrument to Measure Undergraduate Interdisciplinary Science Understanding. CBE-Life Sciences Education, in revision. 
APPENDIX A: INSTITUTIONAL INFORMATION

\begin{tabular}{llcc}
\hline Category & & $\mathrm{n}$ & $\begin{array}{c}\text { Percentage } \\
(\%)\end{array}$ \\
\hline Years at current position & 5+ Years & 141 & 77 \\
& 1-2 Year & 25 & 14 \\
& $<$ Year & 16 & 9 \\
Gender & No information & 2 & 1 \\
& Male & 112 & 61 \\
& Female & 68 & 37 \\
& Non-Binary & 2 & 1 \\
Institution Classification & Unidentified & 2 & 1 \\
& Research & 114 & 62 \\
& Master & 35 & 20 \\
& Other & 12 & 7 \\
& Baccalaureate & 7 & 4 \\
& Associate & 5 & 3 \\
& International University & 5 & 3 \\
& Special Focus Profession & 5 & 3 \\
& Funding agency & 1 & 1 \\
& Natural/Physical Science & 118 & 64 \\
& Unidentified & 33 & 18 \\
& Computer Science & 8 & 4 \\
& Science Education & 7 & 4 \\
& Math & 4 & 2 \\
\hline
\end{tabular}




\section{APPENDIX B. ESSAY PROMPTS FOR ASSIGNMENTS}

*Course: Biochemical Virology

Assignment: A new viral disease has been spreading in eastern Europe, killing large numbers of pigs and other domestic animals. A treatment is desperately needed in order to prevent collapse of the economies of these countries. This virus does not seem to be similar to any other known virus and has proven to be elusive to vaccinebased therapy. As a scientist for the World Organization for Animal Health (OIE), you have been tasked with collaborating on strategies to combat this disease. What would you aim to discover about the virus? How would you discover this (e.g. tools, techniques, procedures, considerations)? Craft a proposal to the scientists working for the United Nations to inform them of your decision and plan.

Course: Chemical Ecology and Plant Systematics

Assignment: Over the course of the last 20 years, honeybee colonies have declined significantly due to pesticide use, fertilizers, and agricultural structures. Certain agricultural crops are resistant to these external pressures, while other fruits and vegetables are negatively affected. As a scientist for the United States Department of Agriculture (USDA), you are tasked with collaborating on a proposal to address this problem. What would you aim to discover about this issue? How would you discover this (e.g. tools, techniques, procedures, considerations)? Craft a proposal to the scientists working for the United Nations to inform them of your decision and plan.

Course: Environmental Restoration

Assignment: A recent forest fire has devastated a popular regional park that featured non-native trees. There are various factions within the community, broadly split into two camps: those in favor of eradicating the non-native trees because they interfere with the establishment of native trees, and those who view the non-native trees as culturally important resources that appeal to residents and tourists alike and therefore, should be replanted. As an environmental scientist for a conservation group, you have been tasked with collaborating on a proposal to restore the regional park using your scientific and socioeconomic expertise. What would you aim to discover about this issue? How would you discover this (e.g. tools, techniques, procedures, considerations)? Craft a proposal to the scientists working for the United States Forest Service (USFS) to inform them of your decision and plan.

*Each prompt was followed by the directions below:

Please follow the rubric below. Feel free to pull on all sources in developing your essay. Make sure your paper is in APA format: Times New Roman font, 1" margins, single-spaced, proper APA referencing, etc. Please limit your essay to two pages but 
make sure it is at least one page long. Include appropriate scientific writing and remember who your audience is (the USFS). Include at least two primary, peerreviewed journal articles. Be sure to address this essay from a creative, holistic but realistic viewpoint. Pay close attention to your thesis statement, support your position, and be cognizant of paragraph transitions, grammar, and spelling.

\section{RUBRIC}

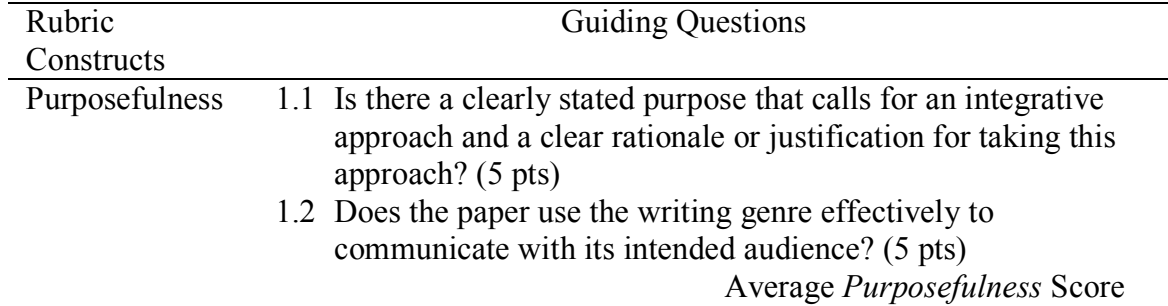

Disciplinary $\quad 2.1 \quad$ Does the paper use disciplinary knowledge accurately Grounding and effectively (e.g. concepts, perspectives, findings, examples, relevant and credible sources)? (5 pts)

2.2 Does the paper use disciplinary methods accurately and effectively (e.g. experimental design)? (5 pts)

Average Disciplinary Grounding Score

Integration $\quad 3.1 \quad$ Does the paper include selected disciplinary perspectives and insights from two or more disciplinary traditions presented in the course or from elsewhere that are relevant to the paper's purpose? (5 pts)

3.2 Is there a sense of balance in the overall composition of the piece with regard to how disciplinary perspectives are brought together to advance the purpose of the piece? ( $5 \mathrm{pts})$

3.3 Do the conclusions drawn by the paper indicate that understanding has been advanced by the integration of disciplinary views (e.g. the paper takes full advantage of the opportunities presented by the integration of disciplinary insights to advance its intended purpose both effectively and efficiently. The integration may result in novel or unexpected insights)? (5 pts)

Average Integration Score

Critical

Awareness
4.1 Does the paper exhibit awareness of the limitations and benefits of the contributing disciplines? (5 pts) 
APPENDIX C. PRACTIONERS VERSION OF RUBRIC

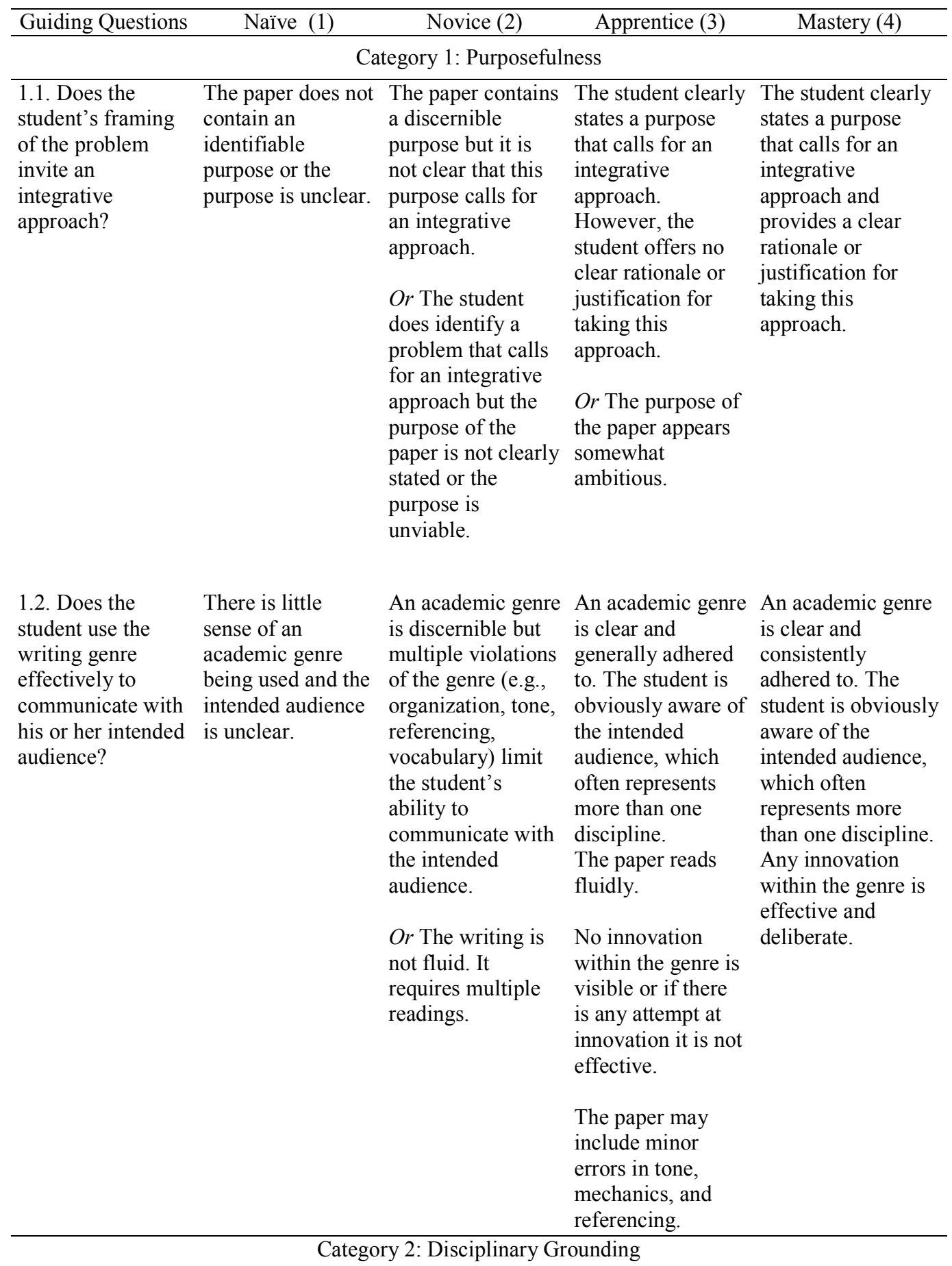




\begin{tabular}{|c|c|c|c|c|}
\hline $\begin{array}{l}\text { 2.1. Does the } \\
\text { student use } \\
\text { disciplinary } \\
\text { knowledge } \\
\text { accurately and } \\
\text { effectively (e.g., } \\
\text { concepts, theories, } \\
\text { perspectives, } \\
\text { findings, } \\
\text { examples)? }\end{array}$ & $\begin{array}{l}\text { A disciplinary } \\
\text { knowledge base is } \\
\text { not discernible in } \\
\text { the sense that the } \\
\text { ideas and } \\
\text { information } \\
\text { included do not } \\
\text { stem from any } \\
\text { particular } \\
\text { disciplinary } \\
\text { tradition. } \\
\text { Misconceptions } \\
\text { and folk beliefs } \\
\text { abound. In some } \\
\text { cases, jargon is } \\
\text { used with little } \\
\text { evidence of } \\
\text { understanding. } \\
\text { And /or the student } \\
\text { misuses sources in } \\
\text { a major way-e.g., } \\
\text { non-credible } \\
\text { sources, } \\
\text { misunderstanding } \\
\text { the meaning of } \\
\text { source(s), relying } \\
\text { too heavily on one } \\
\text { source. }\end{array}$ & $\begin{array}{l}\text { The student uses } \\
\text { disciplinary } \\
\text { concepts, } \\
\text { theories, } \\
\text { perspectives, } \\
\text { findings, or } \\
\text { examples in } \\
\text { simplistic, general, } \\
\text { or mechanical } \\
\text { ways-as in the } \\
\text { "textbook" version } \\
\text { of a discipline. } \\
\text { Key claims are } \\
\text { sometimes not } \\
\text { supported, or } \\
\text { concrete } \\
\text { disciplinary } \\
\text { examples are } \\
\text { disconnected } \\
\text { from key claims. }\end{array}$ & $\begin{array}{l}\text { Concepts and } \\
\text { theories are used } \\
\text { effectively in } \\
\text { accordance to their } \\
\text { disciplinary } \\
\text { origins, in ways } \\
\text { adopted by } \\
\text { disciplinary } \\
\text { experts. } \\
\text { Theories and } \\
\text { generalizations are } \\
\text { consistently } \\
\text { supported with } \\
\text { examples or } \\
\text { findings from the } \\
\text { disciplines } \\
\text { involved. } \\
\text { Conversely, } \\
\text { concrete cases and } \\
\text { examples are } \\
\text { interpreted with } \\
\text { disciplinary } \\
\text { concepts and } \\
\text { theories. } \\
\text { Relevant and } \\
\text { credible sources } \\
\text { are used } \\
\text { intelligently to } \\
\text { advance the } \\
\text { argument of the } \\
\text { piece, though the } \\
\text { paper may have } \\
\text { too many } \\
\text { unnecessary } \\
\text { sources, or key } \\
\text { sources may be } \\
\text { missing. }\end{array}$ & $\begin{array}{l}\text { In addition to the } \\
\text { qualities outlined at } \\
\text { Level 3, a well } \\
\text { organized network } \\
\text { of concepts, } \\
\text { theories, } \\
\text { perspectives, } \\
\text { findings, and } \\
\text { examples within } \\
\text { one or more of the } \\
\text { selected disciplines } \\
\text { is clearly visible. } \\
\text { Some insightful } \\
\text { new examples, } \\
\text { interpretations, or } \\
\text { responses } \\
\text { within the selected } \\
\text { disciplines } \\
\text { may be present. }\end{array}$ \\
\hline
\end{tabular}




\begin{tabular}{|c|c|c|c|c|}
\hline $\begin{array}{l}\text { 2.2. Does the } \\
\text { student use } \\
\text { disciplinary } \\
\text { knowledge } \\
\text { accurately and } \\
\text { effectively (e.g., } \\
\text { concepts, theories, } \\
\text { perspectives, } \\
\text { findings, } \\
\text { examples)? }\end{array}$ & $\begin{array}{l}\text { The student shows } \\
\text { little to no } \\
\text { awareness of the } \\
\text { methods, } \\
\text { habits of mind, } \\
\text { and validation } \\
\text { criteria by which } \\
\text { knowledge } \\
\text { is constructed and } \\
\text { verified in } \\
\text { the disciplines. } \\
\text { Opinions and } \\
\text { information } \\
\text { summaries are } \\
\text { presented as } \\
\text { matters of fact. }\end{array}$ & $\begin{array}{l}\text { The student shows } \\
\text { awareness of or } \\
\text { uses disciplinary } \\
\text { methods and } \\
\text { modes of } \\
\text { thinking in one or } \\
\text { more of the } \\
\text { included } \\
\text { disciplines, but } \\
\text { employs them } \\
\text { mechanically, } \\
\text { superficially, or } \\
\text { algorithmically. } \\
\text { There may be } \\
\text { oversimplification } \\
\text { s and } \\
\text { misconceptions } \\
\text { about methods } \\
\text { (e.g., if someone } \\
\text { assumes statistics } \\
\text { results are } \\
\text { true). }\end{array}$ & $\begin{array}{l}\text { The student } \\
\text { accurately } \\
\text { employs methods, } \\
\text { modes of thinking } \\
\text { (e.g., ways to } \\
\text { select evidence or } \\
\text { construct causal } \\
\text { accounts), and } \\
\text { validation criteria } \\
\text { to construct } \\
\text { knowledge in one } \\
\text { or more of the } \\
\text { selected } \\
\text { disciplines. }\end{array}$ & $\begin{array}{l}\text { The student } \\
\text { accurately employs } \\
\text { methods, habits of } \\
\text { mind, and } \\
\text { validation criteria } \\
\text { to construct } \\
\text { knowledge in one } \\
\text { or more of the } \\
\text { selected disciplines } \\
\text { He or she does so } \\
\text { effectively, } \\
\text { exhibiting language } \\
\text { that } \\
\text { describes the } \\
\text { constructed nature } \\
\text { of disciplinary } \\
\text { knowledge (e.g., } \\
\text { the provisional } \\
\text { nature of } \\
\text { insights, the limits } \\
\text { of } \\
\text { generalizations, the } \\
\text { multiplicity of } \\
\text { interpretations). }\end{array}$ \\
\hline
\end{tabular}

Category 3: Integration

\begin{tabular}{|c|c|c|c|c|}
\hline 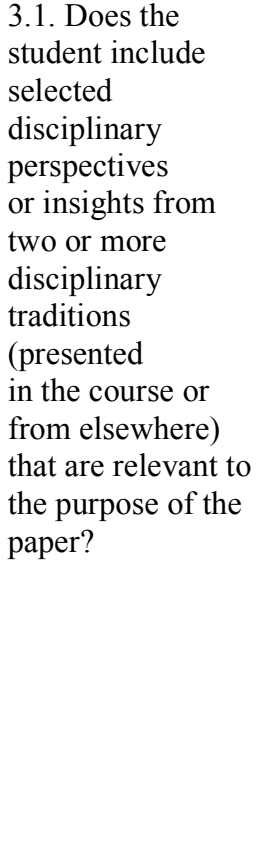 & $\begin{array}{l}\text { The paper shows } \\
\text { no evidence } \\
\text { that disciplinary } \\
\text { perspectives are } \\
\text { used to address the } \\
\text { paper's purpose. } \\
\text { Multiple } \\
\text { perspectives or } \\
\text { points of view may } \\
\text { be considered but } \\
\text { these do not } \\
\text { represent } \\
\text { disciplinary views } \\
\text { and/or are not } \\
\text { clearly related to } \\
\text { the paper's } \\
\text { purpose. }\end{array}$ & $\begin{array}{l}\text { The paper includes } \\
\text { two or more } \\
\text { relevant } \\
\text { disciplinary } \\
\text { perspectives } \\
\text { or fields but the } \\
\text { connections } \\
\text { between the } \\
\text { included } \\
\text { disciplinary } \\
\text { insights and the } \\
\text { purpose of the } \\
\text { work are } \\
\text { superficial or } \\
\text { unclear. }\end{array}$ & $\begin{array}{l}\text { The paper includes } \\
\text { two or more } \\
\text { relevant } \\
\text { disciplines or } \\
\text { fields. Selected } \\
\text { disciplinary } \\
\text { insights are } \\
\text { clearly connected } \\
\text { to the purpose } \\
\text { of the work. }\end{array}$ & $\begin{array}{l}\text { The paper includes } \\
\text { two or more } \\
\text { relevant disciplines } \\
\text { or fields. Selected } \\
\text { disciplinary } \\
\text { insights are clearly } \\
\text { connected to the } \\
\text { purpose of the } \\
\text { work. No unrelated } \\
\text { disciplinary } \\
\text { insights appear and } \\
\text { no crucial } \\
\text { perspectives are } \\
\text { missing. }\end{array}$ \\
\hline
\end{tabular}




\begin{tabular}{|c|c|}
\hline $\begin{array}{l}3.2 . \text { Is there an } \\
\text { integrative device } \\
\text { or strategy (e.g., a } \\
\text { model, } \\
\text { metaphor, } \\
\text { analogy)? }\end{array}$ & $\begin{array}{l}\text { The student may } \\
\text { explore the } \\
\text { topic in a holistic } \\
\text { way but } \\
\text { connections are } \\
\text { unclear and there } \\
\text { is no obvious } \\
\text { sense of } \\
\text { integration. }\end{array}$ \\
\hline
\end{tabular}

3.3. Is there a The paper shows sense of balance in an imbalance in the overall the way particular composition of the disciplinary piece with regard to how the student brings disciplinary perspectives or insights together to advance the purpose of the piece?
The student may explore the topic in a holistic way, making valid connections across disciplinary or field perspectives; however, insights from different perspectives are not integrated coherently or effectively. In some cases, disciplinary concepts, theories, perspectives, findings, or examples are placed side by side; connections and analogies are made but no overall coherent integration is discernible.
An integrative device (e.g., a leading metaphor, a complex causal explanation) clearly brings disciplinary insights together in used to bring a generally coherent and effective way.
A novel, imaginative, or well-articulated integrative device (e.g., a leading metaphor, a complex causal explanation) is used to bring
disciplinary insights together in a coherent and effective way.

$\begin{array}{lll}\begin{array}{l}\text { The student } \\ \text { attempts to balance }\end{array} & \begin{array}{l}\text { Disciplinary } \\ \text { insights in the } \\ \text { perspectives but }\end{array} & \begin{array}{l}\text { Disciplinary } \\ \text { paper are generally }\end{array} \\ \begin{array}{l}\text { insights are } \\ \text { delicately balanced } \\ \text { artificial or }\end{array} & \begin{array}{l}\text { balanced on } \\ \text { substantive }\end{array} & \begin{array}{l}\text { to maximize } \\ \text { the effectiveness of }\end{array} \\ \begin{array}{l}\text { algorithmic } \\ \text { grounds in light of }\end{array} & \text { the paper in } \\ \text { than substantive } & \text { wo purpose of the } & \text { light of the purpose } \\ \text { ones (e.g., giving } & \text { one or more } & \text { of the work. The } \\ \text { equal weight to } & \text { aspects of the } & \begin{array}{l}\text { integration is } \\ \text { elegant and }\end{array} \\ \text { each disciplinary } & \text { argument may be } & \text { coherent and there } \\ \text { perspective studied } & \text { weakly addressed. } & \begin{array}{l}\text { are no } \\ \text { distractions in the }\end{array} \\ \text { irrespective of its } & & \text { building of the } \\ \text { substantive } & & \text { argument. } \\ \text { relevance to the } & & \end{array}$

perspectives are

presented in

light of the purpose of the work (e.g., particular disciplinary perspectives are given disproportionate weight for no obvious reason). 


\begin{tabular}{|c|c|c|c|c|}
\hline $\begin{array}{l}\text { 4.1. Does the } \\
\text { student show } \\
\text { awareness of the } \\
\text { limitations and } \\
\text { benefits of the } \\
\text { contributing } \\
\text { disciplines or how } \\
\text { the disciplines } \\
\text { intertwine? }\end{array}$ & $\begin{array}{l}\text { There is no } \\
\text { awareness of the } \\
\text { differing } \\
\text { contributing } \\
\text { disciplines } \\
\text { or fields or their } \\
\text { benefits or } \\
\text { limitations (e.g., } \\
\text { the topic is only } \\
\text { approached from a } \\
\text { common sense or } \\
\text { very general } \\
\text { standpoint). }\end{array}$ & $\begin{array}{l}\text { There is awareness } \\
\text { of which } \\
\text { disciplines are } \\
\text { being used but } \\
\text { there is no or only } \\
\text { brief discussion of } \\
\text { the limitations } \\
\text { and/or benefits of } \\
\text { the disciplinary } \\
\text { contributions. } \\
\text { There may be } \\
\text { some } \\
\text { misconceptions } \\
\text { about how the } \\
\text { disciplines are } \\
\text { being used. }\end{array}$ & $\begin{array}{l}\text { The benefits } \\
\text { and/or limitations } \\
\text { of the differing } \\
\text { contributing } \\
\text { disciplines or } \\
\text { fields are } \\
\text { sufficiently and } \\
\text { clearly discussed. } \\
\text { Some of the points } \\
\text { made may be } \\
\text { general or obvious. }\end{array}$ & $\begin{array}{l}\text { The benefits and/or } \\
\text { limitations of the } \\
\text { differing } \\
\text { contributing } \\
\text { disciplines or fields } \\
\text { are discussed } \\
\text { clearly, } \\
\text { insightfully, and in } \\
\text { relationship to one } \\
\text { another (e.g., } \\
\text { students not only } \\
\text { describe } \\
\text { individual } \\
\text { contributions but } \\
\text { highlight how } \\
\text { views complement, } \\
\text { balance, add } \\
\text { empirical } \\
\text { grounding or put } \\
\text { into question } \\
\text { insights from other } \\
\text { disciplines included } \\
\text { in the work). }\end{array}$ \\
\hline $\begin{array}{l}\text { 4.2. Does the } \\
\text { student exhibit } \\
\text { self-reflection? }\end{array}$ & $\begin{array}{l}\text { The student does } \\
\text { not consider } \\
\text { the strengths and } \\
\text { limitations of his } \\
\text { or her own paper. } \\
\text { Ideas are presented } \\
\text { at face value } \\
\text { without } \\
\text { skepticism or } \\
\text { reflection. }\end{array}$ & $\begin{array}{l}\text { Comments on the } \\
\text { strengths and } \\
\text { limitations of the } \\
\text { paper and its } \\
\text { integrative } \\
\text { approach seem } \\
\text { mechanical, } \\
\text { superficial, or in } \\
\text { passing. Ideas are } \\
\text { mostly presented } \\
\text { at face value } \\
\text { without } \\
\text { skepticism or } \\
\text { reflection. }\end{array}$ & $\begin{array}{l}\text { There is sufficient } \\
\text { comment on } \\
\text { the strengths and } \\
\text { /or limitations } \\
\text { of the paper and its } \\
\text { integrative } \\
\text { approach, although } \\
\text { the points made } \\
\text { may be general or } \\
\text { obvious. }\end{array}$ & $\begin{array}{l}\text { There is consistent } \\
\text { awareness of } \\
\text { the strengths and } \\
\text { limitations of the } \\
\text { paper and its } \\
\text { integrative } \\
\text { approach. A } \\
\text { tentative tone is } \\
\text { adopted and } \\
\text { alternative } \\
\text { integrative } \\
\text { approaches may be } \\
\text { considered. }\end{array}$ \\
\hline
\end{tabular}




\section{APPENDIX D. STUDENT INTERVIEW QUESTIONS}

Introduction

1. What is your major here at PSU?

2. How long have you been at PSU? When do you anticipate graduating?

3. In your science classes, do you prefer laboratory courses that have predetermined labs or courses that you can choose your laboratory experiment direction?

4. Have you ever done research as an undergraduate in a research lab?

5. What attracted you to the chemical ecology* course that you took this last winter term?

Interdisciplinary understanding

1. What does chemistry* mean to you?

2. What does biology* mean to you?

3. What does ecology* mean to you?

4. What does chemical ecology* mean to you?

5. What does interdisciplinary science mean to you?

6. Do you think that biophysics answers questions that biology and/or physics cannot answer on its own?

-Please explain.

7. Do you see benefit in learning disciplines by themselves?

-Please explain.

8. Do you feel like the biophysics course helped you bridge multiple disciplines together in a cohesive way?

- If yes, can you please explain?

- If no, can you please explain?

9. Can you give me an example of a moment during the biophysics course that challenged your understanding of biology, chemistry, physics, and or the intersection of the three?

10. Can you give me an example of a moment during the biophysics course that enhanced your understanding of biology, chemistry, physics, and/or the intersection of the three?

11. Do you think interdisciplinary science is important?

- If so, why?

- If not, why not?

12. Is there anything that you would like to share regarding your experiences as an undergraduate STEM student at PSU that we did not talk about?

*Course and discipline were exchanged based on the course that the interviewees were enrolled in. 
APPENDIX E. FACULTY PARTICIPANT DEMOGRAPHICS

\begin{tabular}{|c|c|}
\hline & $\begin{array}{l}\text { Participants } \\
(\%)\end{array}$ \\
\hline \multicolumn{2}{|l|}{ Years at current position } \\
\hline $5+$ Years & 89 \\
\hline 2-4 Years & 9 \\
\hline$<1$ Year & 4 \\
\hline \multicolumn{2}{|l|}{ Gender } \\
\hline Male & 63 \\
\hline Female & 37 \\
\hline \multicolumn{2}{|c|}{ Carnegie Institution Classification } \\
\hline Research & 49 \\
\hline Master & 27 \\
\hline Other & 7 \\
\hline Baccalaureate & 6 \\
\hline International University & 4 \\
\hline Special Focus Profession & 4 \\
\hline Associate & 3 \\
\hline \multicolumn{2}{|l|}{ Department } \\
\hline Natural/Physical Science & 80 \\
\hline STEM Centers & 15 \\
\hline Computer Science & 4 \\
\hline Math & 2 \\
\hline
\end{tabular}




\section{APPENDIX F. FACULTY SURVEY QUESTIONS}

1. How do you define interdisciplinary science?

2. Do you teach courses that you consider to be interdisciplinary?

3. Does your course(s) have learning outcomes related to students' understanding of the interdisciplinary nature of science?

4. Please explain how you assess these learning outcomes related to students' understanding of the interdisciplinary nature of science. 


\section{APPENDIX G. ESSAY PROMPTS FOR ASSIGNMENTS}

*COURSE $\mathrm{A}^{+}$and A2:

Background: The President of the United States approved the construction of the $4^{\text {th }}$ Keystone XL Pipeline upon taking office. Keystone XL (KXL) is the $4^{\text {th }}$ phase of construction of the larger Keystone Pipeline System. KXL construction has previously been blocked due to multiple concerns, mostly environmental. Construction is now projected to start in 2020.

Your Assignment: As a lead environmental scientist working in the State of Nebraska office of the Environmental Protection Agency (EPA), you have been assigned to lead a taskforce to identify key issues that may result from the construction of KXL. You are not necessarily an energy expert, but are expected to develop an initial plan for managing and offsetting potential impacts of the pipeline. You have no control over the fact the construction is slated to begin.

How will you approach your task, and who should be involved (e.g. tools, techniques, procedures, individuals, groups)? Craft a proposal for the Nebraska state representatives in congress, informing them of your team's overall perspective and initial plan of action. Make sure to use the RUBRIC below when writing your essay!!

\section{*COURSE B}

Background: The original paper that linked autism and the measles, mumps and rubella (MMR) vaccine was published 20 years ago in The Lancet by Wakefield et al. It is now known that the subjects in this study were fabricated by the authors, and The Lancet has since retracted this article. Despite the lack of evidence for this link between Autism and vaccines in the scientific community, the misconception is pervasive, and a decline in MMR vaccines remains a significant health concern.

Your Assignment: You are an immunologist working for the Centers for Disease Control \& Prevention (CDC). You have been tasked to work to solve the problem of public misinformation and mistrust surrounding vaccines. You have been given funding for five years. How will you design a platform to inform the public that current research does not support a link between Autism and vaccines? Your mission is to construct a program for the dissemination of reliable information that the public can understand \& trust. You will be pitching your program to the CDC, the World Health Organization (WHO), and a board of citizen scientists $\&$ private equity firms eager to invest in a new program. You are not an expert in education or science communication, however, you can form your team as you see appropriate in order to effectively tackle this problem. This essay will describe your proposed 5-year program.

What information will be needed to develop and disseminate the program? What team will you need to effectively carry out the plan to best educate the general public? Craft your essay as a proposal to the board described above, outlining your program and the 
team that will help you best accomplish this during and after the 5 years. Make sure to use the RUBRIC below when writing your essay!!

\section{*COURSE C}

Background: A costal town in Louisiana would like to clean up a contaminated waterfront area and make it a park with a large portion dedicated to community vegetable gardens. The site has a long history of contamination due to industrial runoff and to make matters worse it is now also contaminated with light, sweet crude oil from the BP oil spill. To begin the clean-up process they analyzed soil samples from various locations in the park and along the shoreline. Not only did they find that soil samples still have a great deal of the oil from the spill, but also substantial amounts of alkyl halides. Committee members who have been hired to oversee the project would like to apply "green" methods for cleaning up the site and by reducing the concentrations and/or the toxicity of chemical compounds and restoring natural conditions.

Your Assignment: The city hires you, a lead environmental scientist with a Ph.D. in Microbiology, to craft a long-term plan for cleaning up the site. Craft a plan for the city and be sure to be specific regarding the science used to address the problems. Also be sure to include how you will approach your task and who should be involved (e.g. tools, techniques, procedures, individuals, groups).

What information will be needed to develop your plan? What team will you need to effectively carry out your plan? Craft your essay as a proposal to the city, outlining your program and the team that will help you best accomplish the task. Make sure to use the RUBRIC below when writing your essay!!

\section{*COURSE D}

Background: Since 2013 there has been a 67\% increase in reported cases of gonorrhea and a $76 \%$ increase in reported cases of syphilis. Left unchecked, the rise of these STDs can result in a public health crisis with profound ramifications.

Your Assignment: You are part of a team tasked with fully understanding the drivers of this rise in reported STD cases, as well as determining an appropriate solution that leads toward a reduction in STD incidence. Based on all that you have come to appreciate and understand about 'No Boundary Thinking', craft a proposal to an audience that includes government officials and potential funders outlining how your team would approach arriving at a possible solution. Your essay need not be 'the solution'. I am more interested how you will approach your task, and who should be involved (e.g. tools, techniques, procedures, individuals, groups).

What information will be needed to develop and disseminate information? What team will you need to effectively carry out your plan? Craft your essay as a proposal to the officials described above, outlining your program and the team that will help you best accomplish the task. Make sure to use the RUBRIC below when writing your essay!! 
*Each prompt was followed by the directions below ( ${ }^{+}$Except course A1, which was provided a previous version):

Please follow the rubric below. Feel free to pull on all sources in developing your essay. Make sure your paper is in APA format: Times New Roman font, 1" margins, single-spaced, proper APA referencing, etc. Please limit your essay to two pages but make sure it is at least one page long. Include appropriate scientific writing and remember who your audience is (the USFS). Include at least two primary, peerreviewed journal articles. Be sure to address this essay from a creative, holistic but realistic viewpoint. Pay close attention to your thesis statement, support your position, and be cognizant of paragraph transitions, grammar, and spelling.

\begin{tabular}{|c|c|c|}
\hline Category & Rubric Criteria & Score \\
\hline \multirow{4}{*}{ 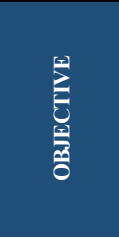 } & $\begin{array}{l}\text { 1.1 Purpose: What is the problem and task? Provide background information to introduce and frame } \\
\text { the problem/ task. }\end{array}$ & $/ 2$ \\
\hline & $\begin{array}{l}\text { 1.2 Approach: How will you approach the problem/task? Formulate a plan that clearly outlines your } \\
\text { approach (steps/procedures). }\end{array}$ & 12 \\
\hline & $\begin{array}{l}\text { 1.3 Credibility: What sources will you include? Use peer-reviewed articles and/or other supporting } \\
\text { information that are relevant to the problem/task.. }\end{array}$ & 12 \\
\hline & Average Objective Score & $/ 2$ \\
\hline \multirow{4}{*}{ 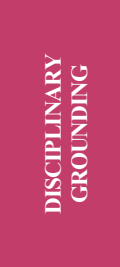 } & $\begin{array}{l}\text { 2.1 Disciplines/Experts: What disciplines and/or experts will be involved? Include two or more } \\
\text { disciplines and/or experts in your approach to the problem/task. }\end{array}$ & 12 \\
\hline & $\begin{array}{l}\text { 2.2 Disciplinary Reasoning: Why are you including each discipline and/or expert? Meaningfully } \\
\text { explain the reasoning behind the use of each discipline and/or expert. }\end{array}$ & $/ 2$ \\
\hline & $\begin{array}{l}\text { 2.3 Methods \& Tools: What methods will each discipline and/or expert use? Include } \\
\text { techniques/procedures/tools from contributing disciplines and/or experts. }\end{array}$ & $/ 2$ \\
\hline & Average Disciplinary Grounding Score & 12 \\
\hline \multirow{3}{*}{ 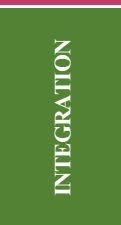 } & $\begin{array}{l}\text { 3.1 Leveraging Disciplines/Experts: How will each contributing discipline and/or expert build off } \\
\text { one another to effectively address the problem/task in a way that one contributor cannot? } \\
\text { Specifically address how each discipline's and/or expert's contribution (knowledge/methods) will be } \\
\text { useful for the other disciplines and/or experts. }\end{array}$ & 12 \\
\hline & $\begin{array}{l}\text { 3.2 Collaboration: How will you foster successful partnerships? Include and explain two or more } \\
\text { ways to build community and respect among different disciplinary team members (e.g. establishing } \\
\text { common ground and language, overcoming different perspectives, etc.). }\end{array}$ & $/ 2$ \\
\hline & $\begin{array}{ll}\text { Average Integration Score }\end{array}$ & 12 \\
\hline \multirow{3}{*}{ 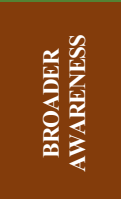 } & $\begin{array}{l}\text { 4.1 Societal Impact: How does your proposed solution impact society? Include why your solution is } \\
\text { locally and more broadly relevant to society and what/who will be affected (e.g. economics, politics, } \\
\text { social, health, etc.). }\end{array}$ & 12 \\
\hline & $\begin{array}{l}\text { 4.2 Limitations: What are the potential limitations to your plan and how will you overcome these } \\
\text { barriers? Forecast possible limitations of your plan and provide resolutions. }\end{array}$ & \\
\hline & Average Broader Awareness Score & $/ 2$ \\
\hline \multirow[t]{2}{*}{ FORMAT } & $\begin{array}{l}\text { 4.1 Format, Grammar, Structure: Have you followed all formatting guidelines? Does your } \\
\text { proposal have an introduction, body, and conclusion? }\end{array}$ & 12 \\
\hline & TOTAL SCORE & $/ 8$ \\
\hline
\end{tabular}




\section{APPENDIX H. STUDENT INTERVIEW QUESTIONS}

Introduction

To get started:

6. What is your major at [insert institution]?

7. How long have you been at [insert institution]?

8. When do you anticipate graduating?

9. Have you ever done research as an undergraduate in a research lab?

a. If so, what does/did that look like?

10. What attracted you to the [insert course] course that you took this winter term?

11. How would you describe a discipline?

12. How would you describe interdisciplinary science?

Assignment and Rubric

1. How did you decide how to approach your essay? (What did you do to decide what they were going to write?) $\rightarrow$ change to process

2. What was your feeling about the overall level of difficulty or ease of the assignment?

3. Could you rank this assignment on a scale of $1-10-1$ being the easiest and 10 being the hardest?

4. Was anything unclear about the assignment?

5. Was it clear to you how to apply the rubric to the assignment?

Rubric Interpretation

6. Can you please explain how you interpreted these points under the theme purposefulness? 
7. Can you please explain how you interpreted these points under the theme disciplinary grounding?

8. Can you please explain how you interpreted these points under the theme integration?

9. Can you please explain how you interpreted these points under the theme critical awareness?

10. Was the rubric useful in guiding your understanding of expectations for the assignment?

11. What was the most challenging part of the assignment?

12. What was the most challenging part of the rubric?

\section{General Questions}

13. Did the assignment have any impact on your understanding of what it means to think like a scientist?

14. Do you think interdisciplinary science is important?

- If so, why?

- If not, why not?

15. Is there anything else you would like to add? 


\section{APPENDIX I. INSTRUCTOR INTERVIEW QUESTIONS}

\section{Introduction}

1. What institution do you hold a faculty position at?

2. How many years have you been in this position?

3. Tell me a little bit about what you do in this position.

4. Is your expertise centralized around research, teaching, or both?

Interdisicplinary Science

5. What prior experience do you have working interdisciplinarily?

6. How do you define interdisciplinary science?

Rubric

7. Can you please explain how you interpreted the instructor rubric category purposefulness and the associated criteria?

a. What was clear about these criteria?

b. What was unclear?

8. Can you please explain how you interpreted the instructor rubric category disciplinary grounding and the associated criteria?

a. What was clear about these criteria?

b. What was unclear?

9. Can you please explain how you interpreted the instructor rubric category integration and the associated criteria?

a. What was clear about these criteria?

b. What was unclear?

10. Can you please explain how you interpreted the instructor rubric category critical awareness and the associated criteria?

a. What was clear about these criteria?

b. What was unclear?

11. Are there any other parts of interdisciplinary science understanding that you feel are missing from the rubric? 
12. What improvements could be made to the instructor rubric to make it more user friendly?

13. Were there categories or sub-categories of the rubric that you thought were not appropriate for the level of your students? If so, do you have suggestions or recommendations?

14. What level of course do you feel this assignment might be best suited to?

15. Is there anything else you would like to share about this assignment/rubric? 


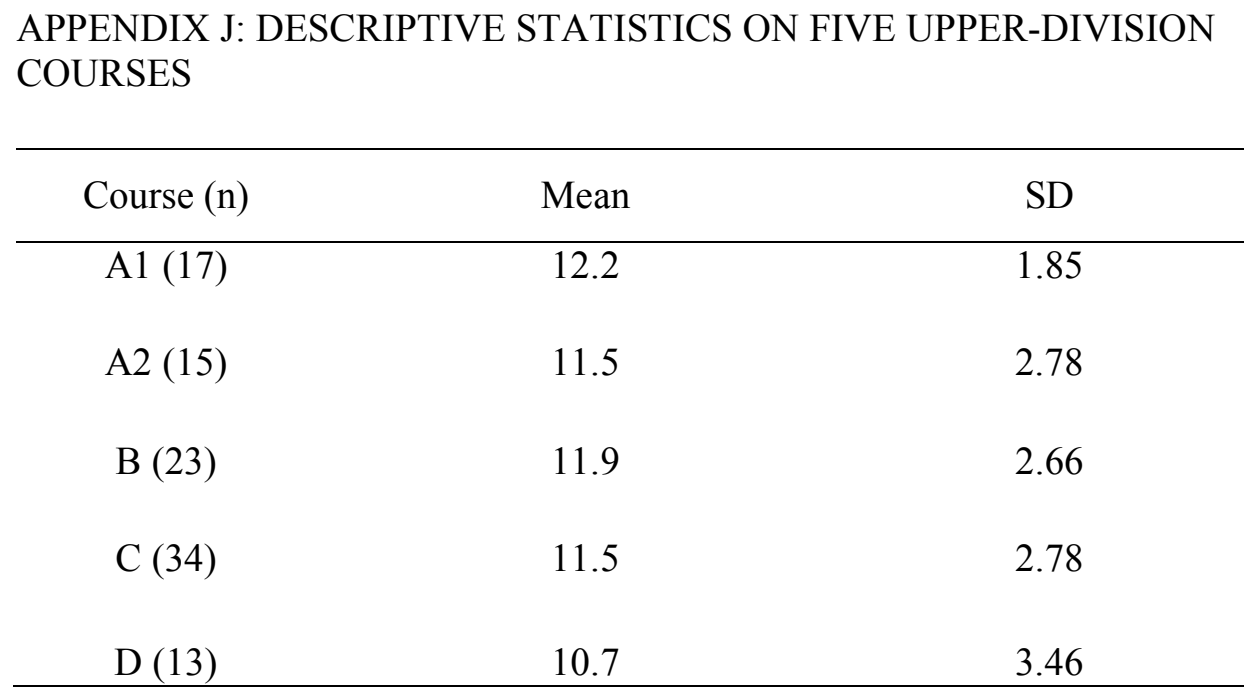

